\title{
Beta uncertainty
}

Article

Accepted Version

Creative Commons: Attribution-Noncommercial-No Derivative Works 4.0

Hollstein, F., Prokopczuk, M. and Wese Simen, C. (2020) Beta uncertainty. Journal of Banking \& Finance, 116. 105834. ISSN 0378-4266 doi: https://doi.org/10.1016/j.jbankfin.2020.105834 Available at https://centaur.reading.ac.uk/90228/

It is advisable to refer to the publisher's version if you intend to cite from the work. See Guidance on citing.

To link to this article DOI: http://dx.doi.org/10.1016/j.jbankfin.2020.105834

Publisher: Elsevier

All outputs in CentAUR are protected by Intellectual Property Rights law, including copyright law. Copyright and IPR is retained by the creators or other copyright holders. Terms and conditions for use of this material are defined in the End User Agreement.

\section{www.reading.ac.uk/centaur}

\section{CentAUR}

Central Archive at the University of Reading

Reading's research outputs online 


\title{
Beta Uncertainty
}

\author{
March 16, 2020
}

\begin{abstract}
A stock's exposure to systematic risk factors is surrounded by substantial uncertainty. This beta uncertainty is both economically and statistically significantly priced in the cross-section of stock returns. Stocks with high beta uncertainty substantially underperform those with low beta uncertainty: a two-standard-deviation increase in the measure decreases average annual returns by $9.7 \%$. These results cannot be explained by previously discovered determinants of cross-sectional stock returns. Aggregate beta uncertainty negatively predicts market excess returns in the short and medium term. We find supporting evidence for a mispricing explanation of the beta uncertainty premium.
\end{abstract}

JEL classification: G12, G11, G17

Keywords: Beta, CAPM, disagreement, ambiguity, parameter uncertainty 


\section{Introduction}

The Capital Asset Pricing Model (CAPM) by Sharpe (1964), Lintner (1965), and Mossin (1966) and the arbitrage pricing theory (APT) by Ross (1976) are important cornerstones in the finance literature. These models posit that cross-sectional differences in expected returns can be traced back to differences in sensitivities to risk factors, i.e., betas. In the case of the CAPM, the beta with respect to the aggregate market portfolio is the sole asset specific determinant of expected returns. Graham \& Harvey (2001) document the model's popularity among chief financial officers of large U.S. companies. Examining mutual fund flows, Barber et al. (2016) and Berk \& Van Binsbergen (2016) also show that in practice most investors use the CAPM for capital allocation.

Unfortunately, the betas are not directly observable and the theory remains silent on how beta should be estimated. In practice, betas are generally estimated using historical data. However, already the length of the historical window involves a trade-off. On the one hand, one wants to operate with a short historical window to obtain conditional estimates. On the other, a short window contains fewer observations and thus yields less precise estimates. Furthermore, some stocks may be infrequently traded. These stocks may react to systematic news with several days' delay, in which case it might be useful to adjust beta to account for lagged market returns. Thus, although beta is very important for financial decisions, its estimation involves many choices, which in turn could lead to various estimates.

In this paper, we study the asset pricing implications of the uncertainty surrounding beta. We define beta uncertainty for each stock as the total range spanned by the $95 \%$ confidence intervals of different possible beta estimates made at the same point in time. If the estimates derived from different approaches vary substantially for a firm and the confidence intervals are wide, its beta is highly uncertain, and there is a large potential for disagreement about beta among investors. In contrast, if all approaches yield similar estimates and the 
confidence intervals are tight, the uncertainty about beta is low. Using a large cross-section of stock returns and a long sample period covering 65 years, we empirically test whether beta uncertainty has an impact on average stock returns.

We find that beta uncertainty carries an economically large and statistically significant negative premium in the cross-section of stock returns. Buying stocks with high beta uncertainty while simultaneously selling stocks with low beta uncertainty yields an average annualized value-weighted return and 4 -factor alpha of $-7.9 \%$ and $-10.6 \%$, respectively. In univariate cross-sectional regressions, we find that a two-standard-deviation increase in beta uncertainty yields a significant decrease in average returns by roughly $9.7 \%$. These results are significant under the rigorous criterion defined by Harvey et al. (2016). Our results are also robust to the inclusion of a large set of control variables.

Next, we examine the implications of an aggregate measure of beta uncertainty (valueweighted average across stocks) for the predictability of market excess returns. We find that aggregate beta uncertainty significantly negatively predicts future market excess returns for in-sample horizons between 1 and 12 months. We also find that aggregate beta uncertainty outperforms the historical mean in out-of-sample market excess return forecasts for horizons between 1 and 3 months.

Having documented that beta uncertainty predicts returns both in the cross-section (of stocks) and the time series (market), we next analyze the mechanisms underlying this predictability. We find that a mispricing explanation is more likely than a risk-based alternative. Stocks with high beta uncertainty show several signs of overpricing. We find that the negative abnormal returns of stocks in the high beta uncertainty portfolio are the main driver of the beta uncertainty premium. The negative relation between aggregate beta uncertainty and future returns is also consistent with higher aggregate overpricing when beta uncertainty is high on aggregate. More importantly, we find that the beta uncertainty premium gets stronger the more binding short-sale restrictions of the stocks are. 
Our results are inconsistent with ambiguity-aversion and information uncertainty explanations since they both counterfactually predict a positive beta uncertainty premium. Our main empirical observations are consistent with (potentially heterogeneous) ambiguity-loving investors, a convexity explanation put forward by Armstrong et al. (2013), as well as with the disagreement model of Miller (1977). The intuition behind the convexity theory is that prices may be convex functions of betas. Thus, if different agents use different beta estimates, the average of these prices will be higher than the price obtained by using the average beta. On the other hand, in the disagreement model of Miller (1977), investors disagree about the correct valuation of a stock (potentially because they use different beta estimates). In the presence of short-selling restrictions, the stock prices will mainly reflect the views of the investors with high valuations.

Finally, we split beta uncertainty into uncertainty about stock volatility and correlation. We document that the correlation uncertainty part of the beta uncertainty measure is the main driver of the related premium.

We perform a battery of tests to document the robustness of our results to the measure of beta uncertainty. First, we expand the set of beta estimates and randomly select a subset of these to obtain alternative beta uncertainty measures. For all of these subsets, we obtain a significant negative beta uncertainty premium. Indeed, we find that most of the random subsets yield even larger magnitudes for the beta uncertainty premium than our main specification. Second, a beta uncertainty measure orthogonalized with respect to beta performs similarly to the raw measure. Third, instead of the total confidence interval we examine several alternative beta uncertainty definitions and obtain a robust and significant negative premium for all of these. These alternatives include: the simple standard deviation of the different point estimates, the range of beta point estimates, the standard error of the best estimate, and the past prediction error of the best estimate.

Numerous studies analyze the performance of the CAPM, mostly challenging it empiri- 
cally (e.g., Fama \& French, 1992; Jagannathan \& Wang, 1996; Ang et al., 2006b; Lewellen \& Nagel, 2006; Frazzini \& Pedersen, 2014). These studies essentially examine a "level" effect, implicitly assuming that there is only one beta estimate. However, in practice there are many different ways to estimate beta and, hence, several possible beta estimates. In this paper, we explore the asset pricing implications of the standard deviation across these estimates.

Our paper relates to the literature dealing with changes in beta. Adrian \& Franzoni (2009) build a model with long-run changes in beta, where investors learn about these changes from return observations. Our analysis is related in that we examine uncertainty about beta. Patton \& Verardo (2012) show that a firm's beta typically increases following earnings announcements, i.e., when the uncertainty about the earnings is resolved. Our study differs from theirs in that we focus on the uncertainty about a stock's beta. Furthermore, we directly examine the impact of beta uncertainty on the cross-section of stock returns. Hollstein \& Prokopczuk (2016), Levi \& Welch (2017), Becker et al. (2019), Hollstein et al. (2019, 2020), and Hollstein (2020) study and evaluate different predictors for beta. In this paper, we study how the dispersion across different measures impacts stock returns.

Our paper also connects to Baltussen et al. (2018), who show that the time-series volatility of a firm's option-implied volatility carries a negative premium in the cross-section of stock returns. Our measure of beta uncertainty is fundamentally different. Their measure mainly captures changes over time in the market's perception of future (idiosyncratic) volatility as well as changes in the volatility risk premium. Hollstein \& Prokopczuk (2018) show that aggregate volatility-of-volatility is priced in the cross-section of stock returns. In a sense, we complement these papers by showing that beta uncertainty is an important determinant for the cross-section of stock returns. Furthermore, our results indicate that the correlation channel is the main determinant for the pricing of beta uncertainty.

Our study also relates to Armstrong et al. (2013). The authors introduce uncertainty about a firm's risk factor loadings in a partial equilibrium model and show that higher factor- 
loading uncertainty decreases expected returns. The authors also validate their model's prediction empirically. Our empirical study involves several important differences to theirs. First, we show that the beta uncertainty premium is robust to the inclusion of the measure of Armstrong et al. (2013). Second, we intuitively motivate beta uncertainty from a practical point of view with the choice of the estimator faced by investors.

The remainder of this paper is organized as follows. In Section II, we introduce the data and the methodology for the estimation of our main variables as well as summary statistics. We present our main empirical results for beta uncertainty and the cross-section of stock returns in Section III. Section IV examines aggregate beta uncertainty as a predictor of future market excess returns. In Section V, we discuss and analyze potential theoretical explanations for the beta uncertainty premium. In Section VI, we present additional analyses and test the robustness of our results. Section VII concludes.

\section{Data and Methodology}

\section{A Data}

We obtain daily data on stock returns, prices, and shares outstanding from the Center for Research in Security Prices (CRSP). We use all stocks traded on the New York Stock Exchange (NYSE), the American Stock Exchange (AMEX), and the National Association of Securities Dealers Automated Quotations (NASDAQ) that are classified as ordinary common shares (CRSP share codes 10 or 11). We exclude closed-end funds and REITs (SIC codes 6720-6730 and 6798). Furthermore, following Amihud (2002) and Zhang (2006), we exclude highly illiquid stocks. We expunge firm-month observations with prices below 1 dollar (e.g., Hou \& Loh, 2016). We also adjust for delisting returns following Shumway (1997) and Shumway \& Warther (1999). 
Balance sheet and income statement data come from Compustat. We start our sample period in January 1951 with the beginning of the Compustat database and end it in December 2015. ${ }^{1}$ We obtain data on analysts' earnings forecasts from the Institutional Brokers' Estimate System (I/B/E/S). Data on the risk-free (1-month Treasury Bill) rate as well as the Carhart (1997) and Fama \& French (2015) factors come from Kenneth French's data library. We obtain data on the Pástor \& Stambaugh (2003) (traded) liquidity factor from Robert Stambaugh's homepage. To proxy for the market return, we use the CRSP valueweighted index. We obtain data on different stock market predictor variables from Amit Goyal's webpage.

\section{B Estimation Methodology}

To account for the parameter uncertainty surrounding the estimation of beta, we first obtain beta estimates using different estimators. To draw from a realistic set of estimators that investors might reasonably use, we use the following estimators for our main analysis: historical estimators with 6-month and 12-month estimation windows, two EWMA estimators with different half-life specifications (one third and two thirds of a 1-year window), Dimson estimators with 1 up to 4 lags, and the Scholes-Williams (SW) estimator. ${ }^{2}$

Admittedly, the literature also proposes further reasonable estimators that we could in principle include in the computation of the beta uncertainty measure. For example, Buss \& Vilkov (2012) and Chang et al. (2012) suggest estimators using option-implied data. Bollerslev et al. (2016) and Hollstein et al. (2020) use different estimators based on highfrequency data. However, due to high data requirements these classes of estimators are only

\footnotetext{
${ }^{1}$ Alternative starting dates, e.g., 1963 after the expansion of the CRSP database, yield qualitatively and quantitatively very similar results.

${ }^{2}$ For later analysis, we also use the Frazzini-Pedersen estimator (FP). However, for our main analysis, we need standard errors for the estimators. The FP measure is a combination of different components, for which the aggregation to one standard error is not straightforward. Therefore, we do not include the FP estimator for the main analysis.
} 
available for a smaller number of stocks and a shorter time period. We limit our attention to estimators available for the full set of stocks and sample period. If we were to include estimators that are only available for a subset, the measure would not be comparable across stocks and over time. We also refrain from adding further, less prominent, alternatives just because they are feasible since these are very rarely used even in academic studies.

As is standard practice in the literature, we directly use past estimates of the betas as forecasts for future betas (e.g., Fama \& MacBeth, 1973; Frazzini \& Pedersen, 2014). We provide details on the beta estimators in Appendix A.

Beta Uncertainty For each beta estimate, we obtain both the point estimates and the standard errors belonging to each beta estimate. Equipped with both, we obtain the 95\% confidence interval for each estimate. Our main measure for beta uncertainty is the total range spanned by all confidence intervals, i.e., the maximum beta that is spanned by the entirety of confidence intervals minus the minimum beta spanned by the entirety of confidence intervals:

$$
\mathrm{Unc}_{\beta, j, t}=\max _{i}\left(\beta_{j, t}^{C I,(i)}\right)-\min _{i}\left(\beta_{j, t}^{C I,(i)}\right)
$$

$\mathrm{Unc}_{\beta, j, t}$ is the measure for beta uncertainty of stock $j$ at time $t . \beta_{j, t}^{C I,(i)}$ is $95 \%$ beta confidence interval of estimation approach $i$. If the heterogeneity in the beta estimates derived from the different estimators is high, we obtain a high entire confidence interval and, hence, high beta uncertainty. On the other hand, if all estimators yield similar estimates for beta and tight confidence intervals, there is only little beta uncertainty.

Naturally, the differences in the beta estimators are in part mechanical. EWMA betas and 6-month historical betas differ from simple 12-month historical betas mainly if betas are highly time-varying. Dimson, Scholes-Williams, and Frazzini-Pedersen betas differ most strongly from historical betas if the underlying stock is infrequently traded. One might 
argue that there are alternative ways to account for infrequent trading and differences in these betas do not reflect uncertainty. However, even if one is convinced that the beta of a certain stock is highly time-varying or that the stock is traded only very infrequently, it is still challenging to find the "right" estimator. Time-variation could be a major source of uncertainty: what window length or half-life should one choose? There might also be uncertainty regarding the correction for liquidity. How many lags for the Dimson estimator are optimal? Is the stock really traded too infrequently? What is "too infrequently"? By considering all the models described above, we aim to reflect the uncertainty about beta without imposing too much structure on the stocks' properties. $^{3}$

To document that our results are not specific to the chosen subset of beta estimators or the measure of beta uncertainty, we perform extensive robustness analyses. In Section VI.B, we randomly draw beta estimators from an enlarged set of estimators and show that the results are (i) similar for virtually all random subsets of estimators and (ii) on average even stronger than for our main measure. Furthermore, in Section OA1 of the Online Appendix, we document very similar results for numerous alternative beta uncertainty definitions (e.g., based on the simple standard deviation of beta point estimates and the standard error of the best estimator).

\section{Control Variables}

The literature shows that several stock characteristics are related to returns. To test if our results are robust to these previously documented effects, we explicitly control for: beta, firm size, book-to-market ratio, investment, profitability, illiquidity (ILLIQ), momentum, shortterm reversals, firm's leverage ratio, idiosyncratic volatility (iVol), maximum daily return (MAX), co-skewness, co-kurtosis, downside beta, vol-of-vol, forecast dispersion (Disp), and

\footnotetext{
${ }^{3}$ Our main beta uncertainty includes the uncertainty surrounding the liquidity correction by taking into account different estimators for this (Scholes-Williams as well as Dimson with different numbers of lags).
} 
the squared standard error of a historical beta estimate (SE). The construction of these control variables follows the standard procedure described in the literature. Details are provided in Appendix B.

\section{Summary Statistics}

We start by examining the summary statistics of the main beta estimates used to construct the beta uncertainty measure. We present these in Table 1. For all estimators, the value-weighted average beta is between 1.01 and 1.02, suggesting that these contain similar information on average. The estimates differ, though, in the equally weighted averages. With an increasing number of lags considered for the Dimson estimator, the equally weighted average increases. Thus, including betas toward lags of the market return appears to increase the beta estimates primarily for small stocks. Based on this finding, we might expect a somewhat higher beta uncertainty for small stocks.

The cross-sectional and time-series standard deviations are highest for the historical estimator with a short estimation window and the Dimson estimators. HIST and Dim1 have the highest cross-sectional and time-series correlations with the average betas. Thus, these estimators' contribution to the beta uncertainty is likely small. On the other hand, HIST6, and Dim4 have comparably low correlations with the average beta and, consequently, their contributions to the beta uncertainty are likely higher. The average standard errors of the estimates are highest for HIST6 and in particular for the sum betas (Dim and SW). This is mainly because the coefficients with respect to lagged and leaded market returns are typically measured imprecisely. Naturally, the EWMA estimates, for which the estimation windows are longest, yield the smallest average standard errors.

In Table 2, we present summary statistics and Spearman Rank Correlations of our main variables. The beta uncertainty measure yields an average value of 1.252 with an average 
cross-sectional standard deviation of 1.306. The average cross-sectional 5th percentile is 0.873 while the average of the 95 th percentile is at 4.593 . The averages and distributions of our control variables are comparable to those reported in the previous literature. ${ }^{4}$

Turning the focus on the average cross-sectional Spearman Rank Correlations, we find some characteristics that are moderately correlated with our main measure for beta uncertainty. Beta uncertainty is positively correlated with beta itself, with an average rank correlation of 0.30 . Thus, the beta of stocks with higher average beta also tends to be somewhat harder to estimate. Furthermore, beta uncertainty is negatively correlated with size and positively correlated with illiquidity with correlation coefficients of -0.56 and 0.56 , respectively. This finding is likely caused by the fact that the Dimson beta estimator is designed to account for delayed stock reactions to systematic news which are most relevant for small and illiquid stocks. Hence, for these stocks the simple historical and the Dimson estimator can differ strongly and the beta uncertainty is high. Nevertheless, we find that the relation of beta uncertainty to these measures is only moderate. Finally, the beta uncertainty measure is also correlated with other measures of volatility like idiosyncratic volatility, MAX, and SE, with average rank correlations of $0.75,0.63$, and 0.79 , respectively. ${ }^{5}$ Hence, the relation to beta uncertainty might be part of the mechanism creating the idiosyncratic volatility puzzle. Interestingly, although the measures appear to be somewhat related, the average rank correlations of beta uncertainty with vol-of-vol and Disp amount to only 0.16 and 0.37 , respectively.

\footnotetext{
${ }^{4}$ Note that information on Disp is available only for a small subset of the total stock-month observations. This reduces the sample size for double sorts and regression specifications that include this variable.

${ }^{5}$ As discussed in Section OA1 of the Online Appendix, the correlations with all these control variables of an alternative, simple standard deviation measure of beta uncertainty, which only makes use of the point estimates, are substantially lower. Nevertheless, all our empirical results are qualitatively similar for this simpler beta uncertainty measure.
} 


\section{Beta Uncertainty and the Cross-Section of Stock Re-}

\section{turns}

\section{A Portfolio Sorts}

To test whether beta uncertainty has an effect on stock returns, we first perform portfolio sorts. At the end of each month, we sort the stocks in ascending order with respect to their estimates of beta uncertainty. We form quintile portfolios, so that quintile 1 contains the stocks with the lowest beta uncertainty while quintile 5 contains the stocks with the highest beta uncertainty. The hedge portfolio (5 minus 1) buys the quintile of stocks with the highest beta uncertainty and simultaneously sells the stocks in the quintile with the lowest values for beta uncertainty. The portfolio-sorting approach maximizes the spread in beta uncertainty and, thus, differences in average returns can be attributed to differences in the sorting variable. Fama \& French (2008) point out that by building value-weighted portfolios the hedge portfolio can be dominated by few big stocks, whereas for equally weighted portfolios the hedge portfolio can be dominated by micro caps. To address this issue, we analyze both value-weighted and equally weighted portfolios.

We present the results for value-weighted portfolios in Table 3. Sorting by beta uncertainty, we find that the average portfolio returns generally decrease with increasing uncertainty about beta. The portfolio of the stocks with the highest beta uncertainty yields a lower average return than the other portfolios. The average annualized return of the 5 minus 1 portfolio amounts to $-7.9 \%$, which is statistically significant at $5 \%$. Thus, investors do not demand a positive premium for holding stocks with high beta uncertainty, but these stocks actually appear to be relatively overpriced.

Controlling for systematic risk factors, we obtain largely similar results. The CAPM alpha for the 5 minus 1 portfolio is almost twice as large in magnitude as the average excess 
return and highly statistically significant at 1\%. For the Carhart (1997) 4-factor model or the 5-factor model including the Pástor \& Stambaugh (2003) liquidity factor, we obtain similar results. Considering the Fama \& French (2015) 5-factor model (FF5), the alpha is somewhat smaller in magnitude at $-6.4 \%$, but remains statistically significant at $1 \%$. Thus, stocks with low beta uncertainty significantly outperform stocks with high beta uncertainty.

Next, we analyze the average firm characteristics of the five portfolios sorted by beta uncertainty. Naturally, we find that the beta uncertainty measured at the end of the previous month $\left(\mathrm{Unc}_{\beta, t}\right)$ increases monotonically for the portfolios. However, we also find that already after 1 month (when the portfolio returns are realized) the beta uncertainty of the 5 minus 1 portfolio decreases from 2.9 to 2.7. This finding indicates that there is some meanreversion in the beta uncertainty measure. On top of that, stocks with high beta uncertainty have on average higher betas (measured as the average across the different estimators), a smaller market capitalization, a somewhat higher book-to-market ratio, higher investment, a lower profitability, higher illiquidity, higher momentum, higher iVol, higher analyst forecast dispersion, and a higher SE. These results indicate that the betas of small stocks, stocks with high investment, low profitability, high illiquidity, high momentum, and high analyst forecast dispersion are substantially more uncertain and harder to estimate. Thus, part of why these characteristics yield risk premia in the cross-section of stock returns could be due to difficulties with estimating their betas. On the other hand, we have to be careful to document that the beta uncertainty premium cannot simply be explained by either of these 
characteristics. $^{6,7}$

In Table A2 of the Online Appendix, we present further portfolio sort results. First, we present the results for equally weighted portfolios. These are qualitatively similar to the value-weighted results, suggesting that the beta uncertainty premium is neither concentrated only among the largest stocks nor microcaps. Second, we perform the sorts based on NYSE breakpoints (Hou et al., 2019) and obtain risk-adjusted returns that are slightly smaller (4-factor alpha of $-4.9 \%$ ) but still statistically significant at $1 \%$. Third, we add the bettingagainst-beta (BAB) factor of Frazzini \& Pedersen (2014) to the factor models and find that the alphas remain statistically significant at $5 \%$.

To further disentangle the effects of beta uncertainty and beta itself, we also present portfolio sorting results for an orthogonalized beta uncertainty measure in Table A3 of the Online Appendix. We cross-sectionally orthogonalize our main measure to the level of beta and sort the stocks based on the orthogonalized measure. The results are qualitatively similar

\footnotetext{
${ }^{6}$ In Table A1 of the Online Appendix, we also present the value-weighted portfolio averages of the various beta measures used to compute the beta uncertainty measure. Overall, the numbers of the ingredient betas line up rather well with those of the average beta. Dim4 has the highest beta spread in the 5 minus 1 portfolio while HIST6 and EWMA 168 yield the lowest spreads. One interesting observation is that the beta-uncertainty-sorted portfolios increase with the average beta of all the different estimators. This finding motivates us to control for the level of beta. An alternative way to define beta uncertainty while controlling for beta would be to scale the measure by the average betas. However, we believe that an unscaled measure of beta uncertainty is economically more sensible than a scaled one. Consider the CAPM: the linearity of the security market line implies that beta differences in absolute (not relative) terms always have the same impact on differences in expected returns. More importantly, beta is theoretically unbounded. Beta can be close to or even equal to zero. In case the beta equals zero, a scaled measure would be undefined. For betas close to zero, the measure would be inflated. Finally, for negative betas the measure would be hard to interpret. Therefore, we refrain from scaling the beta uncertainty measure. As an alternative, below we show that the results are very similar when using a beta uncertainty measure orthogonalized with respect to beta.

${ }^{7}$ The factor loadings on the different risk factors of the Carhart (1997) 4-factor models reveal market betas close to those reported in Table 3 . The 5 minus 1 portfolio thus has a significant positive beta. In addition, the loading on $S M B$ is 1.51 , that on $H M L$ is -0.39 , and that on $U M D$ is -0.21 . All factor loadings are statistically significant. For the Fama \& French (2015) FF5 model, the market factor loadings are similar. The $S M B$ loading is 1.19 , the $H M L$ loading is -0.19 , the $R M W$ loading is -1.43 , and the $C M A$ loading is -0.81 . Again, all factor loadings are statistically significant. Thus, these factor loadings line up well with the average characteristics observed for the portfolios. This indicates that the factor models do a good job in accounting for the characteristics-based exposure of the beta uncertainty sorted portfolio.
} 
to those for the main measure. ${ }^{8}$

In Table A4 of the Online Appendix we present further results for subsamples. To do so, we build three non-overlapping 22-year windows (the last window contains 21 years only). For each of these, we repeat the previous analysis. We find that the 4 -factor alphas for all subsamples and for both equally weighted and value-weighted portfolios are significantly negative. Thus, the beta uncertainty premium appears to be discernible across the various subsamples. Finally, we also present the results when using the full CRSP sample period starting from 1926, and obtain very similar results.

\section{B Double Sorts}

From the univariate sorts, we detect a strong negative relation between beta uncertainty and future stock returns. This relation cannot be explained by systematic risk factors. However, we also find that beta uncertainty is related to several characteristics that have been shown to predict the cross-section of returns in earlier studies. Thus, in this section, we perform double sorts to dissect the effects of beta uncertainty and these variables.

To do so, at the end of each month, we first sort the stocks into 5 portfolios according to a control characteristic. Second, within each of these 5 portfolios, we sort the stocks into another 5 quintile portfolios based on their beta uncertainty. This results in a total of 25 portfolios. Throughout this section, we present Carhart (1997) 4-factor alphas for value-weighted double-sorted portfolios. ${ }^{9}$

We begin the analysis by presenting the full 25 double-sorted portfolios when controlling for the most natural explanatory variable: the level of beta. These results are in Table 4. Consistent with Frazzini \& Pedersen (2014), we find that the beta-sorted 5 minus 1 portfolios

\footnotetext{
${ }^{8}$ The further results in this paper are also qualitatively similar for the orthogonalized beta uncertainty measure.

${ }^{9}$ To limit the number of tables, we only present the value-weighted results for 4 -factor alphas. The results are qualitatively similar for equally weighted portfolios as well as for other factor models, i.e., the CAPM, 5-factor, and Fama \& French (2015) 5-factor models.
} 
have negative alphas. More importantly, we detect significantly negative alphas for the 5 minus 1 portfolio for beta uncertainty within each beta quintile. The average 5 minus 1 alpha when sorting on beta uncertainty while controlling for the level of beta amounts to $-8.0 \%$ per annum. Thus, beta uncertainty appears to be priced completely independently of the level of beta.

In the same table, we also present the full 25 portfolios for a second very important control variable: size. Consistent with the findings about the characteristics of the single portfolio sorts, we find that the magnitude of the beta uncertainty premium is largest for small stocks. Thus, limits-to-arbitrage likely play a role for the magnitude of the premium. However, similar to the case when controlling for beta, we detect a significant negative beta uncertainty premium for each size group. Thus, even for the largest stocks a higher beta uncertainty is associated with lower future returns. The average 4-factor alpha amounts to a highly statistically significant $-10.9 \%$.

In a next step, we perform double sorts with all other control variables. To save space, we directly average across the respective beta-uncertainty quintiles within each of the quintiles sorted on the control characteristic, leaving us with 5 consolidated beta-uncertainty-sorted portfolios. These quintile portfolios control for another characteristic without making assumptions on the parametric form of the relationship.

The results are in Table 5. We find that, independently of which variable we control for, stocks with high beta uncertainty significantly underperform stocks with low beta uncertainty. In every single case, the alphas are economically large and statistically highly significant.

We place special emphasis on the results obtained when controlling for illiquidity and idiosyncratic volatility. Due to the use of Scholes \& Williams (1977) and Dimson (1979) betas, which may deviate most strongly from simple historical betas for illiquid stocks, one might argue that there could be a mechanical relation between beta uncertainty and 
illiquidity. However, as reported in Section II.D, the average correlation is only moderate. For double-sorted portfolios with respect to illiquidity, we find that the 4-factor alpha amounts to a highly statistically significant $-11.5 \%$, which is even larger in magnitude than the 4 factor alpha for the univariate sorts. ${ }^{10}$ Additionally, one might wonder about a strong link between beta uncertainty and idiosyncratic volatility, motivated by an average correlation of $75 \%$. We find that the 4 -factor alpha is $-3.6 \%$, which is statistically significant at $1 \%{ }^{11}$ Thus, neither illiquidity nor idiosyncratic volatility are able to explain the negative return premium on beta uncertainty.

When controlling for SE, we obtain a value-weighted alpha of $-5.4 \%$, which is also statistically significant at $1 \%$. To further disentangle the effects of our beta uncertainty measure and the SE measure, in Table A5 of the Online Appendix, we further present the full 25 double-sorted portfolios for beta uncertainty when controlling for SE. We find that stocks with the highest negative returns are concentrated in the portfolio of both high beta uncertainty and high SE. Hence, to identify the stocks with the lowest expected returns, it might prove worthwhile to use both signals, our beta uncertainty measure and SE. On the other hand, we find that for 4 out of the $5 \mathrm{SE}$ quintiles, there is a significant negative premium for beta uncertainty (at $10 \%$ or lower). Thus, although the two measures are related, our beta uncertainty measure carries additional information.

\footnotetext{
${ }^{10}$ We also test double sorts with respect to alternative measures of (il-)liquidity like the average bid-askspread, trading volume, or the percentage of zero-return trading days and obtain qualitatively similar results. The returns and alphas for the double sort on these variables and beta uncertainty remain economically substantial and statistically highly significant.

${ }^{11}$ When measuring idiosyncratic volatility with respect to the CAPM instead of the Fama \& French (1993) 3-factor model, we obtain similar results. The 4-factor alpha for value-weighted portfolios amounts to $-4.4 \%$ and is statistically significant at $1 \%$. We run further robustness tests using alternative definitions of idiosyncratic volatility in Section OA2 of the Online Appendix.
} 


\section{Cross-Sectional Regressions}

The previous sections present evidence that sorting by beta uncertainty yields negative abnormal returns relative to prominent factor models. In this section, we estimate Fama \& MacBeth (1973) regressions that simultaneously control for different variables and test if beta uncertainty contains information about stock returns beyond that of other, previously documented, anomaly variables and risk factors. To run the regressions, we use individual stocks instead of stock portfolios. Lo \& MacKinlay (1990) and Lewellen et al. (2010) argue that when using portfolios, the portfolio formation method can strongly influence the results. Ang et al. (2018) also show that creating portfolios ignores important information on individual factor loadings and leads to higher asymptotic standard errors of risk premium estimates. Hence, we use individual stocks and utilize this additional information, avoiding the specification of breakpoints.

Each month, we perform cross-sectional regressions of stock excess returns on the stocks' beta uncertainty and several control variables. We estimate the following regression:

$$
r_{j, t}-r_{f, t}=\lambda_{t}^{0}+\lambda_{t}^{\mathrm{Unc}^{\mathrm{Unc}}} \mathrm{Un}_{\beta, t}+\lambda_{t}^{1} \bar{\beta}_{j, t}+\lambda_{t}^{\mathrm{C}} \mathrm{Controls}_{t}+\epsilon_{j, t} .
$$

$r_{j, t}$ is the return of stock $j$ in month $t$ and $r_{f, t}$ is the risk-free rate over the same period. $\bar{\beta}_{j, t}$ is

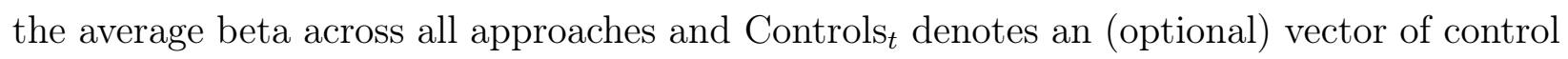
variables, all observed at the end of the previous month $t-1 . \quad \lambda_{t}^{0}$ denotes the regression intercept and $\lambda_{t}^{\mathrm{Unc}}, \lambda_{t}^{1}$, and $\lambda_{t}^{\mathrm{C}}$ are the risk premium estimates associated with the respective variables. $\epsilon_{j, t}$ is the idiosyncratic return component of stock $j$ at time $t .{ }^{12}$

We perform tests on the time-series averages $\bar{\lambda}^{0}, \bar{\lambda}^{\text {Unc }}, \bar{\lambda}^{1}$, and $\bar{\lambda}^{C}$ of the estimated intercept and slope coefficients. We compute robust Newey \& West (1987) (using 6 lags) adjusted standard errors based on the time series of coefficient estimates.

\footnotetext{
${ }^{12}$ To limit the effect of outliers, we winsorize the excess returns at the 1st and 99th percentile.
} 
The results are in Table 6. Univariately, beta uncertainty carries a significant crosssectional premium of -0.0371 . Thus, a two-standard-deviation increase in beta uncertainty is associated with a decrease in average returns by $9.7 \% .{ }^{13}$ Adding the average beta decreases the premium estimate on beta uncertainty only slightly to -0.0357 , while the statistical significance remains unaffected. These results correspond to $t$-statistics of -4.03 in the univariate case and -4.45 when including the average beta. Thus, beta uncertainty clears the hurdle defined by Harvey et al. (2016), who suggest accounting for potential data mining and publication bias by specifying the critical $t$-ratio as 3.0 instead of 2.0.

Further adding size, the book-to-market ratio, investment, profitability, illiquidity, momentum, or short-term reversal does not qualitatively change the results. When we include all these variables, the cross-sectional premium estimate on beta uncertainty is -0.0462 , which is significant at the $1 \%$ level $(t$-stat $=-6.88)$. The risk premium estimates on these characteristics are consistent with the findings of the previous literature (e.g., Fama \& French, 1992; Jegadeesh \& Titman, 1993; Amihud, 2002; Fama \& French, 2006). We detect a negative risk premium estimate on size and a positive value premium. Investment carries a negative risk premium, while profitability is positively priced. The cross-sectional risk premium on illiquidity and the momentum signal is positive and that on short-term reversal is negative. We use the model containing these prominent return anomalies as the baseline specification when adding further return distributions characteristics.

Adding leverage does not affect the results. On the other hand, including idiosyncratic volatility decreases the premium estimate on beta uncertainty to -0.0280 . Thus, as also shown in the summary statistics in Table 2, idiosyncratic volatility seems to be related to beta uncertainty. However, the premium estimate on beta uncertainty is still economically large and statistically significant at $1 \%$ with a t-statistic of -4.37 . Adding another

\footnotetext{
${ }^{13}$ We obtain this figure by multiplying the cross-sectional premium with 2 times the average cross-sectional standard deviation of the beta uncertainty measure of 1.306 .
} 
volatility-related variable, the maximum return, to the baseline model specification, the premium estimate on beta uncertainty amounts to -0.0351 , which is statistically significant relative to the $1 \%$ significance level. For idiosyncratic volatility and the maximum return, we find significant negative cross-sectional risk premium estimates, consistent with the previous literature (e.g., Ang et al., 2006b; Bali et al., 2011).

Co-skewness, co-kurtosis, and downside beta are not significantly priced in the crosssection and also do not affect the risk premium estimate on beta uncertainty. Both volof-vol and the dispersion in analysts' earnings forecasts (Disp) yield significantly negative cross-sectional risk premia, but adding these variables also affects the premium estimate on beta uncertainty only marginally. Thus, even among the subset of stocks for which we can measure the dispersion in analysts' earnings forecasts, beta uncertainty is significantly negatively priced on top of this dispersion. Adding SE to the baseline model also reduces the premium estimate on beta uncertainty, but it is still substantial and highly statistically significant. Consistent with Armstrong et al. (2013), the premium on SE is significantly negative. Note that for each of the models $(i)$ up to (xiii) in Table 6 , the $t$-statistics associated with the beta uncertainty premium exceeds 3.0. For a final specification with (almost) all control variables, the beta uncertainty premium is still statistically significant at $5 \% .14$

\section{Aggregate Beta Uncertainty}

In this section, we examine the time-series implications of an aggregated measure of beta uncertainty for future market returns. We obtain an aggregate beta uncertainty measure as the value-weighted average beta uncertainty over all stocks in our sample (Goyal \& Santa-

\footnotetext{
${ }^{14}$ For this specification, we omit MAX and Dbeta because they are highly correlated with iVol and Beta, respectively. In addition, we omit Disp, which is only available for a subset of the stocks and a shorter sample period. In a regression, where, despite these issues, all these variables are included (untabulated), the beta uncertainty premium even amounts to -0.0186 , with a $p$-value of 0.0095 .
} 
Clara, 2003). Naturally, there is no uncertainty about the beta of the market, which has to be equal to one. However, the extent to which there is uncertainty about the individual stocks on average is likely informative about the aggregate state of the economy.

Figure 1 presents the time series of the aggregate beta uncertainty measure along with the 5th and 95th percentiles of the beta uncertainty of individual stocks. We find that, contrary to what one might intuitively expect, aggregate beta uncertainty evolves rather counter-cyclically and typically does not peak in recessions but rather in expansions. The largest peaks in average beta uncertainty occur in the year 1965 as well as in the period $1993-1996$.

To examine the aggregate return predictability, we run the following regression:

$$
r_{M, t \rightarrow t+h}=\theta_{0}+\theta_{1} U n c_{\beta, t}^{a g g}+\theta_{2} \text { Controls }_{t}+\epsilon_{M, t+h},
$$

where $r_{M, t \rightarrow t+h}$ is the annualized market excess return for the period starting at $t$ and ending at $t+h$ (with $h$ expressed in months). We examine forecast horizons of $1,3,6,9,12,18$, 24, and 36 months. $\theta_{0}$ is the intercept. $\theta_{1}$ and $\theta_{2}$ (optional) are regression slope coefficients. $\epsilon_{M, t+h}$ is the residual of the regression. To account for the overlap in in-sample return predictability regressions, we estimate the standard errors using the approach of Hodrick (1992). ${ }^{15}$ We also examine the out-of-sample predictability, estimating the out-of-sample $R^{2}$ as $R_{O O S}^{2}=1-\frac{\sum_{t=241}^{T}\left(r_{M, t \rightarrow t+h}-\hat{r}_{M, t \rightarrow t+h}\right)^{2}}{\sum_{t=241}^{T}\left(r_{M, t \rightarrow t+h}-\bar{r}_{M, t}\right)^{2}}$, where $\hat{r}_{M, t \rightarrow t+h}$ is the fitted value from the regression model of Equation (3) using only data available up to time $t . \bar{r}_{M, t}$ is the historical mean return up to time $t$. We specify an initial in-sample window of 240 months. Following Goyal \& Welch (2008), we use an expanding window and test the significance of the out-of-sample $R^{2}$ s using their bootstrap approach.

\footnotetext{
${ }^{15}$ As Ang \& Bekaert (2007) show, the Hodrick (1992) standard errors have better properties than those of Newey \& West (1987) when making inferences on long-horizon forecasting. When using Newey \& West (1987) instead of Hodrick (1992) standard errors, the results are qualitatively similar.
} 
We present the return predictability results in Table 7. Consistent with our cross-sectional analysis, high aggregate beta uncertainty is associated with low future market returns. Thus, not only do stocks with high beta uncertainty generally yield negative future returns, but high aggregate beta uncertainty also predicts negative future market excess returns. For the 1-month forecast horizon an increase in aggregate beta uncertainty by 1-percentagepoint decreases annualized monthly returns by 0.18 percentage points. Similar to the 1month horizon, we find that aggregate beta uncertainty strongly significantly predicts market excess returns up to 12 months, although the impact of a 1-percentage-point change in aggregate beta uncertainty slightly decreases with the return forecast horizon. For the 12month forecast horizon, a 1-percentage-point increase in aggregate beta uncertainty decreases the annual market excess return by 0.10 percentage points. For 18 and 24 months, we still detect a marginally significant negative relation. Turning our focus to the out-of-sample predictability, we find that aggregate beta uncertainty also significantly outperforms the historical mean model for horizons up to 3 months. For example, for the 3 -month horizon, we detect a significant out-of-sample $R^{2}$ of $0.5 \%$.

To test whether our results are robust, in Table A6 of the Online Appendix we also present return predictability regressions controlling for various previously documented predictor variables. The descriptions of these variables are available in Appendix C. We find that the short- and medium-horizon predictive ability of aggregate beta uncertainty is robust to the inclusion of these control variables. In the multivariate predictive regression, aggregate beta uncertainty significantly negatively predicts future market excess returns for all forecast horizons up to 36 months. Consistent with Goyal \& Welch (2008), we find that CAY (Lettau \& Ludvigson, 2001) significantly positively predicts future market excess returns. The remaining predictive variables, including aggregate idiosyncratic volatility, do not consistently yield significant predictions over the different prediction horizons. 


\section{Potential Sources of the Beta Uncertainty Premium}

\section{A Risk or Mispricing?}

Having documented a robust negative premium for beta uncertainty, we next turn to the question whether this premium more likely reflects risk or mispricing. To analyze this, it is worth first taking a more detailed look at the composition of the beta uncertainty premium. From Table 3, we see that the main driver of the 5 minus 1 portfolio risk-adjusted return is portfolio 5: that containing the high-beta-uncertainty stocks. The alpha of this portfolio is significantly negative. One possible explanation for this pattern is that the stocks in this portfolio on average help hedge a risk not accounted for by the risk factor models. The negative premium would then be due to investors' hedging demand. Alternatively, the stocks in portfolio 5 may be overpriced at the time the portfolios are created. The negative return in the following month would thus be a partial correction of this overpricing. Consistent with the latter explanation, Table 3 also reveals that already in the month after portfolio formation, part of the beta uncertainty of the 5 minus 1 portfolio gets resolved. Furthermore, we find that the stocks in portfolio 5 are on average small, illiquid, and have high idiosyncratic volatility. Thus, limits to arbitrage apply to these stocks.

Second, we find that aggregate beta uncertainty negatively predicts future returns. This could also be consistent with both a risk-based and a mispricing explanation. If high beta uncertainty signifies low risk on aggregate, there may also be lower expected future market returns. On the other hand, negative future returns could be a consequence of stronger overpricing characterized by high current beta uncertainty.

To dig deeper into the overpricing hypothesis, we study the impact of short-selling constraints on the beta uncertainty premium. We follow, e.g., Boehme et al. (2006) and use the firms' relative short interest (RSI) as a measure for short-selling constraints. The main intuition for using this proxy is that stocks with high relative short interest likely leave few 
additional stock lending opportunities, which leads to high shorting fees. ${ }^{16}$

We analyze the 25 double-sorted portfolios on beta uncertainty and relative short interest. These results are presented in Table 8 . We find that the beta uncertainty premium is insignificant for the 2 quintiles with the lowest short-selling costs. Thus, consistent with an overpricing explanation, the beta uncertainty premium is small for those stocks, for which arbitrageurs can correct the mispricing. On the other hand, for the 3 quintiles with the highest short-selling costs, there is an economically large and statistically significant beta uncertainty premium. More importantly, we find that the magnitude of the beta uncertainty premium increases from quintile 3 of RSI to quintile 5 of RSI. Thus, the higher the shortselling costs get, the more overpriced it seems the stocks with high beta uncertainty get. For the long-only portfolios, we detect significant negative abnormal returns only for the portfolios with both high beta uncertainty and high RSI. These results also point toward a mispricing explanation.

\section{B Potential Mechanisms}

We next discuss several potential mechanisms that could create the observed beta uncertainty premium. First, is it possible that beta uncertainty is a proxy for ambiguity. In this case, stocks with high beta uncertainty would be more ambiguous in that investors could be less certain about their systematic risk than they could be for stocks with low beta uncertainty (where all estimates are rather similar and confidence intervals are tight). The negative sign of the risk premium on beta uncertainty, though, is inconsistent with ambiguity-averse investors. Ambiguity-averse investors dislike stocks with high ambiguity and would require a positive premium on high-ambiguity stocks. Clearly, this is opposite to what we find. The sign of the beta uncertainty premium would be consistent, though, with

\footnotetext{
${ }^{16}$ Using data on real stock loan fees, Boehme et al. (2006) find that these are highly correlated with the relative-short-interest measure.
} 
ambiguity if investors were ambiguity-loving, or if only ambiguity-loving investors participate in the market (Chapman \& Polkovnichenko, 2009).

Second, Klein \& Bawa (1977) and Barry \& Brown (1984, 1985, 1986) introduce a class of models of information uncertainty, which could also be considered as an explanation for a beta uncertainty premium. In these models, investors require a premium for holding stocks with higher parameter estimation risks. The predictions of these models, however, are similar to those of the ambiguity-aversion explanation discussed in the previous paragraph (positive premium).

A third possible explanation for our findings is the convexity of the beta-price function. Armstrong et al. (2013) feature a theoretical model that leverages this property. They argue that the "fair" asset price increases in a convex manner with decreasing beta. Thus, the average price under different possible betas is higher than that when using the average beta, which might imply a lower return in the future for stocks with high beta uncertainty. Clearly, this explanation is consistent with the sign of the beta uncertainty premium.

Finally, it is possible that beta uncertainty is a cause of disagreement among investors. Consistent with the construction of the beta uncertainty measure, different investors may use different beta estimators. Heterogeneity in the choice of the beta estimator is natural because (i) there are numerous possibilities to estimate betas, (ii) there is little guidance on what is the optimal method to use, and (iii) investors themselves are vastly heterogeneous in their preferences, investment styles, and planning horizons (Alfarano \& Lux, 2007; Corsi, 2009; Kamara et al., 2016). Thus, investors may simply use one specific method out of their idiosyncratic taste for it. Others may vary in their investment horizons. Some investors may have short investment horizons and use a EWMA beta with a very small half-life to obtain a good conditional estimate. Others may choose a longer half-life for their estimates simply because they have a very long investment horizon. Investors that consider buying illiquid assets might choose a beta estimator that corrects for illiquidity. However, there is very little 
theoretical guidance on which correction one should employ and how exactly it should be implemented.

As soon as investors disagree about the true beta, the model of Miller (1977) applies: stocks for which investors disagree strongly (i.e., those with high beta uncertainty) and for which short-selling is difficult will be overpriced. This is because investors with low valuations for the shares do not engage in the market because of short-selling constraints and prices reflect only the views of the investors with high valuations. ${ }^{17}$ The disagreement explanation is consistent with the negative sign of the beta uncertainty premium as well as our finding that there is only a significant beta uncertainty premium for the stocks with the highest short-selling costs.

\section{Additional Analyses and Robustness Tests}

\section{A Volatility vs. Correlation Uncertainty}

Beta is defined as the product of a correlation of the stock return with that of the market and the standard deviation of the stock divided by that of the market. Thus, uncertainty about beta can stem from each of these three channels. Uncertainty about the volatility of the market should have only little effect on the cross-sectional ranking of the stocks in terms of beta uncertainty (because it similarly turns up in the denominator of the beta estimator for all stocks). In this section, we thus examine whether uncertainty about the stock volatility, or rather uncertainty about the correlation, are the main driver of the beta uncertainty premium.

\footnotetext{
${ }^{17}$ Note that the disagreement explanation does not require us to specify what the beliefs "optimists" and "pessimists" imply about the kind of betas they use. The mechanism of the Miller (1977) model only needs a source of disagreement. Beta uncertainty likely creates such disagreement. Ultimately, the optimists are those that have very high valuations for a stock. Whether this high valuation is due to an "optimistic" assumption about a low beta or whether the channel is not that direct is irrelevant, as long as the different possible betas create differences in valuations.
} 
As a measure of volatility uncertainty, we use the realized quarticity, which is defined as:

$$
R Q_{j, t}=\frac{k}{3} \sum_{i=1}^{k} r_{j, i}^{4}
$$

where $r_{j, i}$ denotes one of the $k(\log$-)return observations during the estimation period. To be consistent with the main beta estimators, we set the estimation period to the past 12 months. Roughly speaking, the realized quarticity is a measure of the variance-of-variance.

To separate volatility and correlation uncertainty, we cross-sectionally orthogonalize the beta uncertainty measure with respect to the realized quarticity as well as the squared realized quarticity (to account for potential non-linear relations). ${ }^{18}$ The orthogonalized measure of beta uncertainty serves as measure of correlation uncertainty.

We present the results in Table 9 . In a bivariate regression specification using only the volatility and correlation uncertainty measures, both are priced significantly negatively. Thus, both may to some extent drive the pricing of beta uncertainty. However, when adding control variables, we find that only the correlation uncertainty is consistently priced. Thus, we conclude that the uncertainty about the correlation between one asset return and that of the market is the main driver of the beta uncertainty premium.

\section{B Randomized Model Selection}

We document a significant negative relation between beta uncertainty and subsequent returns. However, the definition of the beta uncertainty measure involves an important choice: the subset of beta estimation models to be considered. Any choice of models is necessarily somewhat arbitrary. We could also include the simple historical model with alternative historical sampling windows of, say, 1 or 3 months, or with 60 months of monthly data (e.g., Fama \& MacBeth, 1973). Additionally, we could use Dimson (1979) betas which

\footnotetext{
${ }^{18}$ The results are qualitatively similar both when not accounting for the squared realized quarticity and when instead using the square-root of the realized quarticity in addition to the level of the realized quarticity.
} 
also include 1 up to 4 leaded market excess returns in addition to (the same number of) lagged market excess returns. Moreover, it is also unclear how many models we should use.

In this section, we examine the robustness of our results with respect to these choices. We first augment the set of possible models by those mentioned above. Subsequently, we randomize in two dimensions. First, we draw from a discrete uniform distribution how many of the models available should be used. We require a minimum of 6 models to be selected while the maximum is to use all 16 approaches considered. The second step of randomization involves the selection of the models. We randomly pick from the models without replacement. We repeat these steps 1,000 times and report the average coefficient estimates as well as the shares of significant estimates among the 1,000 repetitions.

We present the results in Table 10 . We find that, for virtually all the subsets, the results are similar to those for our main measure. For all subsets, all factor model alphas are significantly negative. Thus, beta uncertainty appears to be priced rather independently of which models one uses to define it. Indeed, the model selection used for our main tests is rather conservative. On average across the 1,000 random subsets, the coefficient estimates are typically even larger in magnitude than those reported in the main part of the paper. We find that in $86.4 \%$ of the random subsets the value-weighted average return is larger in magnitude (more negative) than for our main measure. For the Carhart (1997) 4-factor model, this is the case for $86.6 \%$ of the random draws.

\section{Further Robustness Tests}

We present further robustness tests in the Online Appendix. In Section OA1, we examine the robustness of our results to various alternative definitions of the beta uncertainty measure. We obtain very similar results for each of these. In Section OA2, we alternatively control for the CAPM idiosyncratic volatility, the natural logarithm of idiosyncratic 
volatility, and idiosyncratic volatility quintile dummies. None of these affects our main results. Finally, in Section OA3 we perform a regression analysis with an errors-in-variables correction. Our conclusions remain unchanged.

\section{Conclusion}

In this paper, we document an economically and statistically significant negative premium for beta uncertainty. Stocks in the high beta uncertainty quintile substantially underperform those in the low beta uncertainty quintile. For value-weighted portfolios, the difference in average returns amounts to $-7.9 \%$ and that in 4 -factor alphas to $-10.6 \%$. Performing double sorts and cross-sectional regressions with numerous control variables, we find that the premium on beta uncertainty cannot be explained by either of these, neither univariately nor jointly. An aggregate measure of beta uncertainty negatively predicts market excess returns in the short and medium term. We find that the pricing patterns of beta uncertainty are consistent with mispricing. In particular, stocks characterized by high beta uncertainty, as well as high short-selling costs, appear overpriced.

In future work, it would be interesting to extend our analysis to a multifactor world. Pursuing this avenue would require new tools to capture the uncertainty about multiple factors in one measure. We leave this to future research. ${ }^{19}$

\footnotetext{
${ }^{19}$ We are grateful to an anonymous reviewer for this suggestion.
} 


\section{Appendix}

\section{A Beta Estimation}

- Historical Beta (HIST) We consider historical beta estimates (HIST) following, e.g., Fama \& MacBeth (1973), regressing an asset's excess return on a constant and the market excess return:

$$
r_{j, \tau}-r_{f, \tau}=\alpha_{j, t}+\beta_{j, t}^{\mathrm{HIT}}\left(r_{M, \tau}-r_{f, \tau}\right)+\epsilon_{j, \tau}
$$

where $\beta_{j, t}^{\text {HIST }}$ denotes the estimate for the historical beta of asset $j$ at time $t$. We use daily data from time $t-k$ to $t$, observed at discrete intervals $\tau$, where $k$ is the length of the estimation window, which we set to 12 months for our main estimators, but also consider a historical estimator with a 6 -month estimation window (HIST6). $r_{j, \tau}$ is the return on asset $j, r_{f, \tau}$ is the risk-free rate, and $r_{M, \tau}$ denotes the return of the market portfolio, all observed at time $\tau$.

- EWMA Beta We also examine a weighted version of the historical estimator with an exponentially weighted moving average structure using an expanding sample window (Boons, 2016; Hollstein et al., 2019). ${ }^{20}$ To be precise, we estimate Equation (A1) with weighted least squares (WLS) using the weights $\frac{\exp (-|t-\tau| h)}{\sum_{\tau=1}^{t-1} \exp (-|t-\tau| h)}$ with $h=\frac{\log (2)}{\iota}$. $\iota$ characterizes the horizon, to which the half-life of the weights converges for large samples. We try two alternatives for $\iota$ : (i) 84 and (ii) 168 trading days. ${ }^{21}$

- Dimson Beta Following Dimson (1979) and Lewellen \& Nagel (2006), we estimate a beta that aims to account for potential infrequent trading effects. If stocks trade less frequently than the market index, stock prices adjust gradually to new information. To account for this possibility, Dimson (1979) adds lagged market returns in the regression:

$$
\begin{aligned}
r_{j, \tau}-r_{f, \tau}= & \alpha_{j, t}+\beta_{j, t}^{(0)}\left(r_{M, \tau}-r_{f, \tau}\right)+\beta_{j, t}^{(1)}\left(r_{M, \tau-1}-r_{f, \tau-1}\right) \\
& +\beta_{j, t}^{(2)}\left(\sum_{k=2}^{K} r_{M, \tau-k}-r_{f, \tau-k}\right)+\epsilon_{j, \tau} .
\end{aligned}
$$

We incorporate $K=1$ up to $K=4$ lagged returns. If $K<2$, the term associated with

\footnotetext{
${ }^{20}$ To reduce the computational burden, we limit the maximum amount of daily returns used to 10 years.

${ }^{21}$ These choices correspond to one third and two thirds of the trading day observations for a 1-year window.
} 
$\beta_{j, t}^{(2)}$ drops. The estimator for beta is then $\beta_{j, t}^{\operatorname{DimK}}=\sum_{i=0}^{\min (2, K)} \beta_{j, t}^{(i)}$, where $\min (\cdot)$ is the minimum operator.

- Scholes-Williams Beta (SW) We also examine the beta estimator of Scholes \& Williams (1977). That is, we estimate three separate regressions. The first regression uses the contemporaneous market return, exactly as in Equation (A1). The second regression uses the lagged market excess return as explanatory variable, that is $r_{j, \tau}-$ $r_{f, \tau}=\alpha_{j, t}+\beta_{j, t}^{-}\left(r_{M, \tau-1}-r_{f, \tau-1}\right)+\epsilon_{j, \tau}$ and the third regression uses the leaded market excess return $r_{j, \tau}-r_{f, \tau}=\alpha_{j, t}+\beta_{j, t}^{+}\left(r_{M, \tau+1}-r_{f, \tau+1}\right)+\epsilon_{j, \tau}$. Note that also $\beta_{j, t}^{+}$uses only information available at time $t$. The final estimator for beta is:

$$
\beta_{j, t}^{\mathrm{SW}}=\frac{\beta_{j, t}^{-}+\beta_{j, t}^{\mathrm{HIST}}+\beta_{j, t}^{+}}{1+2 \rho},
$$

where $\rho$ is the first order autocorrelation of the market excess return. For the Dimson and SW beta estimators, we also use 12-month estimation windows.

- Frazzini-Pedersen Beta (FP) Following Frazzini \& Pedersen (2014), we use an estimator that separates the estimation of volatilities and correlations. The authors estimate volatilities from daily return data and correlations from overlapping 3-day returns to account for asynchronous trading. Additionally, Frazzini \& Pedersen (2014) argue that correlations move more slowly over time, allowing for different estimation windows used to compute volatilities and correlations. We thus obtain the beta as:

$$
\beta_{j, t}^{\mathrm{FP}}=\rho_{j, M, t}^{\mathrm{hor}} \frac{\sigma_{j, t}}{\sigma_{M, t}}
$$

where $\rho_{j, M, t}^{\text {hor }}$ is the correlation between the return of asset $j$ with the market during the past hor months and $\sigma_{j, t}$ and $\sigma_{M, t}$ are the volatilities of the return of asset $j$ and the market, respectively. We follow Frazzini \& Pedersen (2014) and use a 1-year estimation window for the volatilities and a 5-year window for correlations.

\section{B Control Variables}

- Beta is the median beta estimate for a certain stock across all estimation approaches considered.

- Book-to-market (Fama \& French, 1992) is the most current observation for book 
equity divided by the market capitalization at the end of the previous fiscal year. Following the standard literature, we assume that the book equity of the previous year's balance sheet statement becomes available at the end of June. Book equity is defined as stockholders' equity, plus balance sheet deferred taxes and investment tax credit, plus post-retirement benefit liabilities, minus the book value of preferred stock.

- Co-Skewness (Harvey \& Siddique, 2000, "CoSkew") and Co-Kurtosis (Dittmar, 2002, "CoKurt") are the coefficients $\beta_{j, t}^{C S}$ and $\beta_{j, t}^{C K}$ in the regression $r_{j, \tau}-r_{f, \tau}=$ $\alpha_{j, t}+\beta_{j, t}^{M}\left(r_{M, \tau}-r_{f, \tau}\right)+\beta_{j, t}^{C S}\left(r_{M, \tau}-r_{f, \tau}\right)^{2}+\beta_{j, t}^{C K}\left(r_{M, \tau}-r_{f, \tau}\right)^{3}+\epsilon_{j, \tau}$, including the market excess return, the squared market excess return, and the cubed market excess return. The regression is estimated using daily returns over the previous year.

- Downside beta (Ang et al., 2006a) is the coefficient $\beta_{j, t}^{D}$ in the regression $r_{j, \tau}-r_{f, \tau}=$ $\alpha_{j, t}+\beta_{j, t}^{D}\left(r_{M, \tau}-r_{f, \tau}\right)+\epsilon_{j, \tau}$, using daily returns over the previous year only when the market return is below the average daily market return over that year.

- Forecast dispersion (Diether et al., 2002, "Disp") is the standard deviation of analysts' earnings forecasts for the current fiscal year divided by the absolute value of the mean earnings forecast. We obtain the data on the standard deviation and mean of earnings forecasts from the Unadjusted Summary History file of I/B/E/S.

- Idiosyncratic volatility (Ang et al., 2006b, "iVol") is the standard deviation of the residuals $\epsilon_{j, \tau}$ in the Fama \& French (1993) 3-factor model $r_{j, \tau}-r_{f, \tau}=\alpha_{j, t}+\beta_{j, t}^{M}\left(r_{M, \tau}-\right.$ $\left.r_{f, \tau}\right)+\beta_{j, t}^{S} S M B_{\tau}+\beta_{j, t}^{H} H M L_{\tau}+\epsilon_{j, \tau}$, using daily returns over the previous month. $S M B_{\tau}$ and $H M L_{\tau}$ denote the returns on the Fama \& French (1993) factors.

- Illiquidity (Amihud, 2002, "ILLIQ") is the absolute value of the stock's return divided by the daily dollar volume, averaged over the previous year. Specifically, it is Illiq $_{t}=$ $\frac{1}{n} \sum_{\tau=1}^{n} \frac{\left|r_{j, \tau}\right|}{\text { Volume\$ } \$_{\tau}}$, with the daily dollar volume (Volume $\$_{\tau}$, in thousand dollars) being calculated as last trade price times shares traded on day $\tau$, while the summation is taken over all $n$ trading days during the examination period.

- Investment (Fama \& French, 2006) is the annual growth rate in total assets. We update the variable every year at the end of June.

- Leverage (Bhandari, 1988) is defined as one minus book equity (see "Book-to-market") divided by total assets. Book equity and total assets are updated every 12 months at the end of June. 
- Maximum return (Bali et al., 2011, "MAX") is the average of the five highest daily returns during the previous year.

- Momentum (Jegadeesh \& Titman, 1993) is the cumulative stock return over the period from $t-12$ until $t-1$.

- Profitability (Fama \& French, 2006) is total revenue minus cost of goods sold (zero if missing) minus selling, general, and administrative expenses (zero if missing) minus interest expense (zero if missing), scaled by book equity (see Book-to-market). We require that at least one of the expenses is non-missing and update the variable every year in June.

- Relative short interest (Boehme et al., 2006, "RSI") is the ratio of short interest of a firm, obtained from Compustat, over the number of shares outstanding. If available, we use the short interest as of the end of month $t$, otherwise we use the last observation recorded in that month.

- SE (Armstrong et al., 2013) is the squared standard error of the slope coefficient $\beta_{j, t}^{\mathrm{HIST}}$ from the regression $r_{j, \tau}-r_{f, \tau}=\alpha_{j, t}+\beta_{j, t}^{\mathrm{HIST}}\left(r_{M, \tau}-r_{f, \tau}\right)+\epsilon_{j, \tau}$, estimated with monthly returns from a rolling 60 -month window.

- Short-Term reversal (Jegadeesh, 1990) is the preceding month's stock return (from $t-1$ to $t)$.

- Size (Banz, 1981) is the current market capitalization of a firm. Market capitalization is computed as the product of the stock price and the number of shares outstanding. In regressions, we take the natural logarithm to remove the extreme skewness in this variable.

- Vol-of-vol (Baltussen et al., 2018) is the volatility of non-overlapping monthly realized volatilities of a stock during the past year divided by the average of the monthly realized volatility. In dividing by the average volatility, we follow Baltussen et al. (2018). The results are qualitatively similar when using an unscaled version of vol-of-vol.

\section{Macroeconomic Variables}

- CAY (Lettau \& Ludvigson, 2001) is the log consumption-to-wealth ratio. 
- DFSP is the default spread, defined as the difference between BAA- and AAA-rated corporate bond yields.

- EFD is economic forecaster disagreement based on data from the Federal Reserve Bank of Philadelphia's Survey of Professional Forecasters. The data are from www. policyuncertainty. com.

- EPU is the U.S. news-based economic policy uncertainty index of Baker et al. (2016). The data are from www.policyuncertainty. com.

- iVol $^{\text {agg }}$ (Goyal \& Santa-Clara, 2003) is the value-weighted average idiosyncratic volatility of the stocks in our sample.

- $\log (\mathbf{P} / \mathbf{D})$ is the logarithm of the level of the S\&P 500 index over the 12-month trailing sum of dividends paid by S\&P 500 firms.

- $\log (\mathbf{P} / \mathbf{E})$ is the logarithm of the $\mathrm{S} \& \mathrm{P} 500$ price index over the 12 -month trailing sum of earnings.

- MRP1 is the PLS market excess return forecast following Kelly \& Pruitt (2013). We use 1-month out-of-sample market excess return forecasts from a 200-month rolling window that starts with data from 1926 and use the 25 size/book-to-market portfolios obtained from Kenneth French's webpage.

- MRP12 is the PLS 12-month out-of-sample market excess return forecasts. The procedure is similar as for MRP1.

- RREL is the stochastically detrended risk-free rate, i.e., the 1-month U.S. Treasury Bill rate minus its 12-month trailing average.

- TMSP is the term spread, defined as the difference between the U.S. Treasury 10-year yield and the 3-month Treasury Bill rate.

- VIX is the Chicago Board Options Exchange (CBOE) Volatility Index. The data are from the CBOE. 


\section{References}

Adrian, T., \& Franzoni, F. (2009). Learning about beta: Time-varying factor loadings, expected returns, and the conditional CAPM. Journal of Empirical Finance, 16(4), 537556.

Alfarano, S., \& Lux, T. (2007). A noise trader model as a generator of apparent financial power laws and long memory. Macroeconomic Dynamics, $11(\mathrm{~S} 1)$, 80-101.

Amihud, Y. (2002). Illiquidity and stock returns: Cross-section and time-series effects. Journal of Financial Markets, 5(1), 31-56.

Ang, A., \& Bekaert, G. (2007). Stock return predictability: Is it there? Review of Financial Studies, 20(3), 651-707.

Ang, A., Chen, J., \& Xing, Y. (2006a). Downside risk. Review of Financial Studies, 19(4), 1191-1239.

Ang, A., Hodrick, R. J., Xing, Y., \& Zhang, X. (2006b). The cross-section of volatility and expected returns. Journal of Finance, 61(1), 259-299.

Ang, A., Liu, J., \& Schwarz, K. (2018). Using individual stocks or portfolios in tests of factor models. Journal of Financial and Quantitative Analysis, forthcoming.

Armstrong, C. S., Banerjee, S., \& Corona, C. (2013). Factor-loading uncertainty and expected returns. Review of Financial Studies, 26(1), 158-207.

Baker, S. R., Bloom, N., \& Davis, S. J. (2016). Measuring economic policy uncertainty. Quarterly Journal of Economics, 131 (4), 1593-1636.

Bali, T. G., Cakici, N., \& Whitelaw, R. F. (2011). Maxing out: Stocks as lotteries and the cross-section of expected returns. Journal of Financial Economics, 99(2), 427-446.

Baltussen, G., Van Bekkum, S., \& Van Der Grient, B. (2018). Unknown unknowns: Uncertainty about risk and stock returns. Journal of Financial and Quantitative Analysis, 53(4), 1615-1651.

Banz, R. W. (1981). The relationship between return and market value of common stocks. Journal of Financial Economics, 9(1), 3-18.

Barber, B. M., Huang, X., \& Odean, T. (2016). Which factors matter to investors? Evidence from mutual fund flows. Review of Financial Studies, 29(10), 2600-2642.

Barry, C. B., \& Brown, S. J. (1984). Differential information and the small firm effect. Journal of Financial Economics, 13(2), 283-294.

Barry, C. B., \& Brown, S. J. (1985). Differential information and security market equilibrium. Journal of Financial and Quantitative Analysis, 20(4), 407-422.

Barry, C. B., \& Brown, S. J. (1986). Limited information as a source of risk. Journal of Portfolio Management, 12(2), 66-72.

Becker, J., Hollstein, F., Prokopczuk, M., \& Sibbertsen, P. (2019). The memory of beta. Leibniz University Working Paper.

Berk, J. B., \& Van Binsbergen, J. H. (2016). Assessing asset pricing models using revealed preference. Journal of Financial Economics, 119(1), 1-23.

Bhandari, L. C. (1988). Debt/equity ratio and expected common stock returns: Empirical evidence. Journal of Finance, 43(2), 507-528. 
Boehme, R. D., Danielsen, B. R., \& Sorescu, S. M. (2006). Short-sale constraints, differences of opinion, and overvaluation. Journal of Financial and Quantitative Analysis, 41(2), 455-487.

Bollerslev, T., Li, S. Z., \& Todorov, V. (2016). Roughing up beta: Continuous versus discontinuous betas and the cross-section of expected stock returns. Journal of Financial Economics, 120(3), 464-490.

Boons, M. (2016). State variables, macroeconomic activity, and the cross section of individual stocks. Journal of Financial Economics, 119(3), 489-511.

Buss, A., \& Vilkov, G. (2012). Measuring equity risk with option-implied correlations. Review of Financial Studies, 25(10), 3113-3140.

Carhart, M. M. (1997). On persistence in mutual fund performance. Journal of Finance, 52(1), 57-82.

Chang, B.-Y., Christoffersen, P., Jacobs, K., \& Vainberg, G. (2012). Option-implied measures of equity risk. Review of Finance, 16(2), 385-428.

Chapman, D. A., \& Polkovnichenko, V. (2009). First-order risk aversion, heterogeneity, and asset market outcomes. Journal of Finance, 64 (4), 1863-1887.

Christensen, B. J., \& Prabhala, N. R. (1998). The relation between implied and realized volatility. Journal of Financial Economics, 50(2), 125-150.

Corsi, F. (2009). A simple approximate long-memory model of realized volatility. Journal of Financial Econometrics, 7(2), 174-196.

Diether, K. B., Malloy, C. J., \& Scherbina, A. (2002). Differences of opinion and the cross section of stock returns. Journal of Finance, 57(5), 2113-2141.

Dimson, E. (1979). Risk measurement when shares are subject to infrequent trading. Journal of Financial Economics, 7(2), 197-226.

Dittmar, R. F. (2002). Nonlinear pricing kernels, kurtosis preference, and evidence from the cross section of equity returns. Journal of Finance, 57(1), 369-403.

Fama, E. F., \& French, K. R. (1992). The cross-section of expected stock returns. Journal of Finance, $47(2), 427-465$.

Fama, E. F., \& French, K. R. (1993). Common risk factors in the returns on stocks and bonds. Journal of Financial Economics, 33(1), 3-56.

Fama, E. F., \& French, K. R. (2006). Profitability, investment and average returns. Journal of Financial Economics, 82(3), 491-518.

Fama, E. F., \& French, K. R. (2008). Dissecting anomalies. Journal of Finance, 63(4), $1653-1678$.

Fama, E. F., \& French, K. R. (2015). A five-factor asset pricing model. Journal of Financial Economics, 116(1), 1-22.

Fama, E. F., \& MacBeth, J. D. (1973). Risk, return, and equilibrium: Empirical tests. Journal of Political Economy, $81(3), 607-636$.

Frazzini, A., \& Pedersen, L. H. (2014). Betting against beta. Journal of Financial Economics, $111(1), 1-25$. 
Goyal, A., \& Santa-Clara, P. (2003). Idiosyncratic risk matters! Journal of Finance, 58(3), 975-1008.

Goyal, A., \& Welch, I. (2008). A comprehensive look at the empirical performance of equity premium prediction. Review of Financial Studies, 21 (4), 1455-1508.

Graham, J. R., \& Harvey, C. R. (2001). The theory and practice of corporate finance: Evidence from the field. Journal of Financial Economics, 60(2), 187-243.

Harvey, C. R., Liu, Y., \& Zhu, H. (2016). ... and the cross-section of expected returns. Review of Financial Studies, 29(1), 5-68.

Harvey, C. R., \& Siddique, A. (2000). Conditional skewness in asset pricing tests. Journal of Finance, $55(3), 1263-1295$.

Hodrick, R. J. (1992). Dividend yields and expected stock returns: Alternative procedures for inference and measurement. Review of Financial Studies, 5(3), 357-386.

Hollstein, F. (2020). Estimating beta: The international evidence. Leibniz University Working Paper.

Hollstein, F., \& Prokopczuk, M. (2016). Estimating beta. Journal of Financial and Quantitative Analysis, 51(4), 1437-1466.

Hollstein, F., \& Prokopczuk, M. (2018). How aggregate volatility-of-volatility affects stock returns. Review of Asset Pricing Studies, 8(2), 253-292.

Hollstein, F., Prokopczuk, M., \& Wese Simen, C. (2019). Estimating beta: Forecast adjustments and the impact of stock characteristics for a broad cross-section. Journal of Financial Markets, 44, 91-118.

Hollstein, F., Prokopczuk, M., \& Wese Simen, C. (2020). The conditional Capital Asset Pricing Model revisited: Evidence from high-frequency betas. Management Science, forthcoming.

Hou, K., \& Loh, R. K. (2016). Have we solved the idiosyncratic volatility puzzle? Journal of Financial Economics, 121(1), 167-194.

Hou, K., Xue, C., \& Zhang, L. (2019). Replicating anomalies. Review of Financial Studies, forthcoming.

Jagannathan, R., \& Wang, Z. (1996). The conditional CAPM and the cross-section of expected returns. Journal of Finance, 51(1), 3-53.

Jegadeesh, N. (1990). Evidence of predictable behavior of security returns. Journal of Finance, 45(3), 881-898.

Jegadeesh, N., \& Titman, S. (1993). Returns to buying winners and selling losers: Implications for stock market efficiency. Journal of Finance, 48(1), 65-91.

Kamara, A., Korajczyk, R. A., Lou, X., \& Sadka, R. (2016). Horizon pricing. Journal of Financial and Quantitative Analysis, 51(6), 1769-1793.

Kelly, B., \& Pruitt, S. (2013). Market expectations in the cross-section of present values. Journal of Finance, 68(5), 1721-1756.

Klein, R. W., \& Bawa, V. S. (1977). The effect of limited information and estimation risk on optimal portfolio diversification. Journal of Financial Economics, 5(1), 89-111. 
Lettau, M., \& Ludvigson, S. (2001). Resurrecting the (C)CAPM: A cross-sectional test when risk premia are time-varying. Journal of Political Economy, 109(6), 1238-1287.

Levi, Y., \& Welch, I. (2017). Best practice for cost-of-capital estimates. Journal of Financial and Quantitative Analysis, 52(2), 427-463.

Lewellen, J., \& Nagel, S. (2006). The conditional CAPM does not explain asset-pricing anomalies. Journal of Financial Economics, 82(2), 289-314.

Lewellen, J., Nagel, S., \& Shanken, J. (2010). A skeptical appraisal of asset pricing tests. Journal of Financial Economics, 96(2), 175-194.

Lintner, J. (1965). The valuation of risk assets and the selection of risky investments in stock portfolios and capital budgets. Review of Economics and Statistics, 47(1), 13-37.

Lo, A. W., \& MacKinlay, A. C. (1990). Data-snooping biases in tests of financial asset pricing models. Review of Financial Studies, 3(3), 431-467.

Miller, E. M. (1977). Risk, uncertainty, and divergence of opinion. Journal of Finance, 32(4), 1151-1168.

Mossin, J. (1966). Equilibrium in a capital asset market. Econometrica, 34(4), 768-783.

Newey, W. K., \& West, K. D. (1987). A simple, positive semi-definite, heteroskedasticity and autocorrelation consistent covariance matrix. Econometrica, 55(3), 703-708.

Pástor, L., \& Stambaugh, R. F. (2003). Liquidity risk and expected stock returns. Journal of Political Economy, 111(3), 642-685.

Patton, A. J., \& Verardo, M. (2012). Does beta move with news? Firm-specific information flows and learning about profitability. Review of Financial Studies, 25(9), 2789-2839.

Ross, S. A. (1976). The arbitrage theory of capital asset pricing. Journal of Economic Theory, 13(3), 341-360.

Scholes, M., \& Williams, J. (1977). Estimating betas from nonsynchronous data. Journal of Financial Economics, 5(3), 309-327.

Sharpe, W. F. (1964). Capital asset prices: A theory of market equilibrium under conditions of risk. Journal of Finance, 19(3), 425-442.

Shumway, T. (1997). The delisting bias in CRSP data. Journal of Finance, 52(1), 327-340.

Shumway, T., \& Warther, V. A. (1999). The delisting bias in CRSP's NASDAQ data and its implications for the size effect. Journal of Finance, 54(6), 2361-2379.

Zhang, X. (2006). Information uncertainty and stock returns. Journal of Finance, 61(1), $105-137$. 


\section{Figure 1: Time Series of Aggregate Beta Uncertainty}

This figure plots the time series of the cross-sectional value-weighted average of the beta uncertainty measure along with the 5th and 95th percentiles of the cross-sectional beta uncertainty distribution. The shaded areas indicate the time periods marked as business cycle contractions by the National Bureau of Economic Research (NBER).

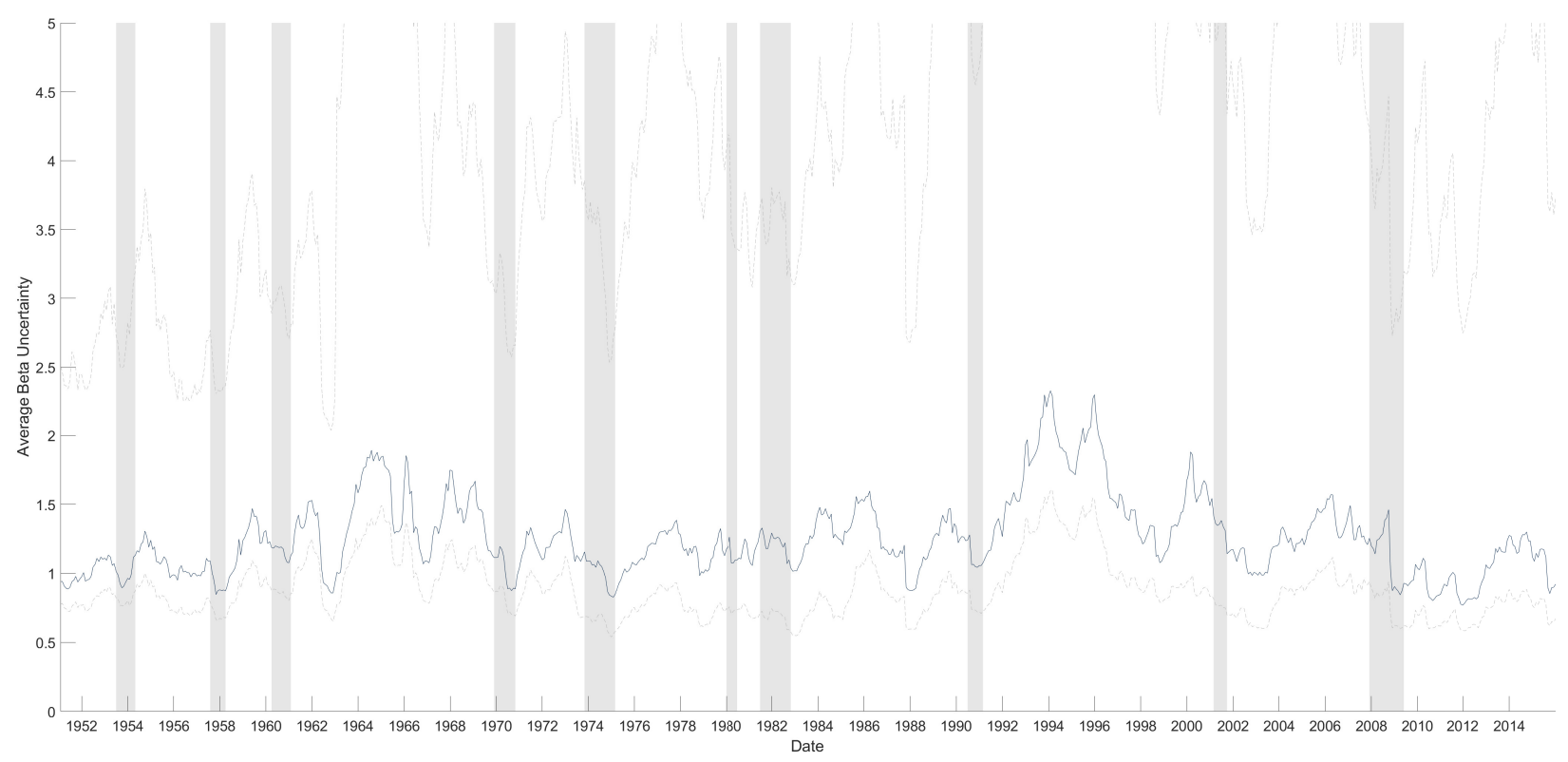




\section{Table 1: Summary Statistics: Beta Estimates}

This table presents the summary statistics of the beta estimates used for our main beta uncertainty measure.

"Mean ${ }_{v w}$ " and "Mean" denote the time-series average of the value-weighted and simple cross-sectional mean, respectively. "SD $C S$ " and "SD" $\mathrm{S}^{T S "}$ are the average cross-sectional and time-series standard deviations, respectively. That is, for the $\mathrm{SD}^{C S}$, we use the time-series average of the cross-sectional standard deviations and for $\mathrm{SD}^{T S}$, we compute the cross-sectional average of the time-series standard deviations of individual firms (requiring a minimum of 50 observations). "q.05" and " $\mathrm{q}^{0.95 "}$ indicate the averages of the cross-sectional 5th and 95th percentiles, respectively. "Corr ${ }^{C S "}$ and "Corr ${ }^{T S "}$ present the average cross-sectional and time-series correlation of the estimates with the average beta for each stock (derived from all estimates), respectively. "SE" denotes the average standard error associated with the different beta estimates. The sample period runs from January 1951 until December 2015.

\begin{tabular}{lccccccccc}
\hline \hline & Mean $_{\mathrm{vw}}$ & Mean & $\mathrm{SD}^{\mathrm{CS}}$ & $\mathrm{SD}^{\mathrm{TS}}$ & $\mathrm{q}^{0.05}$ & $\mathrm{q}^{0.95}$ & $\mathrm{Corr}^{\mathrm{CS}}$ & Corr $^{\mathrm{TS}}$ & $\mathrm{SE}$ \\
\hline HIST & 1.0168 & 0.8329 & 0.5873 & 0.4266 & 0.0225 & 1.8948 & 0.9469 & 0.8667 & 0.2243 \\
HIST6 & 1.0159 & 0.8248 & 0.6624 & 0.5456 & -0.0871 & 2.0025 & 0.8680 & 0.7357 & 0.3245 \\
EWMA $_{84}$ & 1.0164 & 0.8313 & 0.5785 & 0.4164 & 0.0321 & 1.8728 & 0.9364 & 0.8370 & 0.0978 \\
Dim1 $_{168}$ & 1.0156 & 0.8339 & 0.5332 & 0.3319 & 0.0915 & 1.7955 & 0.9281 & 0.8354 & 0.0961 \\
Dim2 & 1.0134 & 0.9301 & 0.6096 & 0.4883 & 0.0594 & 2.0018 & 0.9511 & 0.8927 & 0.3026 \\
Dim3 & 1.0116 & 0.9490 & 0.6388 & 0.5349 & 0.0391 & 2.0671 & 0.9164 & 0.8432 & 0.3685 \\
Dim4 & 1.0107 & 0.9851 & 0.6748 & 0.5820 & 0.0292 & 2.1626 & 0.8768 & 0.7939 & 0.4231 \\
SW & 1.0105 & 1.0122 & 0.7130 & 0.6276 & 0.0116 & 2.2554 & 0.8375 & 0.7411 & 0.4728 \\
\hline \hline
\end{tabular}




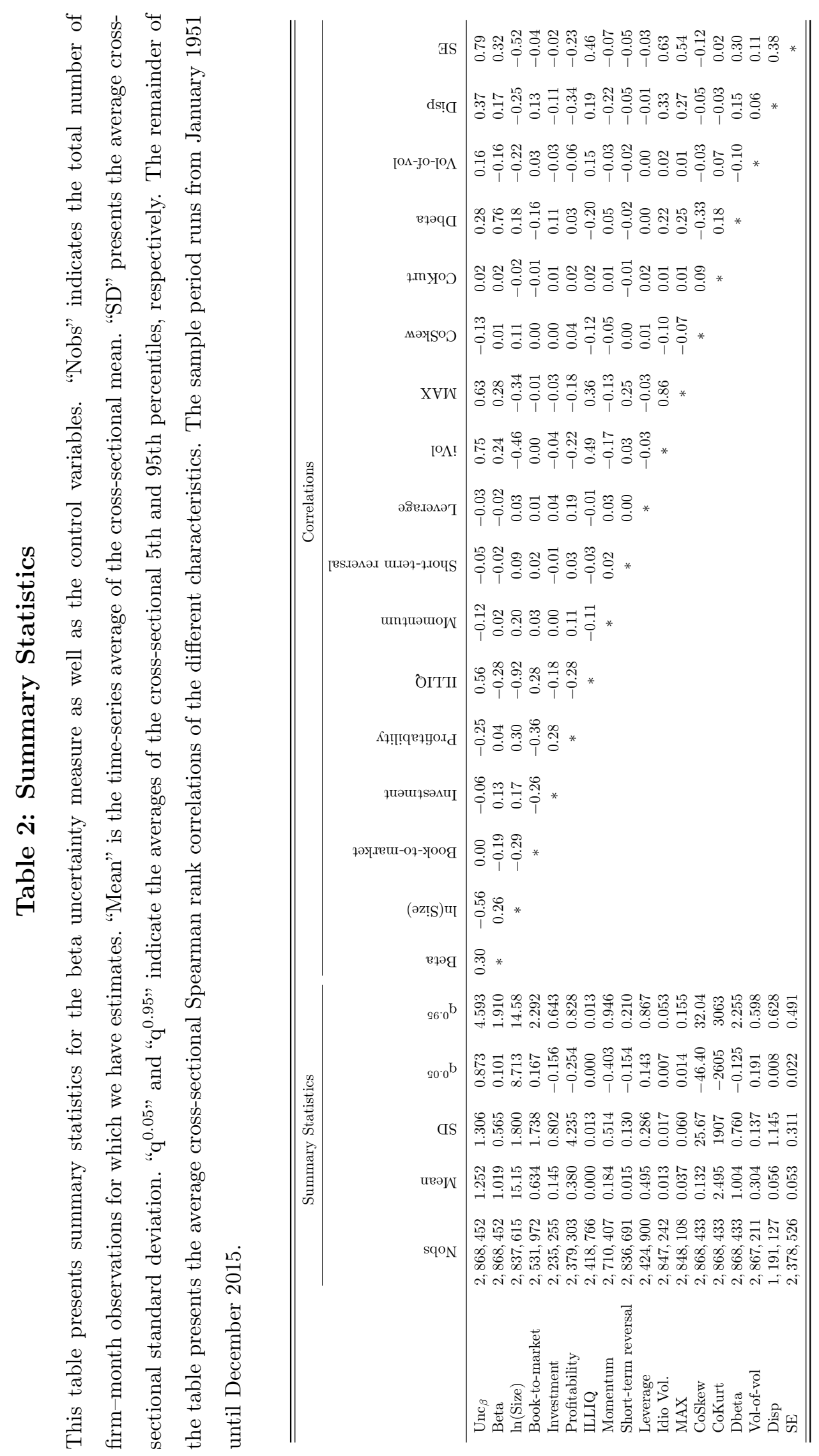




\section{Table 3: Portfolio Sorts: Beta Uncertainty}

At the end of each month, we sort the stocks into 5 value-weighted portfolios according to their beta uncertainty. The column labeled "5 minus 1" refers to the hedge portfolio buying the quintile of stocks with the highest beta uncertainty and simultaneously selling the stocks in the quintile with the lowest beta uncertainty. The row labeled "Mean return" denotes the annualized average portfolio excess return. "CAPM alpha", "4-factor alpha", "5-factor alpha", and "FF5 alpha" refer to the alphas of the CAPM, the Carhart (1997) 4-factor, and the 5-factor models (including Pástor \& Stambaugh, 2003 liquidity), and the Fama \& French (2015) 5-factor model, respectively. Robust Newey \& West (1987) standard errors using 6 lags are reported in parentheses. ${ }^{*},{ }^{* *}$, and ${ }^{* * *}$ indicate significance at the $10 \%, 5 \%$, and $1 \%$ level, respectively. The lower part of the table presents the value-weighted averages of several characteristics for the 5 portfolios. " $\mathrm{Unc}_{\beta, t}$ " is the observation of beta uncertainty used for sorting, while " $\mathrm{Unc}_{\beta, t+1}$ " denotes the beta uncertainty at the end of the month after we sort the portfolios. Size is log-transformed and ILLIQ is multiplied by 1,000. Since most characteristics are strictly positive, we only report the results of significance tests for the 5 minus 1 differences.

\begin{tabular}{l|ccccc|c}
\hline \hline Rank & 1 & 2 & 3 & 4 & 5 & 5 minus 1 \\
\hline Mean return & $0.0746^{* * *}$ & $0.0830^{* * *}$ & $0.0785^{* * *}$ & $0.0563^{*}$ & -0.0044 & $-0.0790^{* *}$ \\
& $(0.0169)$ & $(0.0223)$ & $(0.0286)$ & $(0.0336)$ & $(0.0424)$ & $(0.0330)$ \\
\hline CAPM alpha & $0.0154^{* * *}$ & 0.0047 & -0.0162 & $-0.0495^{* * *}$ & $-0.1211^{* * *}$ & $-0.1365^{* * *}$ \\
& $(0.0050)$ & $(0.0053)$ & $(0.0102)$ & $(0.0167)$ & $(0.0237)$ & $(0.0279)$ \\
4-factor alpha & $0.0091^{* * *}$ & 0.0047 & -0.0053 & $-0.0322^{* * *}$ & $-0.0971^{* * *}$ & $-0.1062^{* * *}$ \\
& $(0.0034)$ & $(0.0056)$ & $(0.0076)$ & $(0.0106)$ & $(0.0185)$ & $(0.0210)$ \\
5-factor alpha & $0.0086^{* *}$ & 0.0069 & -0.0048 & $-0.0346^{* * *}$ & $-0.1157^{* * *}$ & $-0.1243^{* * *}$ \\
& $(0.0042)$ & $(0.0071)$ & $(0.0097)$ & $(0.0129)$ & $(0.0230)$ & $(0.0262)$ \\
FF5 alpha & -0.0017 & -0.0024 & 0.0067 & -0.0016 & $-0.0653^{* * *}$ & $-0.0636^{* * *}$ \\
& $(0.0030)$ & $(0.0069)$ & $(0.0075)$ & $(0.0105)$ & $(0.0169)$ & $(0.0181)$ \\
\hline \hline Portfolio Characteristics & 0.9372 & 1.4523 & 1.9264 & 2.5292 & 3.7999 & $2.8626^{* * *}$ \\
Unc $\beta, t$ & 0.9463 & 1.4440 & 1.9065 & 2.4879 & 3.6881 & $2.7419^{* * *}$ \\
Unc $\beta, t+1$ & 0.8982 & 1.1162 & 1.2913 & 1.4237 & 1.4664 & $0.5682^{* * *}$ \\
Beta & 15.811 & 14.513 & 13.669 & 12.836 & 11.880 & $-3.9310^{* * *}$ \\
Size & 0.6202 & 0.6396 & 0.6627 & 0.7235 & 0.8135 & $0.1933^{* * *}$ \\
Book-to-market & 0.1157 & 0.1620 & 0.2454 & 0.3208 & 0.3391 & $0.2234^{* * *}$ \\
Investment & 0.3952 & 0.3780 & 0.3541 & 0.3407 & 0.1139 & $-0.2812^{* * *}$ \\
Profitability & 0.0283 & 0.0922 & 0.2129 & 0.5160 & 2.7026 & $2.6743^{* * *}$ \\
ILLIQ & 0.1520 & 0.1899 & 0.2484 & 0.3292 & 0.4878 & $0.3358^{* * *}$ \\
Momentum & 0.0098 & 0.0144 & 0.0188 & 0.0244 & 0.0351 & $0.0253^{* * *}$ \\
iVol & 0.0307 & 0.0627 & 0.1107 & 0.1815 & 0.3446 & $0.3139^{* * *}$ \\
SE & 0.0495 & 0.1168 & 0.2025 & 0.2855 & 0.5496 & $0.5001^{* * *}$ \\
Disp & & & & & & \\
\hline \hline
\end{tabular}




\section{Table 4: Double Sorts: Beta Uncertainty, Beta, and Size}

This table reports annualized value-weighted Carhart (1997) 4-factor alphas for double-sorted portfolios. At the end of each month, we first sort the stocks into 5 quintile portfolios according to their betas (size). Within each of these quintiles, we sort the stocks into another 5 portfolios based on their beta uncertainty. We report the alphas of all 25 portfolios as well as the respective long minus short (" 5 minus 1 ") portfolios. The rows labeled "5 minus 1" refer to the hedge portfolio buying the quintile of stocks with the highest beta uncertainty and simultaneously selling the stocks in the quintile with the lowest beta uncertainty. Within each portfolio, we value-weight the stocks. The final column ("Avg.") reports the averages for each beta uncertainty quintile across the quintiles sorted on the respective control characteristic. Robust Newey \& West (1987) standard errors using 6 lags are reported in parentheses. ${ }^{*},{ }^{* *}$, and ${ }^{* * *}$ indicate significance at the $10 \%, 5 \%$, and $1 \%$ level, respectively.

\begin{tabular}{|c|c|c|c|c|c|c|c|c|}
\hline & & \multicolumn{5}{|c|}{ Beta } & \multirow[b]{2}{*}{5 minus 1} & \multirow[b]{2}{*}{ Avg. } \\
\hline & & 1 & 2 & 3 & 4 & 5 & & \\
\hline \multirow{12}{*}{$\operatorname{Unc}_{\beta}$} & 1 & $\begin{array}{c}0.0276^{* *} \\
(0.012)\end{array}$ & $\begin{array}{c}0.0229^{* *} \\
(0.009)\end{array}$ & $\begin{array}{l}0.0092 \\
(0.007)\end{array}$ & $\begin{array}{l}0.0057 \\
(0.008)\end{array}$ & $\begin{array}{c}-0.0143 \\
(0.013)\end{array}$ & $\begin{array}{c}-0.0419^{*} \\
(0.022)\end{array}$ & $\begin{array}{c}0.0102^{* *} \\
(0.004)\end{array}$ \\
\hline & \multirow[t]{2}{*}{2} & 0.0139 & 0.0171 & 0.0040 & -0.0118 & $-0.0449^{* * *}$ & $-0.0588^{* *}$ & -0.0042 \\
\hline & & $(0.014)$ & $(0.011)$ & $(0.010)$ & $(0.009)$ & $(0.016)$ & $(0.024)$ & $(0.006)$ \\
\hline & \multirow[t]{2}{*}{3} & 0.0259 & $0.0178^{*}$ & 0.0074 & 0.0037 & -0.0204 & $-0.0463^{*}$ & 0.0054 \\
\hline & & $(0.017)$ & $(0.011)$ & $(0.010)$ & $(0.012)$ & $(0.017)$ & $(0.027)$ & $(0.007)$ \\
\hline & \multirow[t]{2}{*}{4} & 0.0060 & 0.0132 & $-0.0254^{* *}$ & $-0.0323^{* * *}$ & $-0.0853^{* * *}$ & $-0.0913^{* * *}$ & $-0.0237^{* * *}$ \\
\hline & & $(0.017)$ & $(0.013)$ & $(0.012)$ & $(0.012)$ & $(0.022)$ & $(0.029)$ & $(0.008)$ \\
\hline & \multirow[t]{2}{*}{5} & $-0.0668^{* * *}$ & $-0.0318^{*}$ & $-0.0450^{* * *}$ & $-0.0602^{* * *}$ & $-0.1383^{* * *}$ & $-0.0715^{* *}$ & $-0.0699^{* * *}$ \\
\hline & & $(0.019)$ & $(0.018)$ & $(0.016)$ & $(0.017)$ & $(0.024)$ & $(0.029)$ & $(0.013)$ \\
\hline & \multirow[t]{3}{*}{5 minus 1} & $\begin{array}{c}-0.0944^{* * *} \\
(0.022)\end{array}$ & $-0.0547^{* * *}$ & $-0.0542^{* * *}$ & $-0.0659^{* * *}$ & $-0.1240^{* * *}$ & & $-0.0802^{* * *}$ \\
\hline & & \multicolumn{5}{|c|}{ Size } & \multirow[b]{2}{*}{5 minus 1} & \multirow[b]{2}{*}{ Avg. } \\
\hline & & 1 & 2 & 3 & 4 & 5 & & \\
\hline \multirow{11}{*}{$\mathrm{Unc}_{\beta}$} & 1 & $\begin{array}{c}0.0623^{* * *} \\
(0.013)\end{array}$ & $\begin{array}{c}0.0615^{* * *} \\
(0.010)\end{array}$ & $\begin{array}{c}0.0421^{* * *} \\
(0.008)\end{array}$ & $\begin{array}{c}0.0321^{* * *} \\
(0.008)\end{array}$ & $\begin{array}{c}0.0113^{* *} \\
(0.006)\end{array}$ & $\begin{array}{c}-0.0511^{* * *} \\
(0.013)\end{array}$ & $\begin{array}{c}0.0414^{* * *} \\
(0.007)\end{array}$ \\
\hline & \multirow[t]{2}{*}{2} & $0.0554^{* * *}$ & $0.0368^{* * *}$ & $0.0280^{* * *}$ & $0.0271^{* * *}$ & 0.0042 & $-0.0512^{* * *}$ & $0.0304^{* * *}$ \\
\hline & & $(0.014)$ & $(0.009)$ & $(0.007)$ & $(0.007)$ & $(0.004)$ & $(0.014)$ & $(0.006)$ \\
\hline & \multirow[t]{2}{*}{3} & $0.0365^{* *}$ & 0.0072 & $0.0160^{* *}$ & $0.0206^{* * *}$ & 0.0045 & $-0.0320^{* *}$ & $0.0168^{* * *}$ \\
\hline & & $(0.015)$ & $(0.009)$ & $(0.008)$ & $(0.007)$ & $(0.005)$ & $(0.016)$ & $(0.006)$ \\
\hline & \multirow[t]{2}{*}{4} & -0.0100 & $-0.0317^{* *}$ & $-0.0207^{*}$ & -0.0006 & -0.0035 & 0.0065 & $-0.0130^{*}$ \\
\hline & & $(0.017)$ & $(0.013)$ & $(0.011)$ & $(0.007)$ & $(0.007)$ & $(0.017)$ & $(0.008)$ \\
\hline & \multirow[t]{2}{*}{5} & $-0.0818^{* * *}$ & $-0.0890^{* * *}$ & $-0.0835^{* * *}$ & $-0.0525^{* * *}$ & $-0.0309^{* *}$ & $0.0510^{* *}$ & $-0.0677^{* * *}$ \\
\hline & & $(0.023)$ & $(0.021)$ & $(0.017)$ & $(0.013)$ & $(0.013)$ & $(0.026)$ & $(0.014)$ \\
\hline & \multirow[t]{2}{*}{5 minus 1} & $-0.1442^{* * *}$ & $-0.1505^{* * *}$ & $-0.1255^{* * *}$ & $-0.0846^{* * *}$ & $-0.0421^{* *}$ & & $-0.1091^{* * *}$ \\
\hline & & $(0.023)$ & $(0.024)$ & $(0.021)$ & $(0.018)$ & $(0.017)$ & & $(0.017)$ \\
\hline
\end{tabular}




\section{Table 5: Double Sorts: Beta Uncertainty}

This table reports annualized value-weighted Carhart (1997) 4-factor alphas for double-sorted portfolios. At the end of each month, we first sort the stocks into 5 quintile portfolios according to the characteristic denoted in the first column. Within each of these quintiles, we sort the stocks into another 5 portfolios based on their beta uncertainty. The 5 portfolios reported are the averages of the beta uncertainty quintiles across the quintiles sorted on the control characteristic. The column labeled " 5 minus 1" refers to the hedge portfolio buying the quintile of stocks with the highest beta uncertainty and simultaneously selling the stocks in the quintile with the lowest beta uncertainty. Within each portfolio, we value-weight the stocks. Robust Newey \& West (1987) standard errors using 6 lags are reported in parentheses. ${ }^{*},{ }^{* *}$, and ${ }^{* * *}$ indicate significance at the $10 \%, 5 \%$, and $1 \%$ level, respectively.

\begin{tabular}{|c|c|c|c|c|c|c|}
\hline Rank & 1 & 2 & 3 & 4 & 5 & 5 minus 1 \\
\hline Book-to-market & $\begin{array}{c}0.0066 \\
(0.0045)\end{array}$ & $\begin{array}{c}0.0031 \\
(0.0049)\end{array}$ & $\begin{array}{l}-0.0072 \\
(0.0063)\end{array}$ & $\begin{array}{c}-0.0303^{* * *} \\
(0.0086)\end{array}$ & $\begin{array}{c}-0.0714^{* * *} \\
(0.0148)\end{array}$ & $\begin{array}{c}-0.0780^{* * *} \\
(0.0180)\end{array}$ \\
\hline Investment & $\begin{array}{c}0.0113^{* * *} \\
(0.0044)\end{array}$ & $\begin{array}{c}0.0026 \\
(0.0057)\end{array}$ & $\begin{array}{c}0.0011 \\
(0.0071)\end{array}$ & $\begin{array}{c}-0.0198^{*} \\
(0.0106)\end{array}$ & $\begin{array}{c}-0.0581^{* * *} \\
(0.0162)\end{array}$ & $\begin{array}{c}-0.0695^{* * *} \\
(0.0192)\end{array}$ \\
\hline Profitability & $\begin{array}{c}0.0039 \\
(0.0041)\end{array}$ & $\begin{array}{c}-0.0116^{*} \\
(0.0064)\end{array}$ & $\begin{array}{l}-0.0114 \\
(0.0070)\end{array}$ & $\begin{array}{c}-0.0358^{* * *} \\
(0.0119)\end{array}$ & $\begin{array}{c}-0.0615^{* * *} \\
(0.0142)\end{array}$ & $\begin{array}{c}-0.0654^{* * *} \\
(0.0158)\end{array}$ \\
\hline ILLIQ & $\begin{array}{c}0.0331^{* * *} \\
(0.0065)\end{array}$ & $\begin{array}{c}0.0191^{* * *} \\
(0.0052)\end{array}$ & $\begin{array}{l}0.0125^{* *} \\
(0.0050)\end{array}$ & $\begin{array}{c}-0.0196^{* * *} \\
(0.0069)\end{array}$ & $\begin{array}{c}-0.0816^{* * *} \\
(0.0125)\end{array}$ & $\begin{array}{c}-0.1147^{* * *} \\
(0.0172)\end{array}$ \\
\hline Momentum & $\begin{array}{c}0.0138^{* * *} \\
(0.0042)\end{array}$ & $\begin{array}{l}-0.0002 \\
(0.0053)\end{array}$ & $\begin{array}{c}-0.0213^{* * *} \\
(0.0061)\end{array}$ & $\begin{array}{c}-0.0461^{* * *} \\
(0.0084)\end{array}$ & $\begin{array}{c}-0.0866^{* * *} \\
(0.0133)\end{array}$ & $\begin{array}{c}-0.1004^{* * *} \\
(0.0155)\end{array}$ \\
\hline Short-term reversal & $\begin{array}{c}0.0136^{* * *} \\
(0.0038)\end{array}$ & $\begin{array}{l}-0.0025 \\
(0.0042)\end{array}$ & $\begin{array}{c}0.0035 \\
(0.0073)\end{array}$ & $\begin{array}{c}-0.0212^{* *} \\
(0.0105)\end{array}$ & $\begin{array}{c}-0.0856^{* * *} \\
(0.0152)\end{array}$ & $\begin{array}{c}-0.0992^{* * *} \\
(0.0175)\end{array}$ \\
\hline Leverage & $\begin{array}{c}0.0099^{* * *} \\
(0.0034)\end{array}$ & $\begin{array}{c}0.0054 \\
(0.0055)\end{array}$ & $\begin{array}{l}-0.0006 \\
(0.0072)\end{array}$ & $\begin{array}{c}-0.0262^{* * *} \\
(0.0088)\end{array}$ & $\begin{array}{c}-0.0714^{* * *} \\
(0.0171)\end{array}$ & $\begin{array}{c}-0.0813^{* * *} \\
(0.0189)\end{array}$ \\
\hline $\mathrm{iVol}$ & $\begin{array}{c}-0.0135^{* *} \\
(0.0054)\end{array}$ & $\begin{array}{c}-0.0122^{*} \\
(0.0066)\end{array}$ & $\begin{array}{c}-0.0319^{* * *} \\
(0.0081)\end{array}$ & $\begin{array}{c}-0.0354^{* * *} \\
(0.0092)\end{array}$ & $\begin{array}{c}-0.0496^{* * *} \\
(0.0115)\end{array}$ & $\begin{array}{c}-0.0361^{* * *} \\
(0.0133)\end{array}$ \\
\hline MAX & $\begin{array}{c}0.0005 \\
(0.0037)\end{array}$ & $\begin{array}{l}-0.0101 \\
(0.0062)\end{array}$ & $\begin{array}{c}-0.0298^{* * *} \\
(0.0068)\end{array}$ & $\begin{array}{c}-0.0377^{* * *} \\
(0.0090)\end{array}$ & $\begin{array}{c}-0.0512^{* * *} \\
(0.0108)\end{array}$ & $\begin{array}{c}-0.0517^{* * *} \\
(0.0118)\end{array}$ \\
\hline CoSkew & $\begin{array}{l}0.0069^{*} \\
(0.0040)\end{array}$ & $\begin{array}{l}-0.0035 \\
(0.0046)\end{array}$ & $\begin{array}{l}-0.0081 \\
(0.0062)\end{array}$ & $\begin{array}{c}-0.0281^{* * *} \\
(0.0094)\end{array}$ & $\begin{array}{c}-0.0895^{* * *} \\
(0.0150)\end{array}$ & $\begin{array}{c}-0.0964^{* * *} \\
(0.0166)\end{array}$ \\
\hline CoKurt & $\begin{array}{c}0.0100^{* * *} \\
(0.0035)\end{array}$ & $\begin{array}{l}-0.0014 \\
(0.0050)\end{array}$ & $\begin{array}{l}-0.0042 \\
(0.0070)\end{array}$ & $\begin{array}{c}-0.0317^{* * *} \\
(0.0095)\end{array}$ & $\begin{array}{c}-0.0808^{* * *} \\
(0.0143)\end{array}$ & $\begin{array}{c}-0.0908^{* * *} \\
(0.0164)\end{array}$ \\
\hline Dbeta & $\begin{array}{l}0.0071^{*} \\
(0.0038)\end{array}$ & $\begin{array}{l}-0.0025 \\
(0.0051)\end{array}$ & $\begin{array}{l}-0.0044 \\
(0.0059)\end{array}$ & $\begin{array}{c}-0.0179^{* *} \\
(0.0084)\end{array}$ & $\begin{array}{c}-0.0795^{* * *} \\
(0.0127)\end{array}$ & $\begin{array}{c}-0.0866^{* * *} \\
(0.0147)\end{array}$ \\
\hline Vol-of-vol & $\begin{array}{c}0.0150^{* * *} \\
(0.0042)\end{array}$ & $\begin{array}{c}0.0083 \\
(0.0053)\end{array}$ & $\begin{array}{l}-0.0041 \\
(0.0073)\end{array}$ & $\begin{array}{c}-0.0331^{* * *} \\
(0.0106)\end{array}$ & $\begin{array}{c}-0.0866^{* * *} \\
(0.0164)\end{array}$ & $\begin{array}{c}-0.1015^{* * *} \\
(0.0192)\end{array}$ \\
\hline Disp & $\begin{array}{c}0.0027 \\
(0.0056)\end{array}$ & $\begin{array}{l}-0.0011 \\
(0.0061)\end{array}$ & $\begin{array}{l}-0.0020 \\
(0.0088)\end{array}$ & $\begin{array}{l}-0.0175 \\
(0.0123)\end{array}$ & $\begin{array}{c}-0.0488^{* * *} \\
(0.0178)\end{array}$ & $\begin{array}{c}-0.0516^{* *} \\
(0.0203)\end{array}$ \\
\hline $\mathrm{SE}$ & $\begin{array}{c}0.0041 \\
(0.0062)\end{array}$ & $\begin{array}{l}-0.0048 \\
(0.0065)\end{array}$ & $\begin{array}{l}-0.0067 \\
(0.0067)\end{array}$ & $\begin{array}{c}-0.0378^{* * *} \\
(0.0087)\end{array}$ & $\begin{array}{c}-0.0501^{* * *} \\
(0.0113)\end{array}$ & $\begin{array}{c}-0.0543^{* * *} \\
(0.0134)\end{array}$ \\
\hline
\end{tabular}




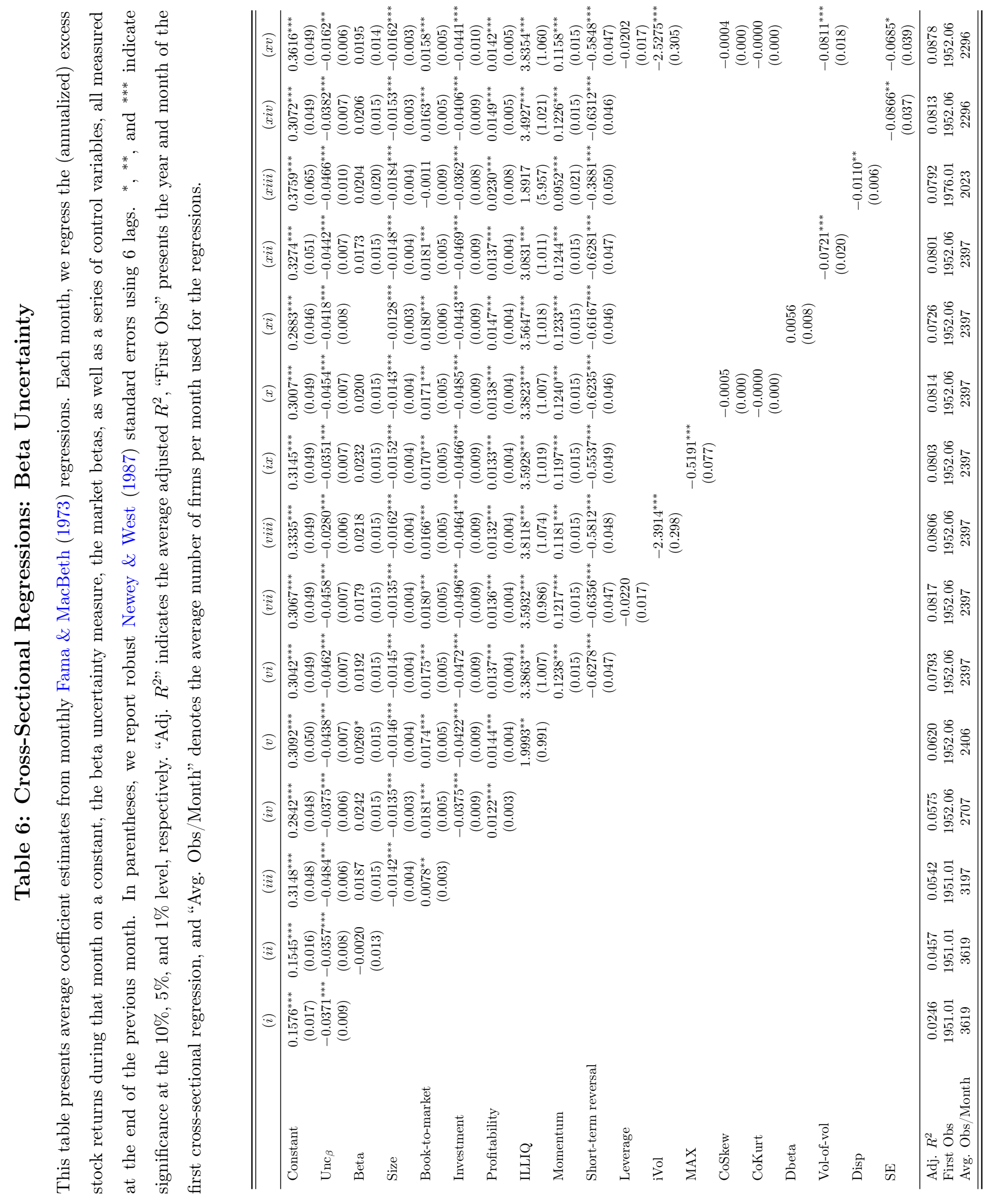




\section{Table 7: Return Predictability of Aggregate Beta Uncertainty}

This table summarizes the results of return predictability regressions for aggregate beta uncertainty. We regress annualized excess returns of the CRSP value-weighted index over $h$ months on a constant and the lagged aggregate beta uncertainty. We consider forecasting horizons $(h)$ of $1,3,6,9,12,18$, 24, and 36 months. To account for overlapping return observations, in parentheses we present Hodrick (1992) corrected standard errors. "Adj. $R^{2}$ " reports the adjusted in-sample $R^{2}$. The line " $R_{O O S}^{2}$ " indicates the out-ofsample $R^{2}$ s for the respective predictive horizons. We test the out-of-sample significance using the bootstrap approach of Goyal \& Welch (2008). ${ }^{*},{ }^{* *}$, and ${ }^{* *}$ indicate significance at the $10 \%, 5 \%$, and $1 \%$ level, respectively.

\begin{tabular}{lcccccccc}
\hline \hline Horizon (Months) & 1 & 3 & 6 & 9 & 12 & 18 & 24 & 36 \\
\hline Constant & $0.2805^{* * *}$ & $0.2724^{* * *}$ & $0.2414^{* * *}$ & $0.2072^{* * *}$ & $0.1884^{* * *}$ & $0.1739^{* * *}$ & $0.1602^{* * *}$ & $0.1208^{* *}$ \\
(s.e.) & $(0.077)$ & $(0.074)$ & $(0.071)$ & $(0.068)$ & $(0.067)$ & $(0.063)$ & $(0.059)$ & $(0.056)$ \\
Unc $_{\beta}^{a g g}$ & $-0.1785^{* * *}$ & $-0.1712^{* * *}$ & $-0.1462^{* * *}$ & $-0.1188^{* * *}$ & $-0.1037^{* *}$ & $-0.0922^{*}$ & $-0.0813^{*}$ & -0.0503 \\
$($ s.e.) & $(0.057)$ & $(0.055)$ & $(0.052)$ & $(0.051)$ & $(0.050)$ & $(0.048)$ & $(0.045)$ & $(0.043)$ \\
Adj. R & 0.002 & 0.002 & 0.005 & 0.019 & 0.037 & 0.053 & 0.073 & 0.248 \\
\hline$R_{O O S}^{2}$ & $0.004^{* *}$ & $0.005^{* * *}$ & -0.010 & -0.026 & -0.038 & -0.092 & -0.152 & -0.253 \\
\hline \hline
\end{tabular}




\section{Table 8: Double Sorts: Beta Uncertainty and Relative Short Interest}

This table reports annualized value-weighted Carhart (1997) 4-factor alphas for double-sorted portfolios. At the end of each month, we first sort the stocks into 5 quintile portfolios according to their relative short interest (RSI). Within each of these quintiles, we sort the stocks into another 5 portfolios based on their beta uncertainty. We report the alphas of all 25 portfolios as well as the respective long minus short (" 5 minus 1") portfolios. The row labeled "5 minus 1" refers to the hedge portfolio buying the quintile of stocks with the highest beta uncertainty and simultaneously selling the stocks in the quintile with the lowest beta uncertainty. Within each portfolio, we value-weight the stocks. The final column ("Avg.") reports the averages for each beta uncertainty quintile across the quintiles sorted on RSI. Robust Newey \& West (1987) standard errors using 6 lags are reported in parentheses. ${ }^{*},{ }^{* *}$, and ${ }^{* * *}$ indicate significance at the $10 \%, 5 \%$, and $1 \%$ level, respectively.

\begin{tabular}{|c|c|c|c|c|c|c|c|c|}
\hline & & \multicolumn{5}{|c|}{ RSI } & \multirow[b]{2}{*}{5 minus 1} & \multirow[b]{2}{*}{ Avg. } \\
\hline & & 1 & 2 & 3 & 4 & 5 & & \\
\hline \multirow{12}{*}{$\mathrm{Unc}_{\beta}$} & \multirow[t]{2}{*}{1} & -0.0100 & 0.0027 & $0.0182^{*}$ & -0.0136 & -0.0119 & -0.0019 & -0.0032 \\
\hline & & $(0.014)$ & $(0.010)$ & $(0.010)$ & $(0.010)$ & $(0.012)$ & $(0.019)$ & $(0.007)$ \\
\hline & \multirow[t]{2}{*}{2} & -0.0225 & 0.0225 & 0.0035 & -0.0106 & -0.0209 & 0.0016 & -0.0055 \\
\hline & & $(0.024)$ & $(0.014)$ & $(0.011)$ & $(0.012)$ & $(0.015)$ & $(0.029)$ & $(0.009)$ \\
\hline & \multirow[t]{2}{*}{3} & -0.0133 & 0.0076 & -0.0042 & -0.0274 & $-0.0558^{* * *}$ & -0.0425 & $-0.0198^{*}$ \\
\hline & & $(0.024)$ & $(0.020)$ & $(0.017)$ & $(0.017)$ & $(0.019)$ & $(0.029)$ & $(0.012)$ \\
\hline & \multirow[t]{2}{*}{4} & -0.0255 & -0.0019 & 0.0067 & -0.0110 & $-0.0686^{* * *}$ & -0.0432 & $-0.0198^{*}$ \\
\hline & & $(0.026)$ & $(0.019)$ & $(0.018)$ & $(0.019)$ & $(0.019)$ & $(0.032)$ & $(0.012)$ \\
\hline & \multirow[t]{2}{*}{5} & $-0.0589^{*}$ & -0.0378 & $-0.0483^{*}$ & $-0.0599^{* * *}$ & $-0.1418^{* * *}$ & $-0.0829^{* *}$ & $-0.0676^{* * *}$ \\
\hline & & $(0.034)$ & $(0.030)$ & $(0.028)$ & $(0.022)$ & $(0.028)$ & $(0.038)$ & (0.018) \\
\hline & \multirow[t]{2}{*}{5 minus 1} & -0.0489 & -0.0405 & $-0.0666^{* *}$ & $-0.0463^{*}$ & $-0.1299^{* * *}$ & & $-0.0644^{* * *}$ \\
\hline & & $(0.039)$ & $(0.033)$ & $(0.030)$ & $(0.024)$ & $(0.031)$ & & $(0.021)$ \\
\hline
\end{tabular}




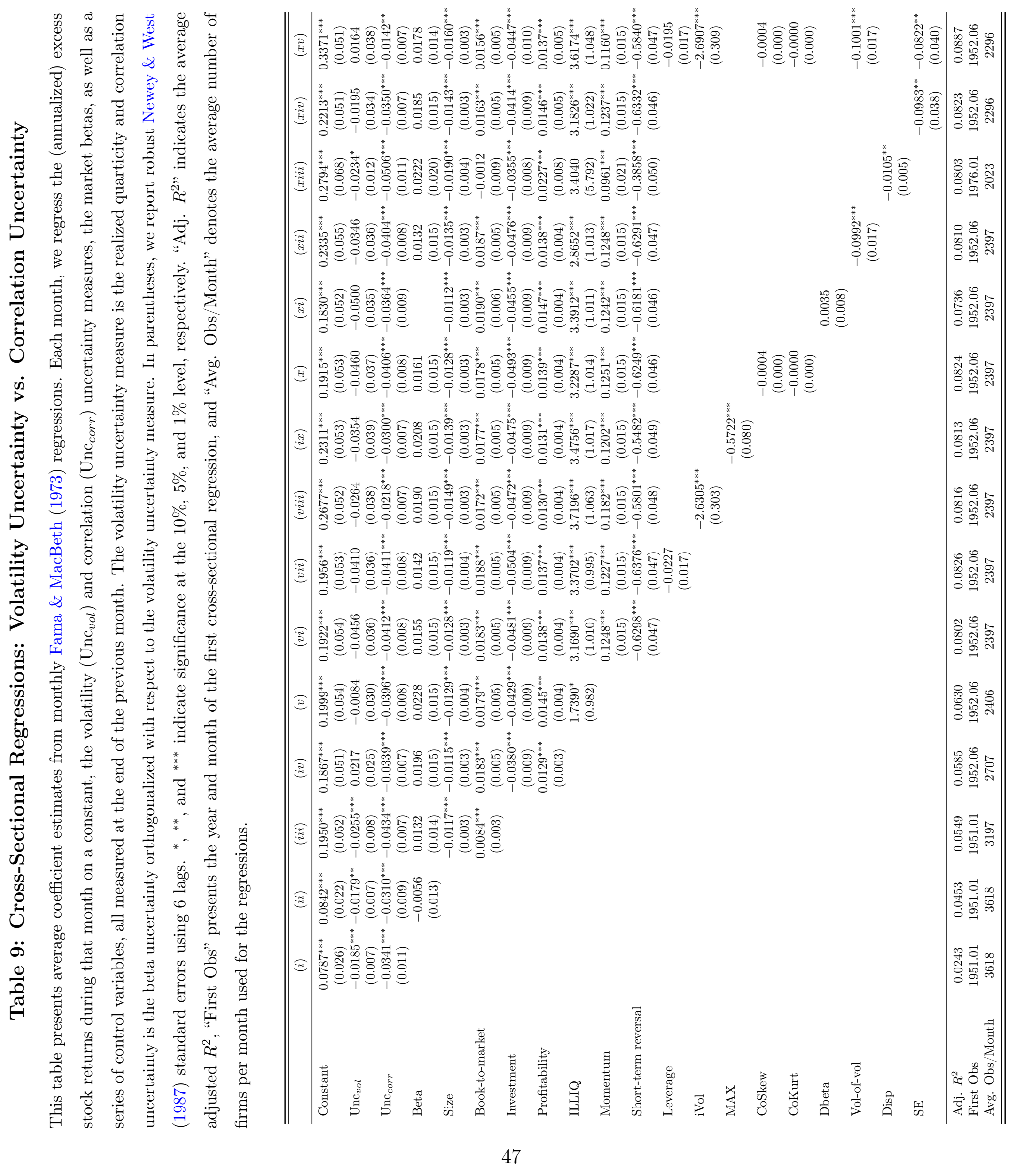




\section{Table 10: Portfolio Sorts: Randomized Model Selection}

At the end of each month, we sort the stocks into 5 portfolios according to their beta uncertainty, computed from a random subset of possible beta estimators. To create this random subset, we first randomize the number of beta estimators to be included (minimum 6) and then randomly assign (without replacement) the estimators. We repeat this procedure 1,000 times. The column labeled " 5 minus 1 " refers to the hedge portfolio buying the quintile of stocks with the highest beta uncertainty and simultaneously selling the stocks in the quintile with the lowest beta uncertainty. The row labeled "Mean return" denotes the annualized average portfolio excess return. "CAPM alpha", "4-factor alpha", "5-factor alpha", and "FF5 alpha" refer to the alphas of the CAPM, the Carhart (1997) 4-factor, and the 5-factor models (including Pástor \& Stambaugh, 2003 liquidity), and the Fama \& French (2015) 5-factor model, respectively. In brackets, we report the share of subsets for which the respective parameter is significant at the $10 \%$ level using robust Newey \& West (1987) standard errors with 6 lags.

\begin{tabular}{|c|c|c|c|c|c|c|}
\hline Rank & 1 & 2 & 3 & 4 & 5 & 5 minus 1 \\
\hline $\begin{array}{l}\text { Value-weighted } \\
\text { Mean return }\end{array}$ & $\begin{array}{l}0.0745 \\
{[1.000]}\end{array}$ & $\begin{array}{l}0.0838 \\
{[1.000]}\end{array}$ & $\begin{array}{l}0.0787 \\
{[1.000]}\end{array}$ & $\begin{array}{l}0.0506 \\
{[0.100]}\end{array}$ & $\begin{array}{c}-0.0161 \\
{[0.000]}\end{array}$ & $\begin{array}{c}-0.0906 \\
{[1.000]}\end{array}$ \\
\hline CAPM alpha & $\begin{array}{l}0.0151 \\
{[1.000]}\end{array}$ & $\begin{array}{l}0.0059 \\
{[0.162]}\end{array}$ & $\begin{array}{c}-0.0131 \\
{[0.095]}\end{array}$ & $\begin{array}{c}-0.0545 \\
{[1.000]}\end{array}$ & $\begin{array}{c}-0.1279 \\
{[1.000]}\end{array}$ & $\begin{array}{c}-0.1431 \\
{[1.000]}\end{array}$ \\
\hline 4-factor alpha & $\begin{array}{l}0.0095 \\
{[1.000]}\end{array}$ & $\begin{array}{l}0.0048 \\
{[0.005]}\end{array}$ & $\begin{array}{c}-0.0005 \\
{[0.000]}\end{array}$ & $\begin{array}{c}-0.0392 \\
{[1.000]}\end{array}$ & $\begin{array}{c}-0.1027 \\
{[1.000]}\end{array}$ & $\begin{array}{c}-0.1122 \\
{[1.000]}\end{array}$ \\
\hline 5-factor alpha & $\begin{array}{l}0.0076 \\
{[0.785]}\end{array}$ & $\begin{array}{l}0.0071 \\
{[0.071]}\end{array}$ & $\begin{array}{l}0.0022 \\
{[0.000]}\end{array}$ & $\begin{array}{c}-0.0419 \\
{[1.000]}\end{array}$ & $\begin{array}{c}-0.1141 \\
{[1.000]}\end{array}$ & $\begin{array}{c}-0.1217 \\
{[1.000]}\end{array}$ \\
\hline FF5 alpha & $\begin{array}{c}-0.0023 \\
{[0.000]}\end{array}$ & $\begin{array}{l}0.0006 \\
{[0.000]}\end{array}$ & $\begin{array}{l}0.0112 \\
{[0.240]}\end{array}$ & $\begin{array}{c}-0.0098 \\
{[0.001]}\end{array}$ & $\begin{array}{c}-0.0741 \\
{[1.000]}\end{array}$ & $\begin{array}{c}-0.0717 \\
{[1.000]}\end{array}$ \\
\hline \multicolumn{7}{|c|}{ Equally Weighted } \\
\hline Mean return & $\begin{array}{l}0.1000 \\
{[1.000]}\end{array}$ & $\begin{array}{l}0.1143 \\
{[1.000]}\end{array}$ & $\begin{array}{l}0.1114 \\
{[1.000]}\end{array}$ & $\begin{array}{l}0.0906 \\
{[1.000]}\end{array}$ & $\begin{array}{l}0.0268 \\
{[0.000]}\end{array}$ & $\begin{array}{c}-0.0732 \\
{[0.988]} \\
\end{array}$ \\
\hline CAPM alpha & $\begin{array}{l}0.0489 \\
{[1.000]}\end{array}$ & $\begin{array}{l}0.0466 \\
{[1.000]}\end{array}$ & $\begin{array}{l}0.0315 \\
{[1.000]}\end{array}$ & $\begin{array}{c}-0.0001 \\
{[0.000]}\end{array}$ & $\begin{array}{c}-0.0712 \\
{[1.000]}\end{array}$ & $\begin{array}{c}-0.1201 \\
{[1.000]}\end{array}$ \\
\hline 4-factor alpha & $\begin{array}{l}0.0339 \\
{[1.000]}\end{array}$ & $\begin{array}{l}0.0327 \\
{[1.000]}\end{array}$ & $\begin{array}{l}0.0256 \\
{[1.000]}\end{array}$ & $\begin{array}{l}0.0035 \\
{[0.000]}\end{array}$ & $\begin{array}{c}-0.0599 \\
{[1.000]}\end{array}$ & $\begin{array}{c}-0.0938 \\
{[1.000]}\end{array}$ \\
\hline 5-factor alpha & $\begin{array}{l}0.0329 \\
{[1.000]}\end{array}$ & $\begin{array}{l}0.0324 \\
{[1.000]}\end{array}$ & $\begin{array}{l}0.0267 \\
{[1.000]}\end{array}$ & $\begin{array}{l}0.0016 \\
{[0.000]}\end{array}$ & $\begin{array}{c}-0.0716 \\
{[1.000]}\end{array}$ & $\begin{array}{c}-0.1046 \\
{[1.000]}\end{array}$ \\
\hline FF5 alpha & $\begin{array}{l}0.0137 \\
{[0.951]}\end{array}$ & $\begin{array}{l}0.0120 \\
{[0.649]}\end{array}$ & $\begin{array}{l}0.0142 \\
{[0.695]}\end{array}$ & $\begin{array}{l}0.0034 \\
{[0.000]}\end{array}$ & $\begin{array}{c}-0.0496 \\
{[1.000]}\end{array}$ & $\begin{array}{c}-0.0633 \\
{[1.000]}\end{array}$ \\
\hline
\end{tabular}




\section{Beta Uncertainty}

\section{Online Appendix}

This Online Appendix contains the robustness tables referenced in the main paper. In addition, Section OA1 provides extensive robustness analyses for the beta uncertainty measure. In Section OA2, we examine the robustness of our main results to alternative definitions of idiosyncratic volatility. Finally, Section OA3 presents an analysis that explicitly accounts for potential errors-in-variables in the beta uncertainty measure.

JEL classification: G12, G11, G17

Keywords: Beta, CAPM, disagreement, ambiguity, parameter uncertainty 


\section{OA1 Alternative Beta Uncertainty Measures}

In this section, we test the robustness of our main results by considering alternative measures for beta uncertainty. First, we use a simpler beta uncertainty measure based only on the individual beta point estimates. Second, we consider the total range spanned by the different beta point estimates instead of all confidence intervals. Third, we consider the standard error of the respective best models. Fourth, we examine the past absolute forecast error of the respective best beta model.

For the first alternative measure, we use the simple standard deviation across the different beta estimates:

$$
\mathrm{Unc}_{\beta, j, t}^{S D}=\sqrt{\frac{1}{N-1} \sum_{i=1}^{N}\left(\beta_{j, t}^{(i)}-\bar{\beta}_{j, t}\right)^{2}}
$$

where $\beta_{j, t}^{(i)}$ is the estimate of one approach and $\bar{\beta}_{j, t}$ denotes the average estimate across the $N$ approaches. Empirically, this simple measure has a correlation of more than $82 \%$ with our main beta uncertainty measure.

The analysis of this simpler beta uncertainty measure is important because the measure's correlations with known cross-sectional return predictors is far lower than those of our main beta uncertainty measure. The correlation coefficients with size and illiquidity amount to only -0.37 and 0.39 , respectively. Those of the standard deviation beta uncertainty measure with other measures of volatility like idiosyncratic volatility, MAX, and SE are also substantially lower than those for our main measure, amounting to $0.55,0.47$, and 0.61 , respectively.

We present the results in Table A7. For all specifications, and independently of which control variables we include, this alternative beta uncertainty measure is negatively priced in the cross-section of stock returns. A two-standard-deviation increase in beta uncertainty 
is associated with a decrease in average returns of $6.4 \% .^{1}$ The effect of this variable is somewhat weaker than that of the main beta uncertainty measure. Thus, a beta uncertainty measure that also takes into account the sampling variation of the individual beta estimates appears to carry a somewhat stronger economic content than the simple measure we use for this analysis.

A second alternative is to measure the dispersion as the range of beta estimates. The measure is:

$$
\mathrm{Unc}_{\beta, j, t}^{\text {Range }}=\max _{i}\left(\beta_{j, t}^{(i)}\right)-\min _{i}\left(\beta_{j, t}^{(i)}\right)
$$

The results for this measure are in Table A8. As for our main measure, we find that also the simple range-based beta uncertainty measure is significantly negatively priced. The economic impact of beta uncertainty is also high with this measure: a two-standard-deviation increase in beta uncertainty is associated with a decrease in average returns of $6.49 \%{ }^{2}$

As a third alternative measure, we use the standard error of the best model. For each beta estimation approach and stock, we obtain estimates for the previous month as well as the corresponding realized beta $\beta_{j, t-1, t}^{R}$ for each stock. For each stock, we use the estimator for which the forecast error $(F E)$

$$
F E=\sqrt{\left(\beta_{j, t-1}^{(i)}-\beta_{j, t-1, t}^{R}\right)^{2}}
$$

is lowest. The beta uncertainty measure is then simply the current standard error of this estimator.

We present the results in Table A9. As in our main result, we find that this alternative

\footnotetext{
${ }^{1}$ We obtain this figure by multiplying the cross-sectional premium with 2 times the average cross-sectional standard deviation of the beta uncertainty measure of 0.166 .

${ }^{2}$ We obtain this figure by multiplying the univariate cross-sectional premium with 2 times the average cross-sectional standard deviation of the alternative beta uncertainty measure of 0.5174.
} 
beta uncertainty measure is also significantly negatively priced. A two-standard-deviation increase in beta uncertainty is associated with a decrease in average returns of $6.68 \% .^{3}$

Our fourth alternative measure of uncertainty about the true beta is to use the lowest squared error from the previous period. That is, for each stock we use the minimum of the FEs as defined in Equation (OA3). A high measure indicates that the stock's beta is difficult to estimate, since none of the estimators comes close to the true realized beta. A small realization indicates that the uncertainty surrounding the beta estimation is low, at least when using an adequate estimator.

The results are in Table A10. As for all other alternative measures, we find that the lowest squared error from the previous period carries a significant negative premium in the crosssection of stock return throughout every specification. A two-standard-deviation increase in this beta uncertainty measure is associated with a decrease in average returns of $5.91 \%{ }^{4}$

\section{OA2 Further Idiosyncratic Volatility Controls}

In this section, we present the Fama \& MacBeth (1973) regression results for alternative ways to control for idiosyncratic volatility. In Table A11 we present the results when using the natural logarithm instead of the level of idiosyncratic volatility, Table A12 uses quintile dummies for idiosyncratic volatility, and for Table A13 we measure the idiosyncratic volatility relative to the CAPM instead of the Fama \& French (1993) model. Our main results are robust to each of these definitions.

\footnotetext{
${ }^{3}$ We obtain this figure by multiplying the univariate cross-sectional premium with 2 times the average cross-sectional standard deviation of the alternative beta uncertainty measure of 0.2691.

${ }^{4}$ We obtain this figure by multiplying the univariate cross-sectional premium with 2 times the average cross-sectional standard deviation of the alternative beta uncertainty measure of 0.6611.
} 


\section{OA3 Errors-In-Variables}

The measure of beta uncertainty has to be pre-estimated before we include it in crosssectional regressions. Therefore, these cross-sectional regressions might be affected by errorsin-variables. While we show that the results are similar when using portfolio sorts that are far less strongly affected by errors-in-variables, in this section we directly account for this in cross-sectional regressions. We use the instrumental variable approach of Christensen \& Prabhala (1998). First, for each stock, we regress the beta uncertainty measures on the measures 12 months before. The measurement errors in these variables should be uncorrelated over time. Second, we replace our beta uncertainty measure with the fitted values from the regressions performed for each stock. Finally, we re-run the regressions of Equation (2) in the main part of the paper using the instrumental variable. In the presence of measurement errors in the independent variable, there is a downward attenuation bias in the slope coefficient. Hence, we expect the regression slopes to rise (in absolute terms) once we use the instrumental variables.

We present the results in Table A14. The results when using the instrumental variable approach are qualitatively similar to our main results. Beta uncertainty earns an economically large and significant negative premium in the cross-section of stock returns. Furthermore, consistent with our expectations, the cross-sectional premium estimates are substantially larger in magnitude for the instrumental variable approach. 


\section{Table A1: Portfolio Sorts: Beta Uncertainty - Beta Estimates}

At the end of each month, we sort the stocks into value-weighted 5 portfolios according to their beta uncertainty. The column labeled "5 minus 1" refers to the hedge portfolio buying the quintile of stocks with the highest beta uncertainty and simultaneously selling the stocks in the quintile with the lowest beta uncertainty. The table presents the value-weighted portfolio averages of the various beta measures used to compute the beta uncertainty measure.

\begin{tabular}{l|ccccc|c}
\hline \hline Rank & 1 & 2 & 3 & 4 & 5 & 5 minus 1 \\
\hline \multicolumn{2}{l}{ Individual Portfolio Betas } & & & & & \\
Beta & 0.8982 & 1.1162 & 1.2913 & 1.4237 & 1.4664 & 0.5682 \\
HIST & 0.9052 & 1.0958 & 1.2674 & 1.4000 & 1.4109 & 0.5057 \\
HIST6 & 0.9048 & 1.0944 & 1.2589 & 1.3962 & 1.4110 & 0.5062 \\
EWMA $_{84}$ & 0.9072 & 1.0940 & 1.2596 & 1.3867 & 1.3989 & 0.4916 \\
EWMA $_{168}$ & 0.9127 & 1.0886 & 1.2458 & 1.3598 & 1.3625 & 0.4497 \\
Dim1 & 0.8872 & 1.1213 & 1.2962 & 1.4219 & 1.4670 & 0.5798 \\
Dim2 & 0.8860 & 1.1188 & 1.2930 & 1.4237 & 1.5004 & 0.6144 \\
Dim3 & 0.8799 & 1.1224 & 1.3026 & 1.4458 & 1.5598 & 0.6799 \\
Dim4 & 0.8731 & 1.1253 & 1.3183 & 1.4742 & 1.6226 & 0.7494 \\
SW & 0.8822 & 1.1252 & 1.3108 & 1.4444 & 1.4704 & 0.5882 \\
\hline \hline
\end{tabular}




\section{Table A2: Portfolio Sorts: Beta Uncertainty - Robustness}

At the end of each month, we sort the stocks into 5 portfolios according to their beta uncertainty. The column labeled "5 minus 1" refers to the hedge portfolio buying the quintile of stocks with the highest beta uncertainty and simultaneously selling the stocks in the quintile with the lowest beta uncertainty. The row labeled "Mean return" denotes the annualized average portfolio excess return. "CAPM alpha", "4-factor alpha", "5-factor alpha", and "FF5 alpha" refer to the alphas of the CAPM, the Carhart (1997) 4-factor, and the 5-factor models (including Pástor \& Stambaugh, 2003 liquidity), and the Fama \& French (2015) 5-factor model, respectively. Robust Newey \& West (1987) standard errors using 6 lags are reported in parentheses. ${ }^{*},{ }^{* *}$, and ${ }^{* * *}$ indicate significance at the 10\%, 5\%, and 1\% level, respectively. With NYSE breakpoints, we first sort only the stocks traded on the NYSE by their beta uncertainty and then assign all stocks based on the quintile breakpoints obtained from the first sort. In the panels denoted by "Models Augmented by BAB Factor", we present the alphas toward the respective models while adding the betting-against-beta factor of Frazzini \& Pedersen (2014) to the set of factors.

\begin{tabular}{|c|c|c|c|c|c|c|}
\hline Rank & 1 & 2 & 3 & 4 & 5 & 5 minus 1 \\
\hline \multicolumn{7}{|c|}{ Equally Weighted } \\
\hline Mean return & $\begin{array}{c}0.0978^{* * *} \\
(0.0172)\end{array}$ & $\begin{array}{c}0.1106^{* * *} \\
(0.0223)\end{array}$ & $\begin{array}{c}0.1063^{* * *} \\
(0.0267)\end{array}$ & $\begin{array}{c}0.0886^{* * *} \\
(0.0324)\end{array}$ & $\begin{array}{c}0.0397 \\
(0.0412)\end{array}$ & $\begin{array}{c}-0.0581^{*} \\
(0.0320)\end{array}$ \\
\hline CAPM alpha & $\begin{array}{c}0.0477^{* * *} \\
(0.0098)\end{array}$ & $\begin{array}{c}0.0433^{* * *} \\
(0.0114)\end{array}$ & $\begin{array}{l}0.0266^{* *} \\
(0.0131)\end{array}$ & $\begin{array}{l}-0.0021 \\
(0.0169)\end{array}$ & $\begin{array}{c}-0.0598^{* *} \\
(0.0252)\end{array}$ & $\begin{array}{c}-0.1075^{* * *} \\
(0.0272)\end{array}$ \\
\hline 4-factor alpha & $\begin{array}{c}0.0326^{* * *} \\
(0.0062)\end{array}$ & $\begin{array}{c}0.0300^{* * *} \\
(0.0057)\end{array}$ & $\begin{array}{c}0.0202^{* * *} \\
(0.0057)\end{array}$ & $\begin{array}{c}0.0025 \\
(0.0084)\end{array}$ & $\begin{array}{c}-0.0495^{* * *} \\
(0.0156)\end{array}$ & $\begin{array}{c}-0.0821^{* * *} \\
(0.0186)\end{array}$ \\
\hline 5-factor alpha & $\begin{array}{c}0.0327^{* * *} \\
(0.0075)\end{array}$ & $\begin{array}{c}0.0305^{* * *} \\
(0.0071)\end{array}$ & $\begin{array}{c}0.0210^{* * *} \\
(0.0068)\end{array}$ & $\begin{array}{l}-0.0003 \\
(0.0098)\end{array}$ & $\begin{array}{c}-0.0619^{* * *} \\
(0.0192)\end{array}$ & $\begin{array}{c}-0.0947^{* * *} \\
(0.0228)\end{array}$ \\
\hline FF5 alpha & $\begin{array}{l}0.0137^{*} \\
(0.0073) \\
\end{array}$ & $\begin{array}{c}0.0092 \\
(0.0069) \\
\end{array}$ & $\begin{array}{c}0.0070 \\
(0.0071) \\
\end{array}$ & $\begin{array}{c}0.0013 \\
(0.0096) \\
\end{array}$ & $\begin{array}{c}-0.0374^{* *} \\
(0.0164) \\
\end{array}$ & $\begin{array}{c}-0.0511^{* * *} \\
(0.0183)\end{array}$ \\
\hline \multicolumn{7}{|c|}{ Value-Weighted and NYSE Breakpoints } \\
\hline 4-factor alpha & $\begin{array}{c}0.0100^{* *} \\
(0.0047)\end{array}$ & $\begin{array}{c}0.0042 \\
(0.0046)\end{array}$ & $\begin{array}{l}-0.0004 \\
(0.0064)\end{array}$ & $\begin{array}{l}-0.0059 \\
(0.0079)\end{array}$ & $\begin{array}{c}-0.0390^{* * *} \\
(0.0109)\end{array}$ & $\begin{array}{c}-0.0490^{* * *} \\
(0.0144)\end{array}$ \\
\hline \multicolumn{7}{|c|}{ Models Augmented by BAB Factor (Value-Weighted) } \\
\hline 4-factor alpha & $\begin{array}{c}0.0015 \\
(0.0035)\end{array}$ & $\begin{array}{c}0.0023 \\
(0.0058)\end{array}$ & $\begin{array}{c}0.0087 \\
(0.0076)\end{array}$ & $\begin{array}{l}-0.0076 \\
(0.0099)\end{array}$ & $\begin{array}{c}-0.0658^{* * *} \\
(0.0195)\end{array}$ & $\begin{array}{c}-0.0673^{* * *} \\
(0.0220)\end{array}$ \\
\hline FF5 alpha & $\begin{array}{c}-0.0052^{*} \\
(0.0030) \\
\end{array}$ & $\begin{array}{l}-0.0022 \\
(0.0073) \\
\end{array}$ & $\begin{array}{l}0.0163^{* *} \\
(0.0077)\end{array}$ & $\begin{array}{c}0.0108 \\
(0.0097) \\
\end{array}$ & $\begin{array}{c}-0.0518^{* * *} \\
(0.0177) \\
\end{array}$ & $\begin{array}{c}-0.0466^{* *} \\
(0.0190)\end{array}$ \\
\hline \multicolumn{7}{|c|}{ Models Augmented by BAB Factor (Equally Weighted) } \\
\hline 4-factor alpha & $\begin{array}{c}0.0152^{* * *} \\
(0.0043)\end{array}$ & $\begin{array}{c}0.0151^{* * *} \\
(0.0041)\end{array}$ & $\begin{array}{l}0.0129^{* *} \\
(0.0055)\end{array}$ & $\begin{array}{c}0.0056 \\
(0.0095)\end{array}$ & $\begin{array}{c}-0.0361^{* *} \\
(0.0175)\end{array}$ & $\begin{array}{c}-0.0512^{* * *} \\
(0.0191)\end{array}$ \\
\hline FF5 alpha & $\begin{array}{c}0.0041 \\
(0.0057)\end{array}$ & $\begin{array}{c}0.0023 \\
(0.0061)\end{array}$ & $\begin{array}{c}0.0038 \\
(0.0075)\end{array}$ & $\begin{array}{c}0.0026 \\
(0.0109)\end{array}$ & $\begin{array}{c}-0.0328^{*} \\
(0.0179)\end{array}$ & $\begin{array}{c}-0.0369^{* *} \\
(0.0185)\end{array}$ \\
\hline
\end{tabular}




\section{Table A3: Portfolio Sorts: Beta Uncertainty - Beta Uncertainty Orthogonalized to Beta}

At the end of each month, we sort the stocks into 5 portfolios according to their orthogonalized beta uncertainty. The column labeled "5 minus 1" refers to the hedge portfolio buying the quintile of stocks with the highest beta uncertainty and simultaneously selling the stocks in the quintile with the lowest beta uncertainty. The row labeled "Mean return" denotes the annualized average portfolio excess return. "CAPM alpha", "4-factor alpha", "5-factor alpha", and "FF5 alpha" refer to the alphas of the CAPM, the Carhart (1997) 4-factor, and the 5-factor models (including Pástor \& Stambaugh, 2003 liquidity), and the Fama \& French (2015) 5-factor model, respectively. Robust Newey \& West (1987) standard errors using 6 lags are reported in parentheses. ${ }^{*},{ }^{* *}$, and ${ }^{* * *}$ indicate significance at the $10 \%, 5 \%$, and $1 \%$ level, respectively.

\begin{tabular}{|c|c|c|c|c|c|c|}
\hline Rank & 1 & 2 & 3 & 4 & 5 & 5 minus 1 \\
\hline $\begin{array}{l}\text { Value-Weighted } \\
\text { Mean return }\end{array}$ & $\begin{array}{c}0.0703^{* * *} \\
(0.0190)\end{array}$ & $\begin{array}{c}0.0848^{* * *} \\
(0.0213)\end{array}$ & $\begin{array}{c}0.0846^{* * *} \\
(0.0256)\end{array}$ & $\begin{array}{l}0.0595^{*} \\
(0.0305)\end{array}$ & $\begin{array}{c}0.0161 \\
(0.0378)\end{array}$ & $\begin{array}{c}-0.0542^{* *} \\
(0.0267)\end{array}$ \\
\hline CAPM alpha & $\begin{array}{c}0.0028 \\
(0.0039)\end{array}$ & $\begin{array}{l}0.0114^{*} \\
(0.0069)\end{array}$ & $\begin{array}{c}0.0016 \\
(0.0110)\end{array}$ & $\begin{array}{c}-0.0329^{* *} \\
(0.0145)\end{array}$ & $\begin{array}{c}-0.0875^{* * *} \\
(0.0216)\end{array}$ & $\begin{array}{c}-0.0903^{* * *} \\
(0.0235)\end{array}$ \\
\hline 4-factor alpha & $\begin{array}{l}0.0086^{* *} \\
(0.0035)\end{array}$ & $\begin{array}{c}0.0057 \\
(0.0064)\end{array}$ & $\begin{array}{l}-0.0063 \\
(0.0090)\end{array}$ & $\begin{array}{c}-0.0412^{* * *} \\
(0.0113)\end{array}$ & $\begin{array}{c}-0.0757^{* * *} \\
(0.0172)\end{array}$ & $\begin{array}{c}-0.0843^{* * *} \\
(0.0183)\end{array}$ \\
\hline 5-factor alpha & $\begin{array}{c}0.0096^{* *} \\
(0.0041)\end{array}$ & $\begin{array}{c}0.0040 \\
(0.0076)\end{array}$ & $\begin{array}{l}-0.0061 \\
(0.0110)\end{array}$ & $\begin{array}{c}-0.0469^{* * *} \\
(0.0140)\end{array}$ & $\begin{array}{c}-0.0910^{* * *} \\
(0.0213)\end{array}$ & $\begin{array}{c}-0.1006^{* * *} \\
(0.0228)\end{array}$ \\
\hline FF5 alpha & $\begin{array}{l}0.0107^{* *} \\
(0.0047)\end{array}$ & $\begin{array}{l}-0.0068 \\
(0.0071)\end{array}$ & $\begin{array}{l}-0.0075 \\
(0.0128)\end{array}$ & $\begin{array}{c}-0.0315^{* *} \\
(0.0140)\end{array}$ & $\begin{array}{c}-0.0621^{* * *} \\
(0.0150)\end{array}$ & $\begin{array}{c}-0.0728^{* * *} \\
(0.0160)\end{array}$ \\
\hline \multicolumn{7}{|c|}{ Equally Weighted } \\
\hline Mean return & $\begin{array}{c}0.0932^{* * *} \\
(0.0199) \\
\end{array}$ & $\begin{array}{c}0.1074^{* * *} \\
(0.0225)\end{array}$ & $\begin{array}{c}0.1026^{* * *} \\
(0.0259)\end{array}$ & $\begin{array}{c}0.0896^{* * *} \\
(0.0309)\end{array}$ & $\begin{array}{c}0.0495 \\
(0.0390) \\
\end{array}$ & $\begin{array}{c}-0.0436^{*} \\
(0.0261)\end{array}$ \\
\hline CAPM alpha & $\begin{array}{c}0.0280^{* * *} \\
(0.0068)\end{array}$ & $\begin{array}{c}0.0376^{* * *} \\
(0.0106)\end{array}$ & $\begin{array}{l}0.0252^{* *} \\
(0.0127)\end{array}$ & $\begin{array}{c}0.0051 \\
(0.0168)\end{array}$ & $\begin{array}{c}-0.0406^{*} \\
(0.0246)\end{array}$ & $\begin{array}{c}-0.0686^{* * *} \\
(0.0234)\end{array}$ \\
\hline 4-factor alpha & $\begin{array}{c}0.0253^{* * *} \\
(0.0056)\end{array}$ & $\begin{array}{c}0.0280^{* * *} \\
(0.0049)\end{array}$ & $\begin{array}{c}0.0180^{* * *} \\
(0.0048)\end{array}$ & $\begin{array}{c}0.0047 \\
(0.0077)\end{array}$ & $\begin{array}{c}-0.0403^{* * *} \\
(0.0151)\end{array}$ & $\begin{array}{c}-0.0656^{* * *} \\
(0.0172)\end{array}$ \\
\hline 5-factor alpha & $\begin{array}{c}0.0291^{* * *} \\
(0.0068)\end{array}$ & $\begin{array}{c}0.0276^{* * *} \\
(0.0061)\end{array}$ & $\begin{array}{c}0.0184^{* * *} \\
(0.0058)\end{array}$ & $\begin{array}{l}-0.0004 \\
(0.0093)\end{array}$ & $\begin{array}{c}-0.0529^{* * *} \\
(0.0191)\end{array}$ & $\begin{array}{c}-0.0820^{* * *} \\
(0.0220)\end{array}$ \\
\hline FF5 alpha & $\begin{array}{l}0.0157^{*} \\
(0.0087)\end{array}$ & $\begin{array}{c}0.0093 \\
(0.0066)\end{array}$ & $\begin{array}{c}0.0059 \\
(0.0062)\end{array}$ & $\begin{array}{l}-0.0030 \\
(0.0092)\end{array}$ & $\begin{array}{c}-0.0341^{* *} \\
(0.0165)\end{array}$ & $\begin{array}{c}-0.0498^{* * *} \\
(0.0188)\end{array}$ \\
\hline
\end{tabular}




\section{Table A4: Portfolio Sorts: Beta Uncertainty - Subsamples}

In this table, we present the portfolio sorting results for 3 separate 22-year subsamples (the last subsample contains only 21 years) as well as an extended sample period starting with data from 1926. At the end of each month, we sort the stocks into 5 portfolios according to their beta uncertainty. The column labeled " 5 minus 1" refers to the hedge portfolio buying the quintile of stocks with the highest beta uncertainty and simultaneously selling the stocks in the quintile with the lowest beta uncertainty. "4-factor alpha" refers to the alpha of the Carhart (1997) 4-factor model. Robust Newey \& West (1987) standard errors using 6 lags are reported in parentheses. ${ }^{*},{ }^{* *}$, and ${ }^{* * *}$ indicate significance at the $10 \%, 5 \%$, and $1 \%$ level, respectively.

\begin{tabular}{|c|c|c|c|c|c|c|}
\hline Rank & 1 & 2 & 3 & 4 & 5 & 5 minus 1 \\
\hline $\begin{array}{l}\text { Value-Weighted } \\
\text { 4-factor alpha }\end{array}$ & $\begin{array}{c}1951-1972) \\
0.0156^{* * *} \\
(0.0032)\end{array}$ & $\begin{array}{l}-0.0060 \\
(0.0056)\end{array}$ & $\begin{array}{c}-0.0219^{* * *} \\
(0.0080)\end{array}$ & $\begin{array}{c}-0.0485^{* * *} \\
(0.0128)\end{array}$ & $\begin{array}{c}-0.0809^{* * *} \\
(0.0166)\end{array}$ & $\begin{array}{c}-0.0965^{* * *} \\
(0.0181)\end{array}$ \\
\hline $\begin{array}{l}\text { Value-Weighted } \\
\text { 4-factor alpha }\end{array}$ & $\begin{array}{c}1973-1994) \\
0.0084^{*} \\
(0.0044)\end{array}$ & $\begin{array}{c}0.0132 \\
(0.0096)\end{array}$ & $\begin{array}{c}0.0032 \\
(0.0119)\end{array}$ & $\begin{array}{c}-0.0514^{* * *} \\
(0.0125)\end{array}$ & $\begin{array}{c}-0.1639^{* * *} \\
(0.0183)\end{array}$ & $\begin{array}{c}-0.1722^{* * *} \\
(0.0209)\end{array}$ \\
\hline $\begin{array}{l}\text { Value-Weighted } \\
\text { 4-factor alpha }\end{array}$ & $\begin{array}{c}1995-2015) \\
0.0162^{* *} \\
(0.0077)\end{array}$ & $\begin{array}{c}0.0090 \\
(0.0112)\end{array}$ & $\begin{array}{l}-0.0215 \\
(0.0177)\end{array}$ & $\begin{array}{c}-0.0428^{*} \\
(0.0230)\end{array}$ & $\begin{array}{c}-0.1213^{* * *} \\
(0.0394)\end{array}$ & $\begin{array}{c}-0.1375^{* * *} \\
(0.0453)\end{array}$ \\
\hline $\begin{array}{l}\text { Equally Weight } \\
\text { 4-factor alpha }\end{array}$ & $\begin{array}{c}(1951-1972 \\
0.0340^{* * *} \\
(0.0078)\end{array}$ & $\begin{array}{c}0.0254^{* * *} \\
(0.0052)\end{array}$ & $\begin{array}{l}0.0128^{* *} \\
(0.0063)\end{array}$ & $\begin{array}{l}-0.0111 \\
(0.0073)\end{array}$ & $\begin{array}{c}-0.0398^{* * *} \\
(0.0109)\end{array}$ & $\begin{array}{c}-0.0738^{* * *} \\
(0.0157)\end{array}$ \\
\hline $\begin{array}{l}\text { Equally Weight } \\
\text { 4-factor alpha }\end{array}$ & $\begin{array}{c}(1973-1994 \\
0.0273^{* * *} \\
(0.0101)\end{array}$ & $\begin{array}{c}0.0397^{* * *} \\
(0.0062)\end{array}$ & $\begin{array}{c}0.0169^{* * *} \\
(0.0054)\end{array}$ & $\begin{array}{c}-0.0212^{* *} \\
(0.0093)\end{array}$ & $\begin{array}{c}-0.1291^{* * *} \\
(0.0202)\end{array}$ & $\begin{array}{c}-0.1564^{* * *} \\
(0.0233)\end{array}$ \\
\hline $\begin{array}{l}\text { Equally Weight } \\
\text { 4-factor alpha }\end{array}$ & $\begin{array}{c}(1995-2015 \\
0.0495^{* * *} \\
(0.0132)\end{array}$ & $\begin{array}{c}0.0360^{* * *} \\
(0.0126)\end{array}$ & $\begin{array}{l}0.0243^{* *} \\
(0.0116)\end{array}$ & $\begin{array}{c}0.0092 \\
(0.0170)\end{array}$ & $\begin{array}{l}-0.0433 \\
(0.0318)\end{array}$ & $\begin{array}{c}-0.0929^{* *} \\
(0.0394)\end{array}$ \\
\hline $\begin{array}{l}\text { Value-weighted } \\
\text { 4-factor alpha }\end{array}$ & $\begin{array}{c}1926-2015) \\
0.0102^{* * *} \\
(0.0029) \\
\end{array}$ & $\begin{array}{c}0.0016 \\
(0.0047)\end{array}$ & $\begin{array}{c}-0.0151^{* *} \\
(0.0066)\end{array}$ & $\begin{array}{c}-0.0355^{* * *} \\
(0.0096)\end{array}$ & $\begin{array}{c}-0.0738^{* * *} \\
(0.0179)\end{array}$ & $\begin{array}{c}-0.0840^{* * *} \\
(0.0198)\end{array}$ \\
\hline $\begin{array}{l}\text { Equally Weight } \\
\text { 4-factor alpha }\end{array}$ & $\begin{array}{c}(1926-2015 \\
0.0303^{* * *} \\
(0.0059)\end{array}$ & $\begin{array}{c}0.0269^{* * *} \\
(0.0051)\end{array}$ & $\begin{array}{c}0.0139^{* * *} \\
(0.0053)\end{array}$ & $\begin{array}{l}-0.0012 \\
(0.0068)\end{array}$ & $\begin{array}{c}-0.0369^{* * *} \\
(0.0131)\end{array}$ & $\begin{array}{c}-0.0673^{* * *} \\
(0.0161)\end{array}$ \\
\hline
\end{tabular}




\section{Table A5: Double Sorts: Beta Uncertainty and SE}

This table reports annualized value-weighted Carhart (1997) 4-factor alphas for double-sorted portfolios. At the end of each month, we first sort the stocks into 5 quintile portfolios according to their SE. Within each of these quintiles, we sort the stocks into another 5 portfolios based on their beta uncertainty. We report the alphas of all 25 portfolios as well as the respective long minus short ("5 minus 1") portfolios. The row labeled "5 minus 1" refers to the hedge portfolio buying the quintile of stocks with the highest beta uncertainty and simultaneously selling the stocks in the quintile with the lowest beta uncertainty. Within each portfolio, we value-weight the stocks. The final column ("Avg.") reports the averages for each beta uncertainty quintile across the quintiles sorted on SE. Robust Newey \& West (1987) standard errors using 6 lags are reported in parentheses. ${ }^{*},{ }^{* *}$, and ${ }^{* * *}$ indicate significance at the $10 \%, 5 \%$, and $1 \%$ level, respectively.

\begin{tabular}{|c|c|c|c|c|c|c|c|c|}
\hline & & \multicolumn{5}{|c|}{$\mathrm{SE}$} & \multirow[b]{2}{*}{5 minus 1} & \multirow[b]{2}{*}{ Avg. } \\
\hline & & 1 & 2 & 3 & 4 & 5 & & \\
\hline \multirow{11}{*}{$\mathrm{Unc}_{\beta}$} & 1 & $\begin{array}{c}0.0187^{* *} \\
(0.008)\end{array}$ & $\begin{array}{c}0.0207^{* *} \\
(0.009)\end{array}$ & $\begin{array}{l}0.0000 \\
(0.011)\end{array}$ & $\begin{array}{l}0.0130 \\
(0.016)\end{array}$ & $\begin{array}{c}-0.0317^{* *} \\
(0.014)\end{array}$ & $\begin{array}{c}-0.0504^{* * *} \\
(0.018)\end{array}$ & $\begin{array}{l}0.0044 \\
(0.006)\end{array}$ \\
\hline & \multirow[t]{2}{*}{2} & 0.0067 & 0.0064 & $\begin{array}{l}(0.011) \\
0.0114\end{array}$ & $\begin{array}{c}(0.016) \\
-0.0069\end{array}$ & $-0.0418^{* *}$ & $-0.0485^{* *}$ & $\begin{array}{c}(0.000) \\
-0.0044\end{array}$ \\
\hline & & $(0.007)$ & $(0.009)$ & $(0.011)$ & $(0.014)$ & $(0.017)$ & $(0.019)$ & $(0.006)$ \\
\hline & \multirow[t]{2}{*}{3} & 0.0094 & 0.0027 & 0.0073 & -0.0004 & $-0.0526^{* * *}$ & $-0.0620^{* * *}$ & -0.0073 \\
\hline & & $(0.007)$ & $(0.010)$ & $(0.012)$ & $(0.014)$ & $(0.019)$ & $(0.022)$ & $(0.007)$ \\
\hline & \multirow[t]{2}{*}{4} & -0.0032 & -0.0076 & $-0.0301^{* *}$ & $-0.0423^{* * *}$ & $-0.1061^{* * *}$ & $-0.1029^{* * *}$ & $-0.0382^{* * *}$ \\
\hline & & $(0.008)$ & $(0.012)$ & $(0.012)$ & $(0.015)$ & $(0.022)$ & $(0.024)$ & $(0.009)$ \\
\hline & \multirow[t]{2}{*}{5} & -0.0015 & -0.0163 & -0.0260 & $-0.0536^{* *}$ & $-0.1532^{* * *}$ & $-0.1517^{* * *}$ & $-0.0497^{* * *}$ \\
\hline & & $(0.010)$ & $(0.015)$ & $(0.017)$ & $(0.024)$ & $(0.026)$ & $(0.029)$ & $(0.011)$ \\
\hline & \multirow[t]{2}{*}{5 minus 1} & $-0.0202^{*}$ & $-0.0370^{*}$ & -0.0260 & $-0.0666^{* *}$ & $-0.1215^{* * *}$ & & $-0.0541^{* * *}$ \\
\hline & & $(0.012)$ & $(0.020)$ & $(0.020)$ & $(0.028)$ & $(0.028)$ & & $(0.013)$ \\
\hline
\end{tabular}




\section{Table A6: Return Predictability of Aggregate Beta Uncertainty: Control Variables}

This table summarizes the results of return predictability regressions on aggregate beta uncertainty. We regress annualized excess returns on the CRSP value-weighted index over $h$ months on a constant and one or several lagged predictive variables. We consider forecasting horizons $(h)$ of $1,3,6,9,12,18$, 24, and 36 months (Panels $A-H$ ). To account for overlapping return observations, in parentheses we present Hodrick (1992) corrected standard errors. Adj. $R^{2}$ reports the adjusted $R^{2} .{ }^{*},{ }^{* *}$, and ${ }^{* * *}$ indicate significance at the $10 \%, 5 \%$, and $1 \%$ level, respectively.

Panel A. 1-Month Horizon

\begin{tabular}{|c|c|c|c|c|c|c|c|c|c|}
\hline & (i) & $(i i)$ & (iii) & $(i v)$ & $(v)$ & $(v i)$ & (vii) & (viii) & $(i x)$ \\
\hline $\begin{array}{l}\text { Constant } \\
\text { (s.e.) }\end{array}$ & $\begin{array}{c}0.2805^{* * *} \\
(0.077)\end{array}$ & $\begin{array}{c}0.0554^{* * *} \\
(0.019)\end{array}$ & $\begin{array}{c}0.0236 \\
(0.050)\end{array}$ & $\begin{array}{c}0.3380^{* *} \\
(0.169)\end{array}$ & $\begin{array}{c}0.1932 \\
(0.156)\end{array}$ & $\begin{array}{c}0.0565^{* * *} \\
(0.019)\end{array}$ & $\begin{array}{l}0.0105 \\
(0.030)\end{array}$ & $\begin{array}{c}0.1979^{* * *} \\
(0.074)\end{array}$ & $\begin{array}{c}0.4696^{* *} \\
(0.223)\end{array}$ \\
\hline $\begin{array}{l}\mathrm{Unc}_{\beta}^{a g g} \\
\text { (s.e.) }\end{array}$ & $\begin{array}{c}-0.1785^{* * *} \\
(0.057)\end{array}$ & & & & & & & & $\begin{array}{c}-0.2537^{* * *} \\
(0.073)\end{array}$ \\
\hline $\begin{array}{l}\text { CAY } \\
\text { (s.e.) }\end{array}$ & & $\begin{array}{c}2.5108^{* * *} \\
(0.751)\end{array}$ & & & & & & & $\begin{array}{c}3.7205^{* * *} \\
(0.905)\end{array}$ \\
\hline $\begin{array}{l}\text { DFSP } \\
\text { (s.e.) }\end{array}$ & & & $\begin{array}{l}3.4647 \\
(5.292)\end{array}$ & & & & & & $\begin{array}{c}-0.2623 \\
(6.663)\end{array}$ \\
\hline $\begin{array}{l}\log (\mathrm{P} / \mathrm{D}) \\
\text { (s.e.) }\end{array}$ & & & & $\begin{array}{c}-7.9893^{*} \\
(4.782)\end{array}$ & & & & & $\begin{array}{l}5.1192 \\
(8.409)\end{array}$ \\
\hline $\begin{array}{l}\log (\mathrm{P} / \mathrm{E}) \\
\text { (s.e.) }\end{array}$ & & & & & $\begin{array}{c}-4.8867 \\
(5.626)\end{array}$ & & & & $\begin{array}{c}-4.4203 \\
(9.333)\end{array}$ \\
\hline $\begin{array}{l}\text { RREL } \\
\text { (s.e.) }\end{array}$ & & & & & & $\begin{array}{c}-59.057^{* *} \\
(23.52)\end{array}$ & & & $\begin{array}{c}-45.438 \\
(30.22)\end{array}$ \\
\hline $\begin{array}{l}\text { TMSP } \\
\text { (s.e.) }\end{array}$ & & & & & & & $\begin{array}{l}2.7273^{*} \\
(1.402)\end{array}$ & & $\begin{array}{l}0.1012 \\
(1.705)\end{array}$ \\
\hline $\begin{array}{l}\text { Idio Vol. }{ }^{a g g} \\
\text { (s.e.) }\end{array}$ & & & & & & & & $\begin{array}{c}-11.123^{*} \\
(6.230)\end{array}$ & $\begin{array}{c}-11.933 \\
(8.105)\end{array}$ \\
\hline Adj. $R^{2}$ & 0.008 & 0.011 & 0.000 & 0.003 & 0.000 & 0.008 & 0.004 & 0.006 & 0.034 \\
\hline
\end{tabular}

Panel B. 3-Month Horizon

\begin{tabular}{|c|c|c|c|c|c|c|c|c|c|}
\hline & (i) & (ii) & (iii) & $(i v)$ & $(v)$ & $(v i)$ & (vii) & (viii) & $(i x)$ \\
\hline $\begin{array}{l}\text { Constant } \\
\text { (s.e.) }\end{array}$ & $\begin{array}{c}0.2724^{* * *} \\
(0.074)\end{array}$ & $\begin{array}{c}0.0563^{* * *} \\
(0.019)\end{array}$ & $\begin{array}{l}0.0189 \\
(0.048)\end{array}$ & $\begin{array}{c}0.3536^{* *} \\
(0.167)\end{array}$ & $\begin{array}{c}0.1804 \\
(0.150)\end{array}$ & $\begin{array}{c}0.0575^{* * *} \\
(0.019)\end{array}$ & $\begin{array}{l}0.0146 \\
(0.030)\end{array}$ & $\begin{array}{c}0.1700^{* *} \\
(0.068)\end{array}$ & $\begin{array}{c}0.4992^{* *} \\
(0.212)\end{array}$ \\
\hline $\begin{array}{l}\mathrm{Unc}_{\beta}^{a g g} \\
\text { (s.e.) }\end{array}$ & $\begin{array}{c}-0.1712^{* * *} \\
(0.055)\end{array}$ & & & & & & & & $\begin{array}{c}-0.2482^{* * * *} \\
(0.069)\end{array}$ \\
\hline $\begin{array}{l}\text { CAY } \\
\text { (s.e.) }\end{array}$ & & $\begin{array}{c}2.4480^{* * *} \\
(0.769)\end{array}$ & & & & & & & $\begin{array}{c}3.4855^{* * *} \\
(0.939)\end{array}$ \\
\hline $\begin{array}{l}\text { DFSP } \\
\text { (s.e.) }\end{array}$ & & & $\begin{array}{l}4.0403 \\
(5.103)\end{array}$ & & & & & & $\begin{array}{c}-0.5779 \\
(6.192)\end{array}$ \\
\hline $\log (\mathrm{P} / \mathrm{D})$ & & & & $-8.4084^{*}$ & & & & & 0.5643 \\
\hline $\begin{array}{l}\text { (s.e.) } \\
\log (\mathrm{P} / \mathrm{E})\end{array}$ & & & & $(4.746)$ & -4.3953 & & & & $\begin{array}{c}(7.659) \\
-1.9203\end{array}$ \\
\hline (s.e.) & & & & & $(5.393)$ & & & & $(8.320)$ \\
\hline $\begin{array}{l}\text { RREL } \\
\text { (s.e.) }\end{array}$ & & & & & & $\begin{array}{c}-43.937^{* *} \\
(22.25)\end{array}$ & & & $\begin{array}{c}-22.027 \\
(27.52)\end{array}$ \\
\hline $\begin{array}{l}\text { TMSP } \\
\text { (s.e.) }\end{array}$ & & & & & & & $\begin{array}{l}2.5389^{*} \\
(1.396)\end{array}$ & & $\begin{array}{c}0.7373 \\
(1.645)\end{array}$ \\
\hline $\begin{array}{l}\text { Idio Vol. }{ }^{a g g} \\
\text { (s.e.) }\end{array}$ & & & & & & & & $\begin{array}{c}-8.8449 \\
(5.721)\end{array}$ & $\begin{array}{c}-8.1724 \\
(6.949)\end{array}$ \\
\hline Adj. $R^{2}$ & 0.022 & 0.030 & 0.002 & 0.011 & 0.002 & 0.012 & 0.012 & 0.011 & 0.090 \\
\hline
\end{tabular}


Table A6: Return Predictability of Aggregate Beta Uncertainty: Control Variables (continued)

Panel C. 6-Month Horizon

\begin{tabular}{|c|c|c|c|c|c|c|c|c|c|}
\hline & (i) & $(i i)$ & (iii) & $(i v)$ & $(v)$ & $(v i)$ & (vii) & (viii) & $(i x)$ \\
\hline $\begin{array}{l}\text { Constant } \\
\text { (s.e.) }\end{array}$ & $\begin{array}{c}0.2414^{* * *} \\
(0.071)\end{array}$ & $\begin{array}{c}0.0556^{* * *} \\
(0.019)\end{array}$ & $\begin{array}{l}0.0091 \\
(0.044)\end{array}$ & $\begin{array}{c}0.3748^{* *} \\
(0.165)\end{array}$ & $\begin{array}{c}0.1855 \\
(0.142)\end{array}$ & $\begin{array}{c}0.0577^{* * *} \\
(0.019)\end{array}$ & $\begin{array}{c}0.0182 \\
(0.030)\end{array}$ & $\begin{array}{c}0.1524^{* *} \\
(0.065)\end{array}$ & $\begin{array}{c}0.4531^{* *} \\
(0.205)\end{array}$ \\
\hline $\begin{array}{l}\mathrm{Unc}_{\beta}^{a g g} \\
\text { (s.e.) }\end{array}$ & $\begin{array}{c}-0.1462^{* * *} \\
(0.052)\end{array}$ & & & & & & & & $\begin{array}{c}-0.2037^{* * *} \\
(0.066)\end{array}$ \\
\hline $\begin{array}{l}\text { CAY } \\
\text { (s.e.) }\end{array}$ & & $\begin{array}{c}2.4367^{* * *} \\
(0.783)\end{array}$ & & & & & & & $\begin{array}{c}3.2376^{* * *} \\
(0.935)\end{array}$ \\
\hline $\begin{array}{l}\text { DFSP } \\
\text { (s.e.) }\end{array}$ & & & $\begin{array}{l}5.0760 \\
(4.599)\end{array}$ & & & & & & $\begin{array}{c}1.3905 \\
(5.637)\end{array}$ \\
\hline $\begin{array}{l}\log (\mathrm{P} / \mathrm{D}) \\
\text { (s.e.) }\end{array}$ & & & & $\begin{array}{c}-9.0107^{*} \\
(4.712)\end{array}$ & & & & & $\begin{array}{c}-1.5106 \\
(7.142)\end{array}$ \\
\hline $\begin{array}{l}\log (\mathrm{P} / \mathrm{E}) \\
\text { (s.e.) }\end{array}$ & & & & & $\begin{array}{c}-4.5754 \\
(5.112)\end{array}$ & & & & $\begin{array}{c}-1.0635 \\
(7.202)\end{array}$ \\
\hline $\begin{array}{l}\text { RREL } \\
\text { (s.e.) }\end{array}$ & & & & & & $\begin{array}{c}-35.130^{*} \\
(21.05)\end{array}$ & & & $\begin{array}{c}-9.1984 \\
(25.00)\end{array}$ \\
\hline $\begin{array}{l}\text { TMSP } \\
\text { (s.e.) }\end{array}$ & & & & & & & $\begin{array}{c}2.3371^{*} \\
(1.358)\end{array}$ & & $\begin{array}{l}0.9322 \\
(1.564)\end{array}$ \\
\hline $\begin{array}{l}\text { Idio Vol. }{ }^{a g g} \\
\text { (s.e.) }\end{array}$ & & & & & & & & $\begin{array}{c}-7.4424 \\
(5.457)\end{array}$ & $\begin{array}{c}-6.8732 \\
(6.374)\end{array}$ \\
\hline Adj. $R^{2}$ & 0.030 & 0.055 & 0.008 & 0.025 & 0.006 & 0.015 & 0.019 & 0.014 & 0.143 \\
\hline
\end{tabular}

Panel D. 9-Month Horizon

\begin{tabular}{|c|c|c|c|c|c|c|c|c|c|}
\hline & (i) & (ii) & (iii) & $(i v)$ & $(v)$ & $(v i)$ & (vii) & (viii) & $(i x)$ \\
\hline $\begin{array}{l}\text { Constant } \\
\text { (s.e.) }\end{array}$ & $\begin{array}{c}0.2072^{* * *} \\
(0.068)\end{array}$ & $\begin{array}{c}0.0557^{* * *} \\
(0.019)\end{array}$ & $\begin{array}{c}0.0178 \\
(0.042)\end{array}$ & $\begin{array}{c}0.3719^{* *} \\
(0.164)\end{array}$ & $\begin{array}{c}0.1921 \\
(0.136)\end{array}$ & $\begin{array}{c}0.0578^{* * *} \\
(0.019)\end{array}$ & $\begin{array}{c}0.0137 \\
(0.030)\end{array}$ & $\begin{array}{c}0.1612^{* *} \\
(0.063)\end{array}$ & $\begin{array}{c}0.4665^{* *} \\
(0.198)\end{array}$ \\
\hline $\begin{array}{l}\mathrm{Unc}_{\beta}^{\text {agg }} \\
\text { (s.e.) }\end{array}$ & $\begin{array}{c}-0.1188^{* *} \\
(0.051)\end{array}$ & & & & & & & & $\begin{array}{c}-0.1613^{* *} \\
(0.063)\end{array}$ \\
\hline $\begin{array}{l}\text { CAY } \\
\text { (s.e.) }\end{array}$ & & $\begin{array}{c}2.2668^{* * *} \\
(0.805)\end{array}$ & & & & & & & $\begin{array}{c}2.7430^{* * *} \\
(0.953)\end{array}$ \\
\hline $\begin{array}{l}\text { DFSP } \\
\text { (s.e.) }\end{array}$ & & & $\begin{array}{l}4.1884 \\
(4.268)\end{array}$ & & & & & & $\begin{array}{l}0.4074 \\
(5.365)\end{array}$ \\
\hline $\begin{array}{l}\log (\mathrm{P} / \mathrm{D}) \\
\text { (s.e.) }\end{array}$ & & & & $\begin{array}{c}-8.9292^{*} \\
(4.678)\end{array}$ & & & & & $\begin{array}{c}-3.1691 \\
(6.857)\end{array}$ \\
\hline $\begin{array}{l}\log (\mathrm{P} / \mathrm{E}) \\
\text { (s.e.) }\end{array}$ & & & & & $\begin{array}{c}-4.8124 \\
(4.915)\end{array}$ & & & & $\begin{array}{c}-1.6819 \\
(6.725)\end{array}$ \\
\hline $\begin{array}{l}\text { RREL } \\
\text { (s.e.) }\end{array}$ & & & & & & $\begin{array}{c}-32.685 \\
(20.33)\end{array}$ & & & $\begin{array}{c}-5.6040 \\
(23.31)\end{array}$ \\
\hline $\begin{array}{l}\text { TMSP } \\
\text { (s.e.) }\end{array}$ & & & & & & & $\begin{array}{c}2.6144^{* *} \\
(1.310)\end{array}$ & & $\begin{array}{l}1.7567 \\
(1.505)\end{array}$ \\
\hline $\begin{array}{l}\text { Idio Vol. }{ }^{a g g} \\
\text { (s.e.) }\end{array}$ & & & & & & & & $\begin{array}{c}-8.1210 \\
(5.272)\end{array}$ & $\begin{array}{c}-6.5018 \\
(6.090)\end{array}$ \\
\hline Adj. $R^{2}$ & 0.030 & 0.069 & 0.008 & 0.037 & 0.010 & 0.019 & 0.037 & 0.026 & 0.186 \\
\hline
\end{tabular}


Table A6: Return Predictability of Aggregate Beta Uncertainty: Control Variables (continued 2)

Panel E. 12-Month Horizon

\begin{tabular}{|c|c|c|c|c|c|c|c|c|c|}
\hline & (i) & (ii) & $(i i i)$ & $(i v)$ & $(v)$ & $(v i)$ & (vii) & (viii) & $(i x)$ \\
\hline $\begin{array}{l}\text { Constant } \\
\text { (s.e.) }\end{array}$ & $\begin{array}{c}0.1884^{* * *} \\
(0.067)\end{array}$ & $\begin{array}{c}0.0553^{* * *} \\
(0.019)\end{array}$ & $\begin{array}{l}0.0223 \\
(0.040)\end{array}$ & $\begin{array}{c}0.3662^{* *} \\
(0.163)\end{array}$ & $\begin{array}{l}0.1930 \\
(0.133)\end{array}$ & $\begin{array}{c}0.0579^{* * *} \\
(0.019)\end{array}$ & $\begin{array}{c}0.0142 \\
(0.030)\end{array}$ & $\begin{array}{c}0.1569^{* *} \\
(0.062)\end{array}$ & $\begin{array}{c}0.4674^{* *} \\
(0.194)\end{array}$ \\
\hline $\begin{array}{l}\mathrm{Unc}_{\beta}^{a g g} \\
\text { (s.e.) }\end{array}$ & $\begin{array}{c}-0.1037^{* *} \\
(0.050)\end{array}$ & & & & & & & & $\begin{array}{c}-0.1410^{* *} \\
(0.060)\end{array}$ \\
\hline $\begin{array}{l}\text { CAY } \\
\text { (s.e.) }\end{array}$ & & $\begin{array}{c}2.1959^{* * *} \\
(0.831)\end{array}$ & & & & & & & $\begin{array}{c}2.5301^{* * *} \\
(0.964)\end{array}$ \\
\hline $\begin{array}{l}\text { DFSP } \\
\text { (s.e.) }\end{array}$ & & & $\begin{array}{l}3.7248 \\
(4.002)\end{array}$ & & & & & & $\begin{array}{c}-0.2504 \\
(5.064)\end{array}$ \\
\hline $\begin{array}{l}\log (\mathrm{P} / \mathrm{D}) \\
\text { (s.e.) }\end{array}$ & & & & $\begin{array}{c}-8.7684^{*} \\
(4.674)\end{array}$ & & & & & $\begin{array}{c}-3.9195 \\
(6.665)\end{array}$ \\
\hline $\log (\mathrm{P} / \mathrm{E})$ & & & & & -4.8411 & & & & -2.0184 \\
\hline (s.e.) & & & & & $(4.790)$ & & & & $(6.402)$ \\
\hline $\begin{array}{l}\text { RREL } \\
\text { (s.e.) }\end{array}$ & & & & & & $\begin{array}{c}-31.838 \\
(19.50)\end{array}$ & & & $\begin{array}{c}-5.9449 \\
(21.91)\end{array}$ \\
\hline TMSP & & & & & & & $2.5921^{* *}$ & & 1.9313 \\
\hline (s.e.) & & & & & & & $(1.260)$ & & (1.435) \\
\hline $\begin{array}{l}\text { Idio Vol. }{ }^{a g g} \\
\text { (s.e.) }\end{array}$ & & & & & & & & $\begin{array}{c}-7.7679 \\
(5.141)\end{array}$ & $\begin{array}{c}-5.5198 \\
(5.947)\end{array}$ \\
\hline Adj. $R^{2}$ & 0.031 & 0.086 & 0.009 & 0.048 & 0.014 & 0.025 & 0.049 & 0.033 & 0.227 \\
\hline
\end{tabular}

Panel F. 18-Month Horizon

\begin{tabular}{|c|c|c|c|c|c|c|c|c|c|}
\hline & (i) & $(i i)$ & (iii) & $(i v)$ & $(v)$ & $(v i)$ & (vii) & (viii) & $(i x)$ \\
\hline $\begin{array}{l}\text { Constant } \\
\text { (s.e.) }\end{array}$ & $\begin{array}{c}0.1739^{* * *} \\
(0.063)\end{array}$ & $\begin{array}{c}0.0551^{* * *} \\
(0.019)\end{array}$ & $\begin{array}{l}0.0339 \\
(0.038)\end{array}$ & $\begin{array}{c}0.3560^{* *} \\
(0.161)\end{array}$ & $\begin{array}{c}0.1696 \\
(0.126)\end{array}$ & $\begin{array}{c}0.0580^{* * *} \\
(0.019)\end{array}$ & $\begin{array}{l}0.0203 \\
(0.029)\end{array}$ & $\begin{array}{c}0.1488^{* *} \\
(0.058)\end{array}$ & $\begin{array}{c}0.4931^{* * *} \\
(0.187)\end{array}$ \\
\hline $\begin{array}{l}\mathrm{Unc}_{\beta}^{\text {agg }} \\
\text { (s.e.) }\end{array}$ & $\begin{array}{c}-0.0922^{*} \\
(0.048)\end{array}$ & & & & & & & & $\begin{array}{c}-0.1377^{* *} \\
(0.055)\end{array}$ \\
\hline CAY & & $2.0805^{* *}$ & & & & & & & $2.3420^{* *}$ \\
\hline (s.e.) & & $(0.866)$ & & & & & & & $(0.978)$ \\
\hline $\begin{array}{l}\text { DFSP } \\
\text { (s.e.) }\end{array}$ & & & $\begin{array}{l}2.5150 \\
(3.702)\end{array}$ & & & & & & $\begin{array}{c}-1.9080 \\
(4.755)\end{array}$ \\
\hline $\begin{array}{l}\log (\mathrm{P} / \mathrm{D}) \\
\text { (s.e.) }\end{array}$ & & & & $\begin{array}{c}-8.4883^{*} \\
(4.627)\end{array}$ & & & & & $\begin{array}{c}-6.9570 \\
(6.523)\end{array}$ \\
\hline $\begin{array}{l}\log (\mathrm{P} / \mathrm{E}) \\
\text { (s.e.) }\end{array}$ & & & & & $\begin{array}{c}-4.0041 \\
(4.549)\end{array}$ & & & & $\begin{array}{l}0.4856 \\
(5.906)\end{array}$ \\
\hline RREL & & & & & & -22.822 & & & 2.3783 \\
\hline (s.e.) & & & & & & (17.09) & & & (18.85) \\
\hline $\begin{array}{l}\text { TMSP } \\
\text { (s.e.) }\end{array}$ & & & & & & & $\begin{array}{c}2.2427^{*} \\
(1.157)\end{array}$ & & $\begin{array}{l}1.9134 \\
(1.343)\end{array}$ \\
\hline $\begin{array}{l}\text { Idio Vol. }{ }^{a g g} \\
\text { (s.e.) }\end{array}$ & & & & & & & & $\begin{array}{c}-7.1212 \\
(4.802)\end{array}$ & $\begin{array}{c}-3.6890 \\
(5.521)\end{array}$ \\
\hline Adj. $R^{2}$ & 0.037 & 0.115 & 0.006 & 0.069 & 0.015 & 0.020 & 0.056 & 0.042 & 0.298 \\
\hline
\end{tabular}


Table A6: Return Predictability of Aggregate Beta Uncertainty: Control Variables (continued 3)

Panel G. 24-Month Horizon

\begin{tabular}{|c|c|c|c|c|c|c|c|c|c|}
\hline & (i) & $(i i)$ & $(i i i)$ & $(i v)$ & $(v)$ & $(v i)$ & (vii) & (viii) & $(i x)$ \\
\hline $\begin{array}{l}\text { Constant } \\
\text { (s.e.) }\end{array}$ & $\begin{array}{c}0.1602^{* * *} \\
(0.059)\end{array}$ & $\begin{array}{c}0.0546^{* * *} \\
(0.019)\end{array}$ & $\begin{array}{l}0.0429 \\
(0.037)\end{array}$ & $\begin{array}{c}0.3335^{* *} \\
(0.160)\end{array}$ & $\begin{array}{c}0.1498 \\
(0.119)\end{array}$ & $\begin{array}{c}0.0579^{* * *} \\
(0.019)\end{array}$ & $\begin{array}{c}0.0241 \\
(0.028)\end{array}$ & $\begin{array}{c}0.1436^{* *} \\
(0.056)\end{array}$ & $\begin{array}{c}0.4831^{* * *} \\
(0.185)\end{array}$ \\
\hline $\begin{array}{l}\text { Unc }_{\beta}^{a g g} \\
\text { (s.e.) }\end{array}$ & $\begin{array}{c}-0.0813^{*} \\
(0.045)\end{array}$ & & & & & & & & $\begin{array}{r}-0.1316^{*} \\
(0.052)\end{array}$ \\
\hline $\begin{array}{l}\text { CAY } \\
\text { (s.e.) }\end{array}$ & & $\begin{array}{c}1.9536^{* *} \\
(0.896)\end{array}$ & & & & & & & $\begin{array}{c}2.1673^{* *} \\
(1.021)\end{array}$ \\
\hline $\begin{array}{l}\text { DFSP } \\
\text { (s.e.) }\end{array}$ & & & $\begin{array}{l}1.5665 \\
(3.529)\end{array}$ & & & & & & $\begin{array}{c}-2.5554 \\
(4.709)\end{array}$ \\
\hline $\begin{array}{l}\log (\mathrm{P} / \mathrm{D}) \\
\text { (s.e.) }\end{array}$ & & & & $\begin{array}{c}-7.8590^{*} \\
(4.613)\end{array}$ & & & & & $\begin{array}{c}-8.3849 \\
(6.336)\end{array}$ \\
\hline $\log (\mathrm{P} / \mathrm{E})$ & & & & & -3.3011 & & & & 2.0454 \\
\hline $\begin{array}{l}\text { (s.e.) } \\
\text { BRFI }\end{array}$ & & & & & $(4.289)$ & & & & $\begin{array}{l}(5.190) \\
13409\end{array}$ \\
\hline $\begin{array}{l}\text { RREL } \\
\text { (s.e.) }\end{array}$ & & & & & & $\begin{array}{c}-12.639 \\
(14.82)\end{array}$ & & & $\begin{array}{l}13.499 \\
(16.50)\end{array}$ \\
\hline TMSP & & & & & & & $2.0182^{*}$ & & 2.0133 \\
\hline (s.e.) & & & & & & & $(1.075)$ & & (1.331) \\
\hline $\begin{array}{l}\text { Idio Vol. }{ }^{a g g} \\
\text { (s.e.) }\end{array}$ & & & & & & & & $\begin{array}{c}-6.7103 \\
(4.583)\end{array}$ & $\begin{array}{c}-2.6433 \\
(5.199)\end{array}$ \\
\hline Adj. $R^{2}$ & 0.042 & 0.141 & 0.003 & 0.084 & 0.015 & 0.008 & 0.065 & 0.054 & 0.372 \\
\hline
\end{tabular}

\section{Panel H. 36-Month Horizon}

\begin{tabular}{|c|c|c|c|c|c|c|c|c|c|}
\hline & (i) & (ii) & $(i i i)$ & $(i v)$ & $(v)$ & $(v i)$ & (vii) & (viii) & $(i x)$ \\
\hline $\begin{array}{l}\text { Constant } \\
\text { (s.e.) }\end{array}$ & $\begin{array}{c}0.1208^{* *} \\
(0.056)\end{array}$ & $\begin{array}{c}0.0522^{* * * *} \\
(0.020)\end{array}$ & $\begin{array}{l}0.0496 \\
(0.035)\end{array}$ & $\begin{array}{c}0.3060^{*} \\
(0.158)\end{array}$ & $\begin{array}{c}0.1505 \\
(0.111)\end{array}$ & $\begin{array}{c}0.0575^{* * *} \\
(0.019)\end{array}$ & $\begin{array}{c}0.0259 \\
(0.026)\end{array}$ & $\begin{array}{c}0.1381^{* * *} \\
(0.052)\end{array}$ & $\begin{array}{c}0.3941^{* *} \\
(0.178)\end{array}$ \\
\hline $\begin{array}{l}\mathrm{Unc}_{\beta}^{a g g} \\
\text { (s.e.) }\end{array}$ & $\begin{array}{c}-0.0503 \\
(0.043)\end{array}$ & & & & & & & & $\begin{array}{c}-0.0813^{*} \\
(0.048)\end{array}$ \\
\hline $\begin{array}{l}\text { CAY } \\
\text { (s.e.) }\end{array}$ & & $\begin{array}{c}1.8047^{* *} \\
(0.912)\end{array}$ & & & & & & & $\begin{array}{c}1.7867^{*} \\
(1.043)\end{array}$ \\
\hline $\begin{array}{l}\text { DFSP } \\
\text { (s.e.) }\end{array}$ & & & $\begin{array}{l}0.8203 \\
(3.221)\end{array}$ & & & & & & $\begin{array}{c}-1.9535 \\
(4.281)\end{array}$ \\
\hline $\begin{array}{l}\log (\mathrm{P} / \mathrm{D}) \\
\text { (s.e.) }\end{array}$ & & & & $\begin{array}{c}-7.0992 \\
(4.560)\end{array}$ & & & & & $\begin{array}{c}-6.9359 \\
(5.678)\end{array}$ \\
\hline $\begin{array}{l}\log (\mathrm{P} / \mathrm{E}) \\
\text { (s.e.) }\end{array}$ & & & & & $\begin{array}{c}-3.3427 \\
(3.993)\end{array}$ & & & & $\begin{array}{l}0.8199 \\
(4.355)\end{array}$ \\
\hline $\begin{array}{l}\text { RREL } \\
\text { (s.e.) }\end{array}$ & & & & & & $\begin{array}{c}-11.330 \\
(11.10)\end{array}$ & & & $\begin{array}{l}10.568 \\
(12.51)\end{array}$ \\
\hline $\begin{array}{l}\text { TMSP } \\
\text { (s.e.) }\end{array}$ & & & & & & & $\begin{array}{c}1.9157^{* *} \\
(0.958)\end{array}$ & & $\begin{array}{l}1.9469 \\
(1.234)\end{array}$ \\
\hline $\begin{array}{l}\text { Idio Vol. }{ }^{a g g} \\
\text { (s.e.) }\end{array}$ & & & & & & & & $\begin{array}{c}-6.2949 \\
(4.208)\end{array}$ & $\begin{array}{c}-2.4606 \\
(4.690)\end{array}$ \\
\hline Adj. $R^{2}$ & 0.027 & 0.202 & 0.001 & 0.117 & 0.027 & 0.011 & 0.100 & 0.081 & 0.457 \\
\hline
\end{tabular}




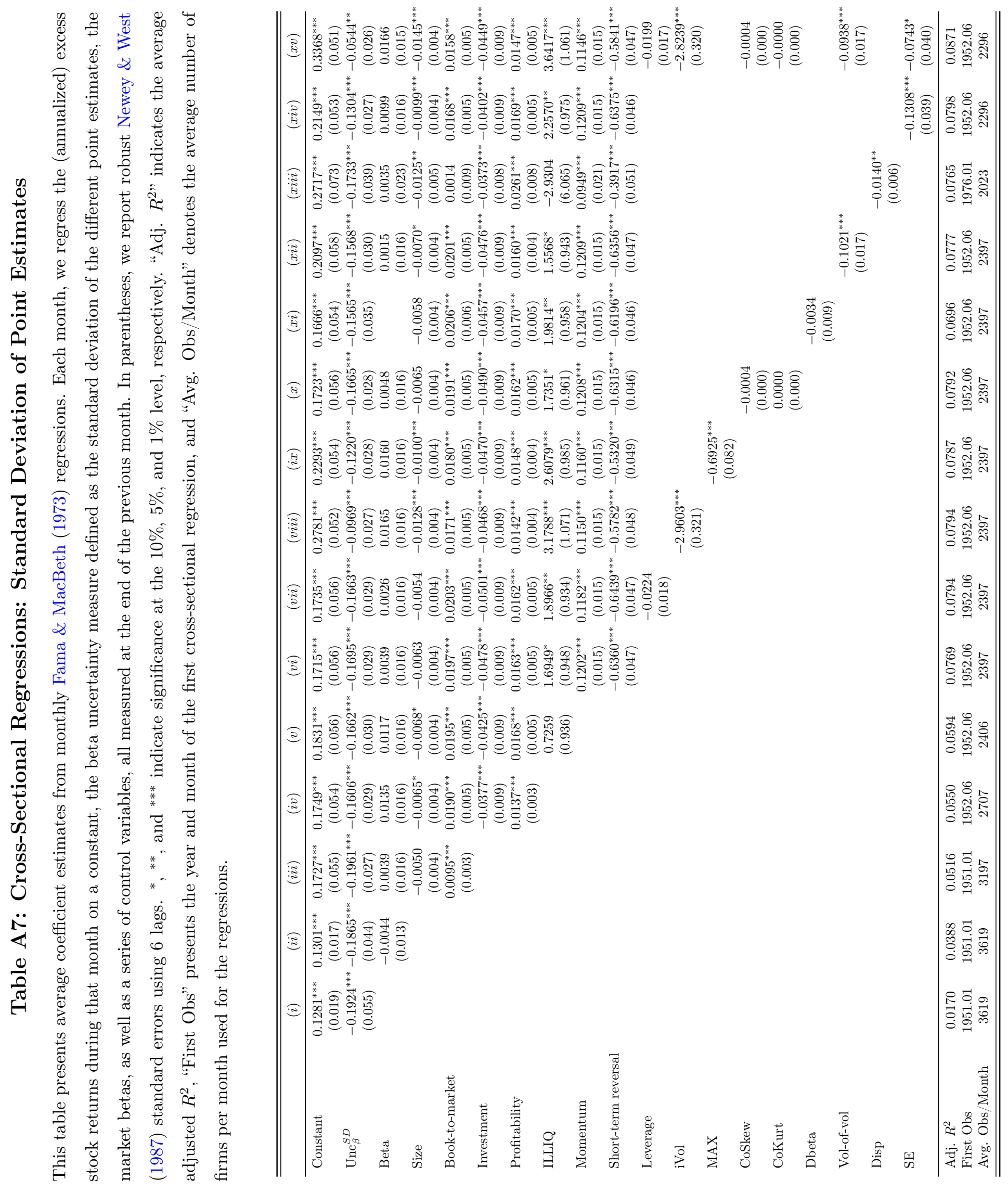




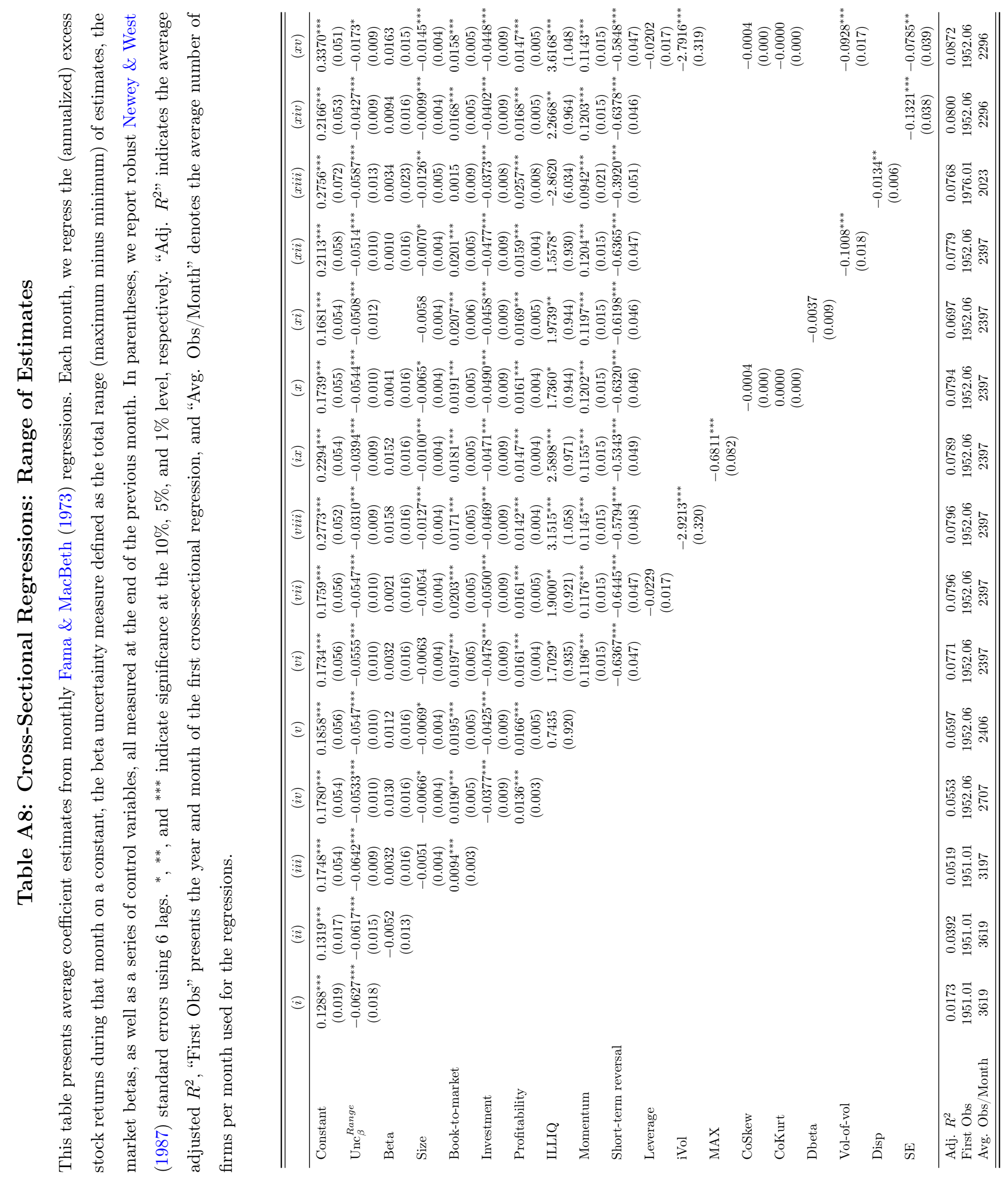




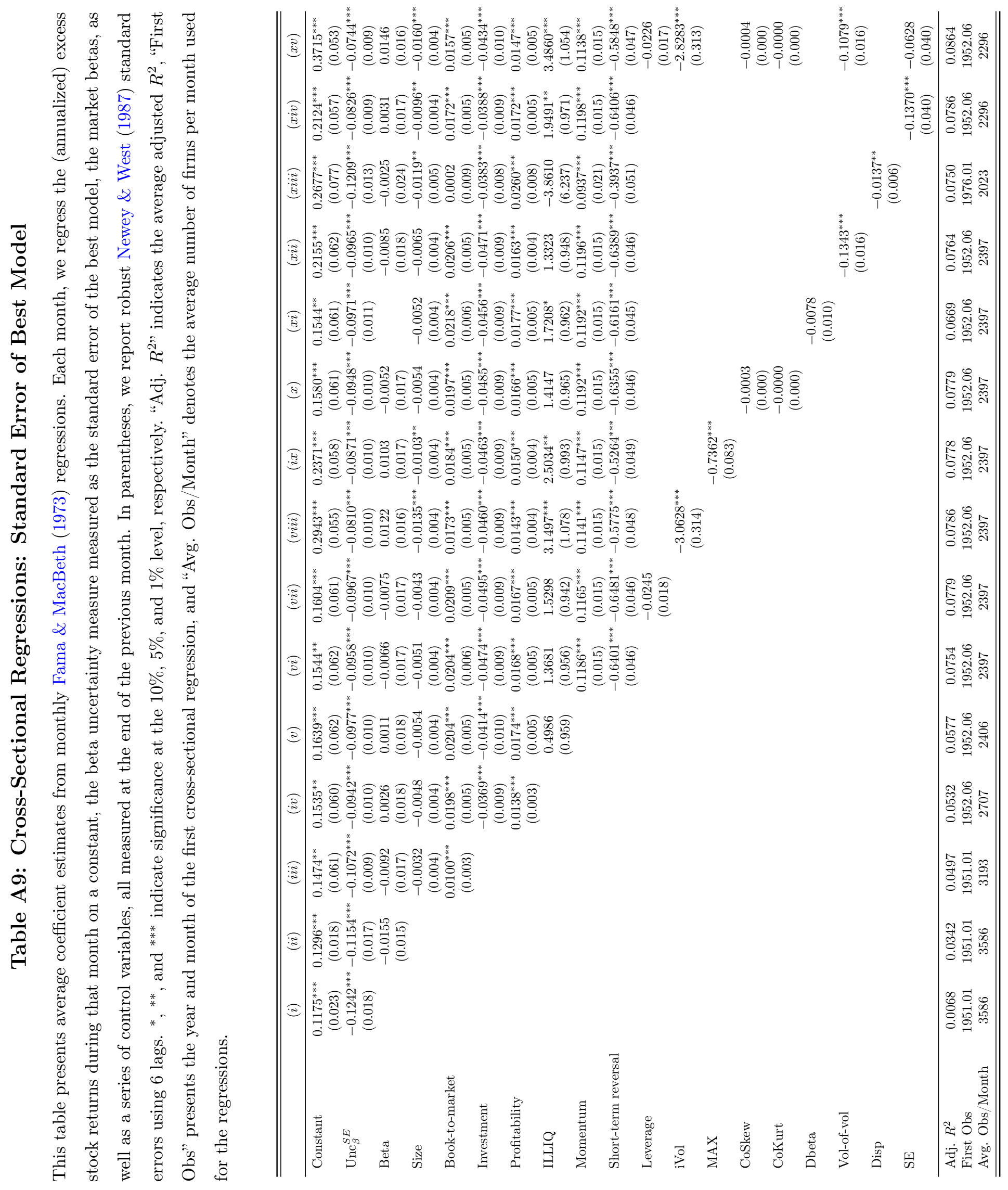




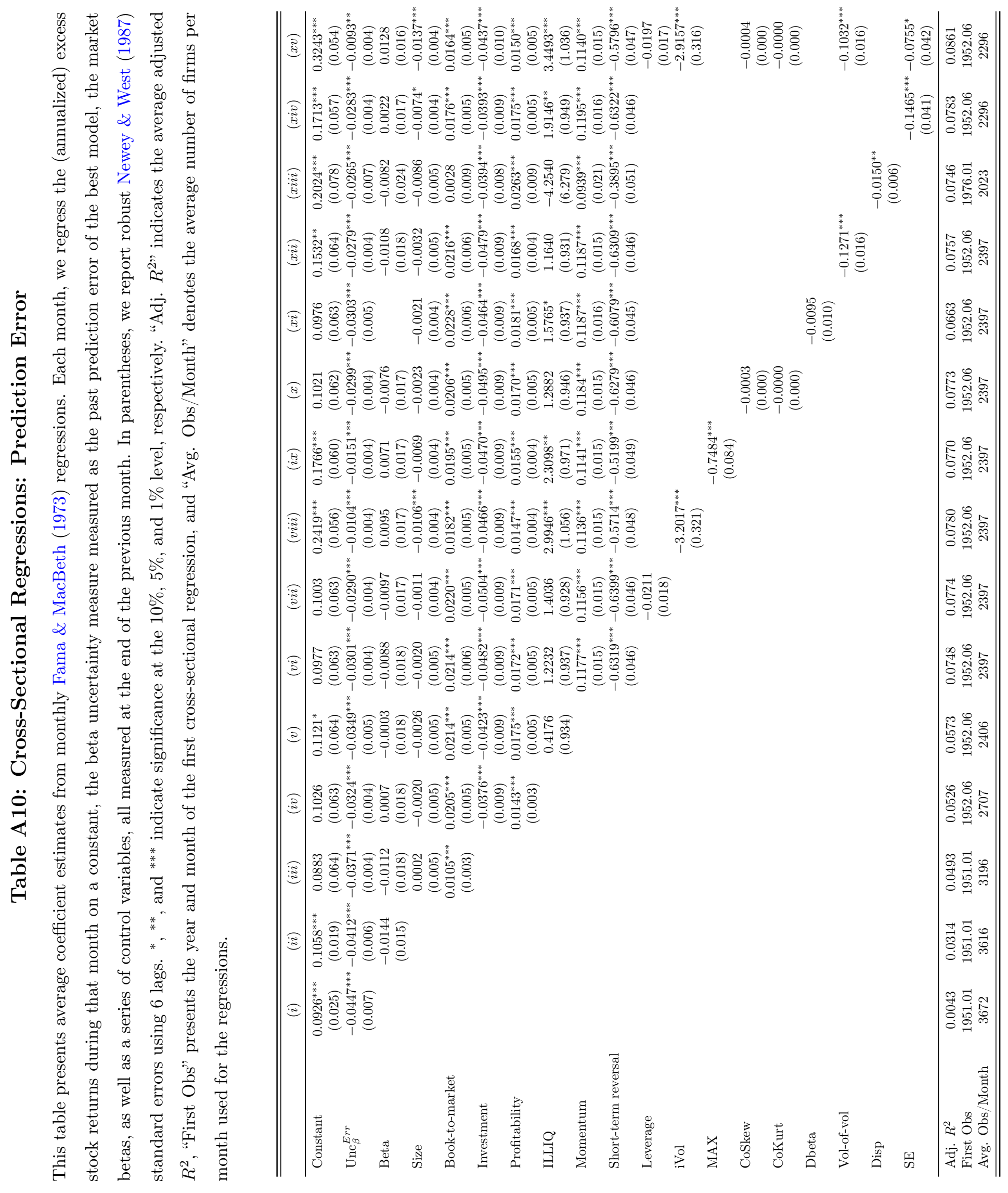




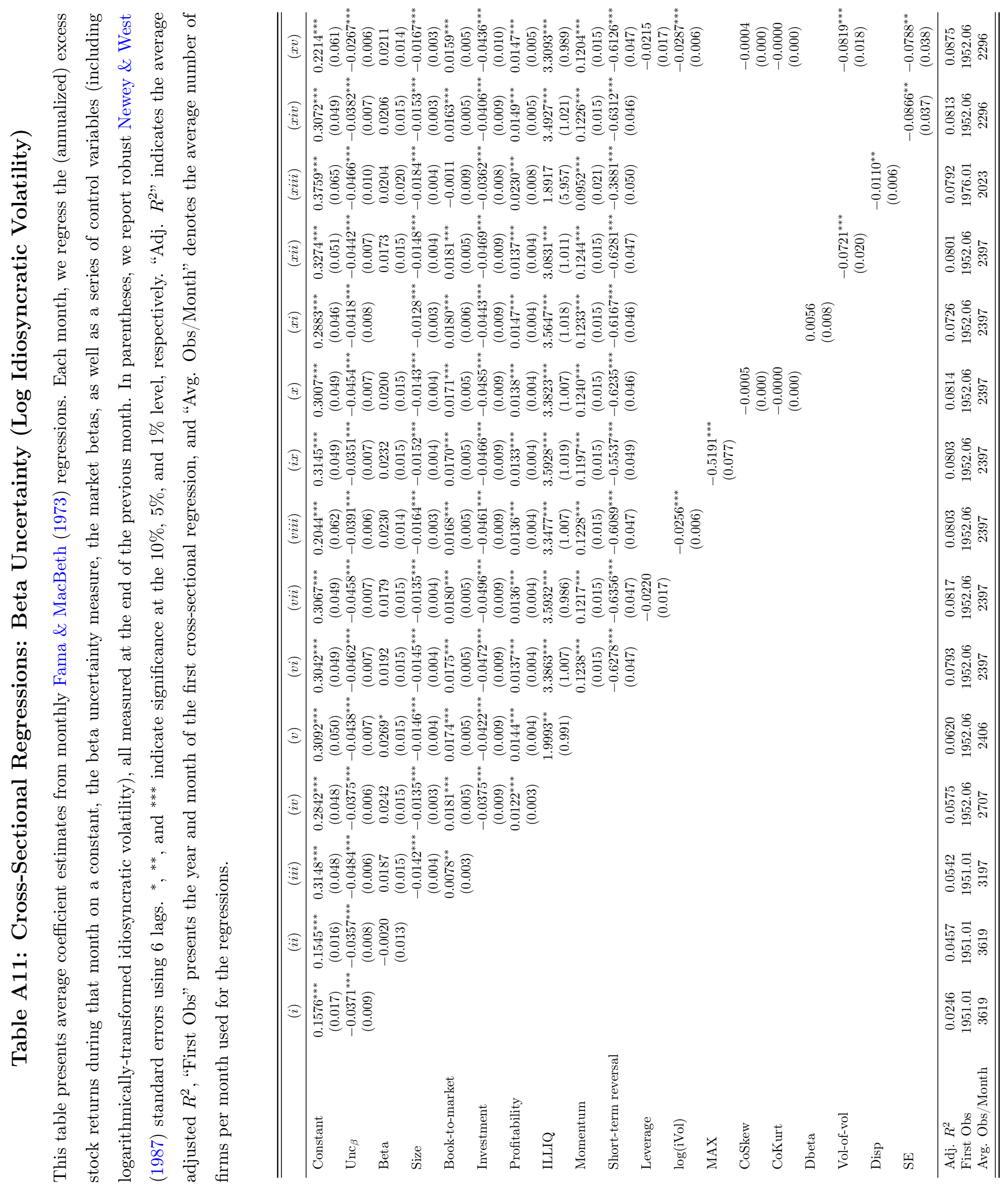




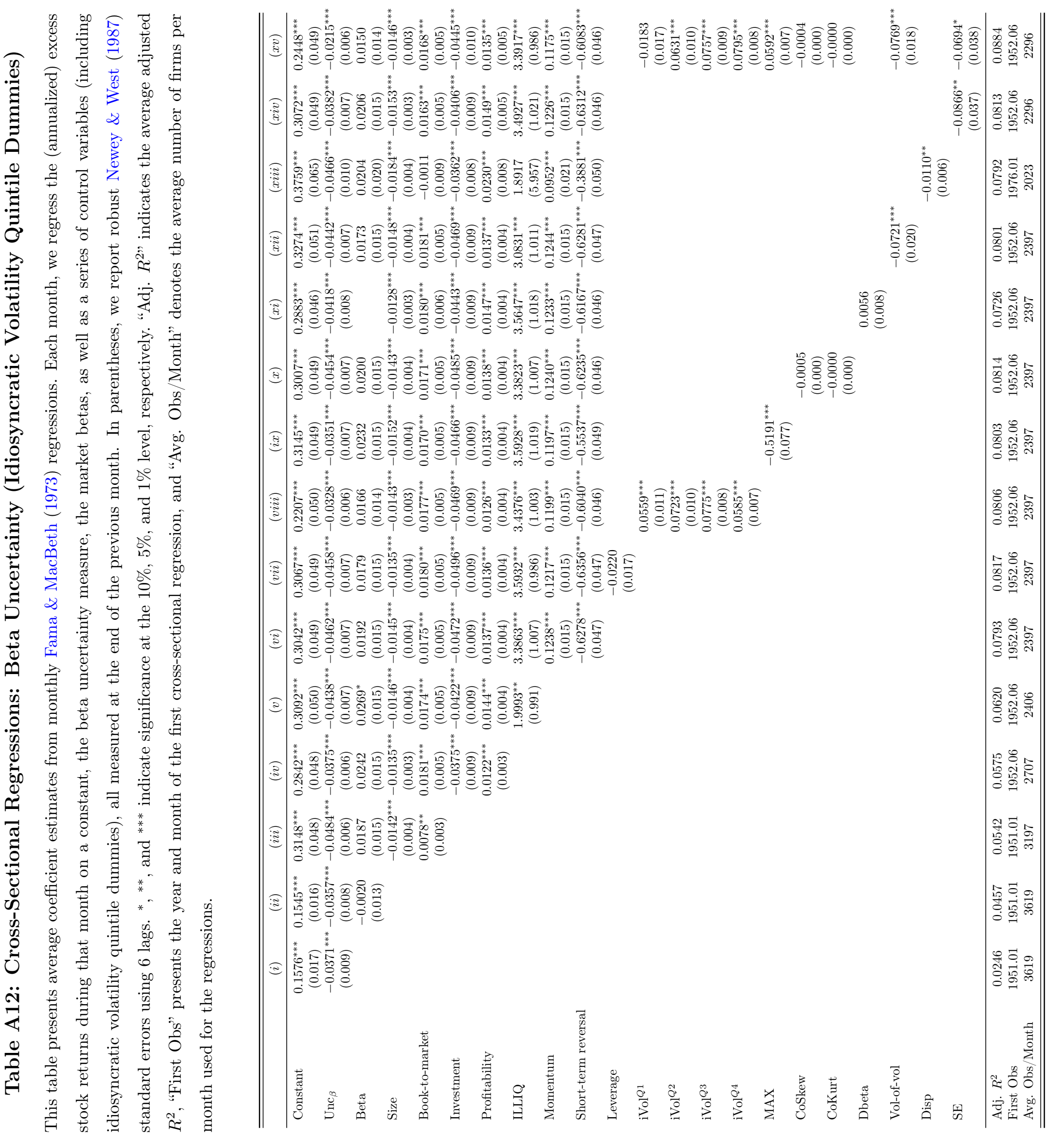









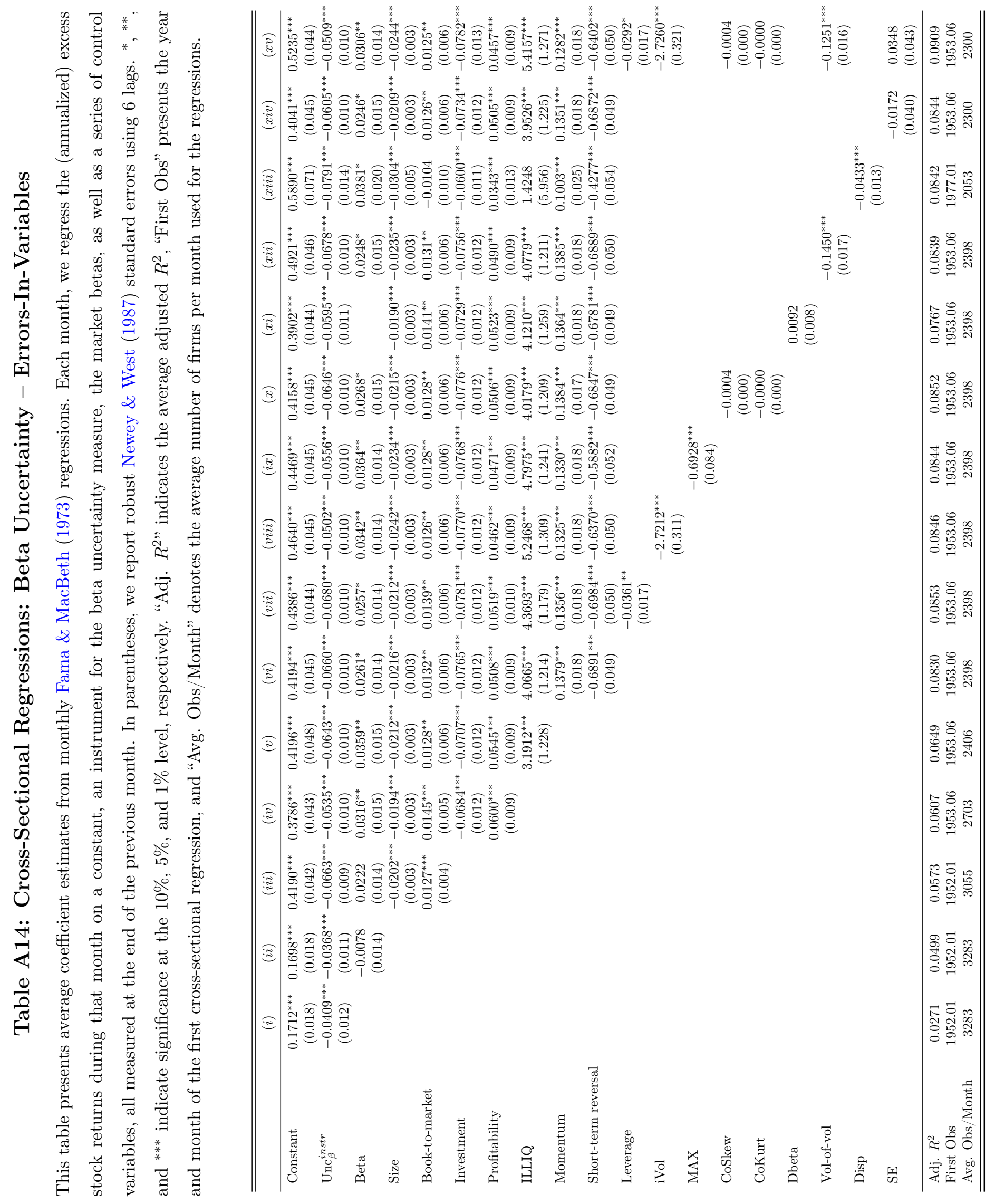

